\title{
International Journal of Ageing and Later Life
}

Volume 5, No. 2, 2010

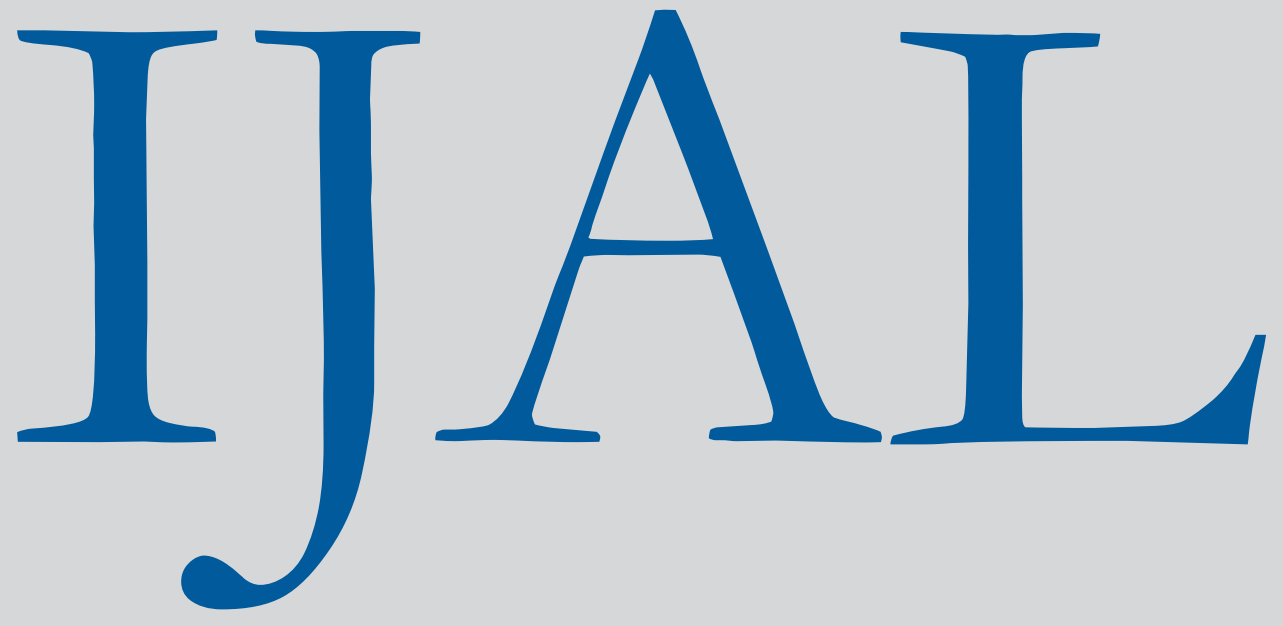





\title{
International Journal of Ageing and Later Life
}

\author{
Volume 5, No. 2, 2010 \\ Published with the support of the Swedish Council \\ for Working Life and Social Research \\ (Forskningsrådet för Arbetsliv och Socialvetenskap, 2008-1788) \\ Linköping University Electronic Press \\ ISSN 1652-8670 (www) \\ URL: http://www.ep.liu.se/ej/ijal/
}




\section{Copyright}

International Journal of Ageing and Later Life is published under the auspices of Linköping University Electronic Press. All Authors retain the copyright of their articles.

The publishers will keep this document online on the Internet - or its possible replacement - for a considerable time from the date of publication barring exceptional circumstances.

The online availability of the document implies a permanent permission for anyone to read, to download, to print out single copies for your own use and to use it unchanged for any non-commercial research and educational purpose. Subsequent transfers of copyright cannot revoke this permission. All other uses of the document are conditional on the consent of the copyright owner. The publisher has taken technical and administrative measures to assure authenticity, security and accessibility.

According to intellectual property law the author has the right to be mentioned when his/her work is accessed as described above and to be protected against infringement.

For additional information about the Linköping University Electronic Press and its procedures for publication and for assurance of document integrity, please refer to its www home page: http://www. ep.liu.se/.

(C) 2010 Linköping University Electronic Press and the Authors 
Editor

Lars Andersson

Editorial Assistant

Laura Machat-From
Associate Editors

Peter Öberg

Sandra Torres

Book Review Editor

Laura Machat-From

\section{Editorial Board}

Sara Arber, University of Surrey, UK

Jan Baars, University for Humanistics, The Netherlands

Vern Bengtson, University of Southern California, USA

Simon Biggs, University of Melbourne, Australia

Sally Bould, University of Delaware, USA

Svein Olav Daatland, Norwegian Social Research (NOVA), Norway

Michael Fine, Macquarie University, Australia

Lliliana Gastron, National University of Lujan, Argentina

Jay Gubrium, University of Missouri, USA

Andreas Hoff, Zittau/Görlitz University of Applied Sciences, Germany

Thérèse Jacobs, University of Antwerp, Belgium

Malcolm Johnson, University of Bristol, UK

Marja Jylhä, University of Tampere, Finland

Stephen Katz, Trent University, Canada

Hans-Joachim von Kondratowitz, German Centre of Gerontology (DZA), Germany

Giovanni Lamura, Italian National Research Center on Ageing, Italy

Pirjo Nikander, University of Tampere, Finland

Marti Parker, Aging Research Center, Sweden

Chris Phillipson, Keele University, UK

Marja Saarenheimo, University of Tampere, Finland

Anneli Sarvimäki, Age Institute, Finland

Nan Stevens, Radboud University, The Netherlands

Christine Swane, EGV, Denmark

Theo van Tilburg, VU University Amsterdam, The Netherlands

Julia Twigg, University of Kent, UK 


\section{Table of Contents}

Acknowledgements

\section{Guest Editorial}

Migrant home care workers caring for older people: fictive kin, substitute and complementary family caregivers in an ethnically diverse environment

Andreas Hoff, Susan Feldman \& Lucie Vidovicova

\section{Migrant Care Workers Caring for Older People in their} Homes

Embodying the ideal carer: the Austrian discourse on migrant carers Bernhard Weicht

Tasks performed by primary caregivers and migrant live-in homecare workers in Israel

Esther Iecovich

Ethno-cultural diversity in home care work in Canada: issues confronted, strategies employed

Anne Martin-Matthews, Joanie Sims-Gould $\mathcal{E}$ John Naslund

\section{Of General Interest}

Lonely older people as a problem in society - construction in Finnish media

Hanna Uotila, Kirsi Lumme-Sandt E Marja Saarenheimo 


\section{Book Review}

Christina Victor, Sasha Scambler and John Bond (2009). The Social World of Older People. Understanding Loneliness and Social Isolation in Later Life. Maidenhead: Open University Press, 262 pp. ISBN 9780335215218 (paperback) 


\section{Acknowledgements}

The Editor of the International Journal of Ageing and Later Life wishes to thank the following referees who generously provided evaluations and constructive criticism on submitted manuscripts in 2010.

Simon Biggs, University of Melbourne, Australia

Neena Chappell, University of Victoria, Canada

Svein Olav Daatland, Norwegian Social Research (NOVA), Norway

Martha Doyle, Trinity College Dublin, Ireland

Susan Feldman, Monash University, Australia

Margaret Gatz, University of Southern California, USA

David Gaunt, Södertörn University, Sweden

Jan-Erik Hagberg, Linköping University, Sweden

Kène Henkens, Netherlands Interdisciplinary Demographic Institute \& University of Tilburg, The Netherlands

Andreas Hoff, Zittau/Görlitz University of Applied Sciences, Germany Stephen Katz, Trent University, Canada

Clary Krekula, Karlstad University, Sweden

Vivian Weiqun Lou, University of Hong Kong, China

Phyllis Moen, University of Minnesota, USA

Judith Phillips, University of Wales Swansea, UK

Chris Phillipson, Keele University, UK

Tine Rostgaard, The Danish National Centre for Social Research (SFI), Denmark

Julia Rozanova, The University of British Columbia, Canada

Neil Selwyn, Institute of Education, University of London, UK

Nan Stevens, Radboud University, The Netherlands

Christine Swane, EGV, Denmark

Aagje Swinnen, Maastricht University, The Netherlands

Cynthia Torges, North Dakota State University, USA

Lucie Vidovicova, Masaryk University, Czech Republic 


\title{
Migrant home care workers caring for older people: fictive kin, substitute, and complementary family caregivers in an ethnically diverse environment
}

\author{
By Andreas Hoff ${ }^{1}$, Susan Feldman ${ }^{2} \mathcal{E}$ Lucie Vidovicova ${ }^{3}$
}

The world's population is ageing, both in the more developed and the less developed regions. Contrary to popular belief, the majority of older people live in less developed countries such as China or India due to the sheer numbers of their populations. More developed societies also have large numbers of older people in their populations relative to that of younger people due to low fertility rates and increasing longevity. Currently, the oldest society in the world is Japan, where $22.7 \%$ of the population are 65 years and older, followed by Germany $(20.4 \%)$ and Italy $(20.1 \%)$, proportions that will increase to almost a third in Japan and more than a quarter in Germany, Italy, Finland, and Slovenia by 2030 (International Institute for Applied System Analysis [IIASA] 2010). A characteristic feature of this population ageing is the accelerated ageing of the "oldest old" i.e. those aged 80 years and older (Eurostat 2010; United Nations [UN] 2010). This is of particular relevance in the context of this Special Issue on Migrant Care Workers Caring for Older People in their Homes,

\footnotetext{
${ }^{1}$ Andreas Hoff, Oxford Institute of Ageing, University of Oxford, UK and Zittau/Görlitz University of Applied Sciences, Görlitz, Germany

${ }^{2}$ Susan Feldman, Healthy Ageing Research Unit, Faculty of Medicine, Nursing and Health Sciences, Monash University, Australia

${ }^{3}$ Lucie Vidovicova, Faculty of Social Studies, Masaryk University, Czech Republic
} 
International Journal of Ageing and Later Life

since people in their 80 s are at a much higher risk of needing care than those in their $60 \mathrm{~s}$ and $70 \mathrm{~s}$ and, thus, represent the majority of care recipients assisted by migrant care workers.

Traditionally, caregiving has been delivered informally by members of an older person's family. However, the combined effects of a shrinking pool of young and middle-aged potential caregivers, increasing labour market pressures, and the extension of working lives - in many cases to supplement public pensions - are making this increasingly difficult. In principle, there are two contrasting solutions to the dilemma of growing demand for care at times of depleting supply by assigning ultimate responsibility for caregiving to two different societal actors: The first solution would be to frame care provision as a societal task rather than a private matter. Accordingly, responsibility for care provision would then lie with the welfare state and funded through general taxation and social insurance contributions. Comprehensive care provision through public care providers, both in institutional and in social care, would be the norm. Families who still have to - or prefer to - provide care would be recompensated for doing so by the state. This solution is sometimes referred to as "high road solution" (Leeson \& Hoff 2009).

In contrast, the "low road solution" aims at saving public expenditure by assuming the continuation of traditional caregiving roles by the family (women), thus assigning families the ultimate responsibility for care provision. However, the latter approach is no longer compatible with the "double earner" reality of working lives as experienced by most men and women in contemporary societies, which inevitably results in the search for solutions that fall "in-between" the above-mentioned "high road/low road" poles. The employment of migrant care workers in older people's homes is an example of such an "in-between" solution, often resorted to by desperate families caught between caring responsibility and the need to earn a living. It is thus an unintended side-effect of public policies promoting the traditional family caregiving model that leaves responsibility for the organisation and provision of care with the family, which - despite slightly increasing numbers of men providing care - effectively still translates into female caring responsibility, ignoring the fact that the context in which contemporary families operate has changed. 
The matter is further complicated by the persistence of traditional caregiving norms and values embedded in contemporary societies' cultural heritage. As a consequence, family care provision is often expected and the preferred arrangement in most European countries. Various studies have confirmed this, such as the European DIALOG project, in which 14 different European countries participated (Höhn et al. 2008). When asked about help from private persons (which may include migrant care workers), $40 \%-60 \%$ would prefer that, with the highest figure in Austria $(77 \%)$ and the lowest in Finland (39\%) (Höhn et al. 2008). These expectations may result in additional tensions when facing the realities of giving care.

In the European context, "high road solutions" to delivering care in an ageing society would be exemplified by the Scandinavian or Nordic care regime (Denmark, Finland, Norway, or Sweden), which is characterised by predominance of public care services, while the Mediterranean or Southern European countries (Cyprus, Greece, Italy, Malta, Portugal, or Spain) would represent the other extreme, with almost exclusively family care provision (Anttonen \& Sipilä 1996). Anttonen and Sipilä did not make any reference to the post-communist societies of Eastern Europe that in our view would be another example for almost total reliance on family care resources, with hardly any public care provision available. The remaining European countries would sit somewhere in-between, with varying degrees of family and state responsibility for care provision - as would Austria, Canada, and Israel, the "migrant care worker receiving" countries covered in this Special Issue.

Most of what has been said above was in reference to the "demand side" of the migrant home care worker debate, i.e. the perspective of families with caregiving responsibility for an older person. However, there is also a "supply side" to the migrant care worker phenomenon. The economic impact of globalisation has seen a growth of migration flows to Western societies, with migrants quickly responding to socio-economic needs in the West while trying to escape socio-economic hardship in their countries of origin in the less developed world. The "surge in female-driven immigration" (Leeson \& Hoff 2009: 1) in response to increasing demand for both formal and informal eldercare labour is a good example. This has also resulted in subtle changes in the gendered experience of migration: while in the past migration was typically associated with young male 
International Journal of Ageing and Later Life

workers, increasing numbers of contemporary migrants are female (Arya \& Roy 2006; George 2005), with many of them working in eldercare (Leeson \& Harper 2006).

Global movements of labour have implications for both the migrant care worker "receiving" and for the migrant care worker "sending" societies. While the former countries benefit from the care labour provided by migrant care workers, the latter may benefit from remittances these migrant workers send home, as is evident in a large body of research literature on remittances (see, for example, Goldring 2004; Rapoport \& Docquier 2006; Russell 1986).

Less well documented are the consequences for migrant care workers' families who are left behind in their home countries. Implications for the families of people who leave to work as carers in other countries range from the need to reorganise their own family care arrangements to possible conflict between legal and moral obligations. The impact of migration on the wider family network also needs to be taken into consideration. Some writers have reported the establishment of other informal support structures (e.g. grandparents, other relatives) to fill the arising gaps in child care and care for older family members (Leeson \& Hoff 2009).

The "migrant sending" versus "receiving" dichotomy also implicitly points to the very dynamic nature of migration processes. Migration flows are far from static - they respond quickly to changing socio-economic circumstances, as the example of a rapidly decreasing inflow of Eastern European immigrants to the UK in response to the 2008 economic crisis demonstrates (BBC 2009). Moreover, several of today's main migrant receiving countries were migrant sending countries not too long ago - see the examples of Italy, Spain, or Ireland. Today, the transition from a migrant sending to a migrant receiving country occurs at an even more rapid pace, sometimes even within the space of a few years. In some cases, this rapid transformation process even results into a situation where societies simultaneously experience the process of both migrant sending and migrant receiving, as the example of Poland shows. Polish migrant care workers are known to be working across Europe (in Germany, Ireland, Italy, Sweden, or the UK, for example). What is less well known is that Poland (at least the metropolitan area around the capital Warsaw) has 
also experienced an influx of migrant care workers from Belarus and the Ukraine (Fratczak 2007).

This type of migration, i.e. the replacement of lost labour through immigration from even poorer countries, however, does not represent a sustainable solution to the problem. Welfare gap theory can be used to explain economic migration from one country to another (see Vobruba 1998, 2003). According to this theory, people from a less well off society (e.g. Poland) migrate to another country where they can earn higher wages (e.g. the UK) relative to their country of origin. That country of origin (Poland), however, may offer better economic prospects to workers from an even more deprived society (the Ukraine, for example). It would however be short-sighted to assume that there will always be a poorer country that would solve the problems of a wealthier one. Assuming that there will be a continuous supply of migrant labour from a particular migrant sending country to replace or supplement family care in a specific migrant receiving country is likely to be fallible in the long-term since it does not take into account future socio-economic changes in both sending and receiving societies, which may change the incentive structure for migration as well as for trying to attract migrants.

Moreover, questions might be raised about ethics for countries striving to solve their problems at the expense of others, as the "brain drain" discourse in regard to attracting the educated elites from developing countries to come and stay in the Western world pointed out. In this debate it was proposed that such a position deprived the home societies of human capital (i.e. a very scarce resource). Likewise, employing care workers from developing countries in Western societies to fill labour shortages in aged care results in a "care drain" in the sending countries (Leeson \& Hoff 2009).

But ethical considerations also apply to the relationship between migrant care worker and indigenous care recipients, which is often characterised by multiple dependencies. Many migrant home care workers actually live in the care recipient's home, which enables them to provide care up to 24 hours a day, seven days a week. Obviously, these working hours would not be tolerated in the formal labour market. Moreover, migrant care workers employed by families on an informal basis are in many, if not in most cases, not appropriately compensated for the long 
International Journal of Ageing and Later Life

hours they work. Additionally, live-in carers depend on the care recipients (and their families) for their accommodation, a dependency that is further emphasised in the case of foreign workers who entered the host society illegally (Leeson \& Hoff 2009).

On the other hand, the care recipient is also dependent on the care worker for providing care, which makes him or her a potential target of physical or mental abuse. In addition, the quality of care provided by an often untrained, unqualified care worker is an issue. Another concern in increasingly culturally diverse societies is that of "culture-sensitive" care. Whereas this concept has so far mainly been applied to older people from ethnic minority backgrounds receiving care, the employment of a migrant care worker (from Latin America, Africa, or Asia) foreign to the host society and who does not necessarily speak the language of the native population for whom they provide care, let alone understand their cultural needs, is problematic (Leeson \& Hoff 2009).

Although there is an abundance of anecdotal and mass media evidence of the increasingly important role migrant care workers play in enabling Western health and social care systems, as well as families coping with the demands of growing numbers of older people needing care, research-based literature is still scarce. Migration statistics are notoriously sketchy, particularly concerning repeated short-term or pendulum migration, as it is the case with migrant care workers, which does not really help the situation. Neither does the fact that illegal employment of a migrant care worker by families trying to avoid legally binding, but expensive social insurance payments in some countries (Germany, for example), makes this a criminal offence.

A few pioneering studies have been published in recent years providing invaluable insights into the increasingly important role played by migrant care workers in delivering family care. Unsurprisingly, most of these studies originate in familialistic societies, such as those clustered around the Mediterranean Sea in Southern Europe. Thereby, Italian researchers are leading the way (see, for example, Bettio et al. 2006; Bettio \& Plantenga 2004; Lamura 2007; Lamura et al. 2008). More recently still, first research evidence of the use of the same coping strategies by families further north in Europe was provided - for Ireland (Doyle \& Timonen 2009; Timonen \& Doyle 2010), the UK (Cangiano et al. 2009), and Germany (Hillmann 2005; 
Theobald 2010). Nevertheless, despite the recently growing popularity of migrant care workers as a research theme, the present Special Issue is still an important step filling a substantial gap in the research-based literature.

This Special Issue takes up the challenge and includes three papers by prominent writers in the field. First is a conceptual paper by Bernhard Weicht, focusing on Austria and the UK. Following a substantial review of existing literature on the migrant care worker problematic, his article focuses on the relation between the moral construction of migrant carers in the family-oriented welfare system of Austria and the ideological understanding of "ideal" care in society. Using Critical Discourse Analysis, the public discussion in newspapers is analysed, which is complemented through focus group interviews. Weicht suggests that migrant carers are constructed as fictive kin in public discourse in Austria, representing an approximation of the idealised family carer.

The following article by Esther Iecovich focuses on the specific situation of migrant live-in homecare workers, based on the case of Israel. The purposes of her study are to examine to what extent migrant live-in homecare workers substitute family caregivers or complement care provided by primary caregivers, and to examine how the employment of a migrant care worker changed the primary caregivers' involvement in providing help with Activities of Daily Living (ADL)/Instrumental Activities of Daily Living (IADL). Her research is based on a study of 335 triads (care recipients, their primary caregivers, and their Filipina live-in homecare workers).

The third paper is written by Anne Martin-Matthews, Joanie Sims-Gould, and John Naslund and extends the perspective to Canada, thereby focusing on the implications of caregiving by migrant care workers in an ethnically diverse social setting. Their paper investigates characteristics of immigrant homecare workers, and the ways in which they differ from non-migrant care workers in Canada. Their research is set in the ethnically very diverse metropolitan area of Vancouver, British Columbia, which has implications for the interaction between client and worker reflecting this ethno-cultural diversity, and the strategies employed by workers to address issues related to this diversity. Their study is based on interviews with 118 migrant care workers. 
International Journal of Ageing and Later Life

\section{Acknowledgements}

The editors would like to acknowledge the support received for preparing this Special Issue of IJAL from Research Committee 11 "Sociology of Aging" of the International Sociological Association (ISA). Furthermore, we would like to thank the participants in session S16 "Migrant Care Workers" of the Research Committee on Ageing (RC 11) conference programme at the First International Sociological Association's Forum of Sociology, held in Barcelona, Spain, on September 5-8, 2008.

Moreover, this editorial was in part inspired and informed by the NORFACE Seminar Series "Migrant Labour in the Eldercare Sectors" (MILES), coordinated by George W. Leeson and Andreas Hoff, Oxford Institute of Ageing, University of Oxford, in 2007 and 2008. Generous funding of the seminar series by NORFACE ERA-Net under the NORFACE Seminar Series 2006 "Immigration and Demographic Challenges in Europe" is gratefully acknowledged, as are the seminar series participants' contributions, which informed the final report of the seminar series (Leeson \& Hoff 2009), and thus indirectly the present editorial paper.

Finally, we would like to thank Laura Machat-From at IJAL for her very kind and highly efficient editorial support and the IJAL Editor in Chief Lars Andersson for his very helpful editorial guidance. Any omissions or mistakes are of course sole responsibility of the authors and guest editors of this Special Issue.

\section{References}

Anttonen, A. \& Sipilä, J. (1996). European social care services: Is it possible to identify models? Journal of European Social Policy 6(1): 87-100.

Arya, S. \& Roy, A. (eds.). (2006). Poverty, Gender and Migration. Thousand Oaks, CA: Sage.

BBC. (2009). More Eastern Europeans leaving UK. Available on http:// news.bbc.co.uk/1/hi/uk/8059122.stm (Accessed May 20, 2009).

Bettio, F. \& Plantenga, J. (2004). Comparing care regimes in Europe. Feminist Economics 10(1): 85-113. 
Bettio, F., Simonazzi, A. \& Villa, P. (2006). Change in care regimes and female migration: The "care drain" in the Mediterranean. Journal of European Social Policy 16(3): 271-285.

Cangiano, A., Shutes, I., Spencer, S. \& Leeson, G. W. (2009). Migrant Care Workers in Ageing Societies: Research Findings in the United Kingdom. Oxford: COMPAS.

Doyle, M. \& Timonen, V. (2009). The different faces of care work: Understanding the experiences of the multi-cultural care workforce. Ageing \& Society 29(3): 337-350.

Eurostat. (2010). Europe in Figures. Eurostat Yearbook 2010. Luxembourg: Publications Office of the European Union.

Fratczak, E. (2007). Poland as a migrant sending country. Paper presented at NORFACE "Migrant Labour in the Eldercare Sectors" Seminar in Oxford, January 8-10, 2007.

George, S. M. (2005). When Women Come First: Gender and Class in Transnational Migration. Berkeley: University of California Press.

Goldring, L. (2004). Family and collective remittances to Mexico. Development and Change 35(4): 799-840.

Hillmann, F. (2005). Migrants care work in private households, or the strength of bilocal and transnational ties as a last(ing) resource in global migration. In B. Pfau-Effinger \& B. Geißler (eds.), Care and Social Integration in European Societies (pp. 93-114). Bristol: Policy Press.

Höhn, C., Avramov, D. \& Kotowska, I. (eds.). (2008). People, Population Change and Policies. Lessons from the Population Policy Acceptance Study, Vol. 2: Demographic Knowledge, Gender, Ageing. Dordrecht: Springer.

International Institute for Applied System Analysis (IIASA). (2010). European demographic data sheet 2010. Available on http://www.iiasa. ac.at/docs/HOTP/2010/Jul10/DataSheet.pdf (Accessed: November 20, 2010).

Lamura, G. (2007). Italy's "familistic" approach to elderly care and the new role of migrant home care workers. In V. Burau, H. Theobald \& R. H. Blank (eds.), Governing Home Care. A Cross-National Comparison (pp. 118-121). Cheltenham: Edward Elgar.

Lamura, G., Melchiorre, M. G., Principi, A., Luccetti, M. \& Polverini, F. (2008). Migrant workers in the eldercare sector: The Italian experience. 
International Journal of Ageing and Later Life

In Securité Sociale t'Assurance Retraite Caisse Nationale (ed.), Retraite et Société Selection 2008 (pp. 125-152). Paris: CNAV.

Leeson, G. W. \& Harper, S. (2006). Foreign Workers in the Health and Social Care Sector in the United Kingdom. Tokyo: Japanese Council of Social Welfare.

Leeson, G. W. \& Hoff, A. (2009). Final Report of the NORFACE Seminar Series "Migrant Labour in the Eldercare Sectors." Oxford: Oxford Institute of Ageing.

Rapoport, H. \& Docquier, F. (2006). The economics of migrants' remittances. In S.-C. Kolm \& J. M. Ythier (eds.), Handbook of the Economics of Giving, Altruism and Reciprocity (pp. 1135-1198). Amsterdam: Elsevier.

Russell, S. S. (1986). Remittances from international migration: A review in perspective. World Development 14(6): 677-696.

Theobald, H. (2010). Migrant family carers in Austria and Germany: Policy fields, policy development and their interplay. Paper presented at the ESPAnet Conference, September 2-4, 2010, Budapest, Hungary.

Timonen, V. \& Doyle, M. (2010). Migrant care workers' relationships with care recipients, colleagues and employers. European Journal of Women's Studies 17(1): 25-41.

United Nations. (2010). United Nations programme on ageing. Available on http:/ / www.un.org/ageing/ popageing.html (Accessed: November 20, 2010).

Vobruba, G. (1998). The social dynamic of welfare gaps. Prolegomena to the transnationalization of sociology. Sociological Analysis 1(3): 27-40.

Vobruba, G. (2003). The enlargement crisis of the European Union: Limits of the dialectics of integration and expansion. Journal of European Social Policy 13(1): 35-49. 


\title{
Embodying the ideal carer: the Austrian discourse on migrant carers
}

\author{
By BERNHARD WEICHT*
}

\begin{abstract}
Demographic developments have caused challenges to national arrangements for elderly care. In Austria one answer has been the employment of migrant carers in the home of people with care needs. The literature on migrant carers has largely discussed economic considerations and specific national welfare state arrangements which underlie the employment of carers. This article focuses on the relation between the moral construction of migrant carers in the family-oriented welfare system of Austria and the ideological understanding of "ideal" care in society. Using Critical Discourse Analysis the discourse is analysed in newspapers and through focus groups. Migrant carers are constructed as fictive kin, representing an approximation of the idealised family carer. Furthermore, investigating the way people think and talk about migrant carers enables a better understanding of what an idealised notion of care entails and how it represents the ideological construction of the welfare state. It will be argued that the migrant carer is constructed in the public discourse as a replacement for a nostalgically imagined ideal care relationship.
\end{abstract}

Keywords: care, migration, discourse, fictive kin, Austria. 
International Journal of Ageing and Later Life

\section{Introduction}

The organisation of care for the elderly at the beginning of the $21^{\text {st }}$ century in most European countries can be characterised by a discourse on the problems and difficulties related to ageing societies in combination with a decline of traditional family structures. This combination, caused by demographic developments, a social restructuring and rearrangement of family units and a redefinition of family attitudes and values, results in heavy pressures on both families and national welfare state regimes. One answer to adapt to these new struggles in the realm of care has been the employment of migrant workers in informal care settings. However, in particular the latter causes substantial ideological, moral and ethical challenges.

In Austria, care for elderly people, still largely seen as a family issue, is challenged by demographic developments related to an ageing society and changing family structures with underlying adaptations in the norms and values people associate with family. In August 2006, the fact that many Austrian families employ migrants to care for their relatives became an issue of public concern. Since then, live-in arrangements with migrant carers have been a widely discussed topic in the political realm, as well as in newspapers and other public media. The newspaper discourses use "ageing" as a concept that society undoubtedly faces and which requires new ideas and initiatives. Migrant carers are then constructed as the ideal actors in a situation of complex care arrangements. The employment of strangers in personal, intimate settings, however, creates a paradoxical situation and raises many moral, cultural and social considerations. Whereas issues of economics and legal and practical matters do play an important role, the construction of care as an issue of love, relationships and close family bonds has fostered the emergence of other factors underlying the discussion on the employment of migrants. In this article I will explore the discourses that negotiate and underlie the current trends to employ migrant carers within family settings and I will focus in particular on the ethical, moral and social difficulties and problems arising due to informal care's cultural and traditional construction. My main aim is to explore to what extent care provided by migrants is constructed as a new form of informal care. Does the employment of migrant carers in Austria challenge the moral framework of care based on family bonds? 
Analysing the construction of migrant care within the moral and political context of care arrangements I will identify to what extent ideas about and opinions on migrant care for the elderly are changing in society. I will investigate how the employment is justified, morally and ideologically (see also Weicht forthcoming). I will then point out that the employment of migrants enables a continuation of the traditional care and welfare model, financially and economically, but also morally and culturally. The situation of migrants caring for elderly people comes close to the discursive notion of nostalgia about what is perceived as "ideal" care. The aim here is to identify to what extent the discourse on migrant carers reproduces constructions of care in general. What does this discourse show about the meaning of care in Austria?

I will start this article by reviewing several aspects of the literature on the employment of migrant carers which has been developed over the last decade. I will show that the literature covers large parts of the specific discourses in Austria, but that aspects of morality and the link between migrant care and the ideal of care in general are still under-researched. After some methodological remarks, I will discuss the Austrian discourse in detail giving evidence for the construction of care performed by migrants. I will thus look at the moral construction of care and analyse whether or not migrant carers are seen similarly to the ideal of a family carer. Does this relation mean that carers are constructed as fictive kin? And finally, if the discourse on migrant carers refers to an imagined ideal of care, how can this nostalgia of care be described? Does the employment of migrant carers lead to a "defamilisation" of the Austrian welfare state? In that sense I will argue that migrants in Austria enable a prolongation of nostalgia and the creation of the notion of idealised care arrangements.

\section{Migrants as Link between Formal and Informal Care}

The discussion on care being increasingly related to two striking dimensions of the modern world, namely demographic development and transnational migration (see van der Geest et al. 2004; von Kondratowitz 2005) raises the fundamental question of who can and wants to provide intimate care to elderly people. The employment of migrants in the context of care has received substantial attention in the academic world. Particularly the 
International Journal of Ageing and Later Life

question of domestic workers has become a distinct field of research in several disciplines. Beside others, Anderson's book Doing the dirty work (2000) has drawn huge attention to the employment of migrants in domestic settings, in particular in Europe (Anderson 1997, 1999, 2000; Cox 1999; Lutz 1997, 2008), the US (Hondagneu-Sotelo 2007; Mattingly 1999; Parreñas 2000, 2001), Canada (Arat-Koc 1997; Bakan \& Stasiulis 1997; Henshall Momsen 1999), Australia (Baxter et al. 2009; Bittman et al. 1999; Hugo 2009) and some Asian countries (Chang \& Ling 2000; Cheng 1996; Lan 2003; Yeoh et al. 1999). These accounts cover the phenomenon of domestic workers and its underlying economic and social power relations. Many of the issues discussed in the context of domestic workers are equally important in the particular field of care workers. Bakan and Stasiuslis (1997), for example, point out that paid domestic labour is often not seen as real labour and the people who do it are not regarded as real workers, due to the characteristics of the private home as the workplace. They furthermore argue that family ideology plays an important role and domestic workers are often included into family settings which, however, ignores the "objective economic, political, legal, and social conditions, and the class-based relations between employers and foreign domestics, that exist on a global scale" (Bakan \& Stasiulis 1997: 11).

Another important field of research focuses on the employment of migrant workers in the formal health care and elderly care sector, as care assistants or nurses. In particular in the UK several studies show the enormous importance of migrant workers for the national care sector (Cangiano et al. 2009; McGregor 2007; see also Doyle \& Timonen 2009 for a study in Ireland; for a cross-national comparison see Lyon \& Glucksmann 2008; von Kondratowitz 2005; for a source country perspective see Lorenzo et al. 2007). The idea that care is more and more provided by migrant workers also extends to the informal sector. Rationales for employing migrants in domestic settings on a superficial level also deal with issues of unwillingness of domestic carers. They are, however, also strongly touching on issues of morality and sentiments. The literature focusing particularly on migrant carers in people's households is more restricted and is mainly focused on specific national welfare state contexts. Using a broad categorisation I will group research available on migrant carers into two perspectives. Firstly, I will discuss accounts adapting economic, political and social policy viewpoints. This set of literature is important in demonstrating the global 
power relations in combination with national welfare and migration systems. Secondly, I will present some literature focusing on moral, cultural and ideological questions of the employment of migrants in domestic care settings.

\section{Economic, Political and Social Policy Perspectives}

Care work performed by migrants in both formal and informal contexts is often underlined by national welfare state arrangements. In that sense migration regimes and care arrangements are often intertwined (see for example Lutz 2008; Williams \& Gavanas 2008). Specific welfare state policies have furthermore fostered the employment of migrants in the care sector (Escriva \& Skinner 2008; Gerling 2003; Hillmann 2005; Lutz 2008; Scrinzi 2008; Williams \& Gavanas 2008). Ungerson (2004), for example, presents a comparison of the emergence of commodified care work in various European labour markets and links these to the particularities of national "cash for care" schemes which can promote the existence of migrant care work in people's homes. Hugo (2009) presents some data on the Australian programme of circular migration with which care labour market shortages should be met. Simonazzi (2009) on the other hand focuses on the national employment and migration models which shape the features of the respective care labour markets. A particular economic and social distinction of care arrangements in a country in relation to the specific welfare state conceptualisations have also been of explicit interest in economic, sociological and social policy literature (Daly \& Lewis 2000; Lewis 1992; Pfau-Effinger 2005; Pfau-Effinger \& Geissler 2005; Sainsbury 1994).

An important tool to understand the global implications of the employment of migrant care workers has been developed through the global care chain concept (Lutz 2008; Yeates 2004) which allows an understanding of the relationship between globalisation, migration and care. The focus here is on the consequences of care demands in some parts of the world met through the employment of migrant care workers which produces care shortages in other parts of the world. Care thus needs to be seen as a pivotal issue in migration (Ackers 2004; see also structure of this special issue). Escriva and Skinner (2008), for example, discuss the concept of care chains in Spain showing the various aspects of global and national 
International Journal of Ageing and Later Life

care migration. Much of the literature presented above also strongly focuses on the problematic consequences of the employment of migrant carers which are often due to power differences (e.g. Anderson 2000), such as racism and prejudices (Doyle \& Timonen 2009), problems of illegality (Coyle, 2007; Lutz 2004), problematic dependency relations between the care worker and the cared for elderly person and related lack of freedom (Degiuli 2007) and the significance of language abilities (Brush \& Vasupuram 2006).

Finally, some literature focuses on the reasons why particularly migrants are employed in the care sector, both formally and informally. Dyer et al. (2008), for example, argue that the combination of emotional labour and body work which is poorly paid and has low status can be seen as both reason and consequence of the recruitment of migrant workers. Lutz (2008) discusses the gender implications of elderly care, in the context of migration and globalisation (see also Sassen 2003; Zimmerman et al. 2006). Fine and Mitchell (2007) in the Australian context link low pay and low status to the fact that migrant carers are employed and argue that inevitably class, gender and ethnic power relations are interlinked and that in particular poor women from vulnerable ethnic minorities are employed in the care industries. These accounts raise important questions of cultural and social challenges. This focus, however, is more strongly adopted by another perspective within the realm of literature on migrant carers.

\section{Social, Cultural and Moral Perspectives}

Another set of literature focuses more on cultural circumstances and underlying moral connotations of the employment of migrants in care work, specifically in private households. Several accounts focus on the everyday experiences of migrant carers in domestic settings and its challenges for the moral, social and cultural meanings of care for elderly people in society (Flaquer \& Escobedo 2009; Hillmann 2005; Lutz 2002, 2004; Zimmerman et al. 2006). Anderson (2000), for example, demonstrates that migrant workers are not necessarily paid to deliver specific tasks; rather their personhood and time is bought. I will explore this idea below in the discussion of migrant carers in Austria. Da Roit (2007) writes about the interrelation between intergenerational relationships and the employment 
of migrants in people's homes. Degiuli (2007) also discussing the situation in Italy presents interview data on migrant workers' experiences. Generally it can be noted that the literature on migrant domestic carers is particularly extensive in relation to the Mediterranean countries and the respective welfare states (Bettio et al. 2006; Glucksmann \& Lyon 2006; van der Geest et al. 2004), or Asian societies (Huh 2008; Mehta \& Thang 2008). Comparative perspectives on migration and care in general can also be found in Glucksmann and Lyon (2006) and van der Geest et al. (2004). The specifics of the phenomenon of migration that can be found in the Austrian context are more precisely described by the terms rotational (Bettio et al. 2006) or pendulum migration (Glucksmann \& Lyon 2006).

Several perspectives also focus on the everyday experiences of transnational care giving (Brijnath 2009). Roseneil and Budgeon's (2004) more general discussion of intimacy outside the traditional realm and the focus on non-normative intimacies is very helpful in investigating the situation of migrant carers living with elderly people. Since care needs to be seen "as a hybrid of love and instrumentality" (Ungerson 2000: 627) this tension is of particular interest for those analysing the processes happening in domestic family settings. Bonifacio (2008), for example, discusses the representation of Filipino women in Canada who are live in carers as the "new heroes" and Akalin (2007) analyses the Turkish situation in which women turn from foreign employees to fictitious family members to what is regarded the "the ideal housewife". Similarly, Barker (2002) and Karner (1998) discuss the phenomenon in which carers are "adopted" by the family and are becoming "fictive kin". The situation of migrant carers in Austrian households has not yet received much academic attention. Haidinger (2008) and Kreimer (2006), however, give some context of the particularities of the Austrian long-term care system and its policy responses to demographic developments. Both also include some analysis of the employment of migrant carers. Jandl et al. (2007), Da Roit et al. (2007) and Österle and Hammer (2006) give some information on the specifics of the Austrian cash for care scheme and its relation to the employment of migrant carers. Österle and Hammer (2006) also present a comparison with other European cash for care schemes. Beside this focus on the policy context there is a lack of literature on the link between the Austrian moral and cultural conception of long-term care for elderly people and the situation of migrant carers. In this article I will thus explore 
International Journal of Ageing and Later Life

the specifics of the Austrian system which, however, allows insights in the importance of a focus on the moral basis of care arrangements in other countries.

\section{Methodological Remarks}

The concept of discourse I use in this paper is defined as the way people construct and make sense of their everyday lives and experiences. Discourse is "undertaken by social actors in a specific setting determined by social rules, norms and conventions" (Wodak 2008: 5). For this investigation I utilise Critical Discourse Analysis (CDA) to analyse the discourse in its particular historical, cultural, political and material context (Reisigl \& Wodak 2001; Wodak 2001a, 2001b; for the linguistic categories being used see also Chouliaraki \& Fairclough 1999; Meyer 2001; van Dijk 2001). First, I use a sample of Austrian newspapers in order to identify "what is both acceptable and socially thinkable" (Aldridge 1994: 35) and what could be called the dominant discourses in society reflecting the social mainstream (Mautner 2008). Newspapers can be seen as a representation and reflection of dominant discourses, using narratives, ideas and ideologies that can be expressed publicly and which are hence thought to be shared widely. CDA understands discourse as a social practice and acknowledges that individuals are affected by the very discourse in two ways: as those designing it and as those being shaped by it (Weiss \& Wodak 2003: 13) or, in Mautner's (2008: 32) words, discourses are "socially constituted but also constitutive".

The study is based on a sample of five Austrian newspapers (Kronen Zeitung, Österreich, Kurier, Die Presse, Der Standard) which have been analysed over a period of one year (August 2006-August 2007). The choice of the sample is based on Reisigl and Wodak's (2001) study (for a discussion of various differentiations of newspapers see Bednarek 2006: 219 et sqq.; for a CDA perspective on the analysis of newspapers see Richardson 2007). The choice of newspapers reflects the attempt of generating an exemplifying but nevertheless representative sample. Different newspapers reflect different ideologies and try to build up some shared identity with their readership. Different newspapers, for example, follow different ideas of what and how human beings are (e.g. 
selfish, rational, caring) and how a decent society is composed. It could be said that the relationship between readers and their newspapers is based on the provision of ontological security (see Richardson 2007) by "creating a system of shared values" (Reah 2002: 40). The sample inevitably entails the most popular (i.e. best selling) newspaper (Kronen Zeitung). ${ }^{1}$ It furthermore reflects a combination of "tabloids" and "broadsheets" as well as a reflection of the political spectrum from what are considered to be working class and rather sensationalist papers (Kronen Zeitung, Österreich), a middle range paper (Kurier) to quality newspapers, ranging from conservative to liberal papers (Die Presse, Der Standard). The sample of papers reflects the Austrian market of national daily newspapers.

The analysis of newspapers was carried out in several steps. In a pilot study, covering the period of July-August 2006, I familiarised myself with the field and I constructed preliminary categories for the analysis. The second step was a preliminary text search carried out over the Internet. This enabled an identification of a vast range of articles on care in various newspapers. I ordered these articles and extracted reoccurring themes, narratives, terms and concepts. The third step was a search and analysis of "typical texts" in their various original contexts. I could draw on my preselection in order to identify important, common and relevant materials in the way they originally appeared in the newspapers. For this endeavour I used the newspaper archive of the Austrian National Library in Vienna. The texts studied in detail were then always related back to the whole sample of articles referring to care.

Similarly to Richardson (2007; see also van Leeuwen 1996 and Mautner 2008) I use Wodak's process of analysis starting with the micro-textual level (and here I explicitly refer to the use, the choice and the meaning of certain words and the construction of sentences). As Richardson (2007) points out, when writing articles, journalists choose one word, one category and one term over another one and give in this way a certain meaning to it. This is followed by a mid-level analysis (which includes, for example, a discussion of modalities, i.e. the speakers' attitudes, judgements and evaluations, an analysis of other presuppositions prevalent in the text itself). The last step builds an evaluation of the narratives and plots

\footnotetext{
${ }^{1}$ Sources: Österreichische Auflagenkontrolle (2008).
} 
International Journal of Ageing and Later Life

being used to tell a story, to report news or to construct a commentary. Also, doing justice to a context-aware evaluation, it must not be forgotten in the analysis of texts to think about the aspects that are absent. Aldridge (1994: 3) rightly asks: "what does not make the news?" Strikingly significant differences between the newspapers in their writing on the theme of migrant carers could not be identified. Even populist, rather right-wing papers wrote about (at this point in time illegally employed) migrant carers in a positive way. This suggests recognition and acknowledgement of the fact that Austria needs these workers; it also points, however, to a criticism of political processes through which these workers had to work undocumented and illegally.

The categories and narratives identified in the newspapers were then used in six focus group discussions. I also used materials analysed from national newspapers in the focus groups, such as pictures or statements which I asked the participants to reflect on. Focus groups are, as Bloor et al. (2001) put it, the ideal method to identify group norms and understandings. Similarly, May (2001: 125) emphasises the possibility of focus groups "to explore group norms and dynamics" and states that focus groups are the best way to get as close as possible to normal conversation manners. From a CDA perspective Wodak (2008) also emphasises the strength of focus groups in creating a "semi-public" genre (see also Krzyżanowski 2008). I want to use the characteristic of focus groups "to study the ways in which individuals collectively make sense of a phenomenon and construct meanings around it" (Bryman 2004: 348; italics added) in a way that best resembles everyday interaction. Krzyżanowski (2008) sees the views expressed in focus groups at the borderline between public, collectively held views and views of selected small-scale groups and individuals. He therefore argues that focus groups are the ideal realm to analyse how "the public sphere influences (...) individuals' views on politics and society and how, conversely, the ideas crucial to the "social" (individual) level penetrate (...) into politics, into the media and into other constituents of the public sphere" (Krzyżanowski 2008: 169). I used both pre-existing groups (groups which were constituted in another context and in which people therefore knew each other) and groups of strangers and the participants were recruited through local organisations, clubs, church groups, political parties and informal networks. The focus groups 
consisted of three to six participants and lasted between $1 \frac{1 / 2}{h}$ and more than $2 \mathrm{~h}$. These so called "minigroups" (Bryman 2004) could offer the characteristics of group discussion but also allowed more personal accounts and stories. The focus group discussions took place in various public and private venues in Austria. In the recruitment phase I tried to make sure to have a widespread representation of participants in the focus groups. Both women and men participated, though in general there were more women present (there was one group organised with women only). Participants reflected various age groups and their relatedness to care (whether they themselves have experience with caring) varied significantly.

The main aim of the discourse analysis was to identify how people talk about care. Which narratives do they use? Who are the subjects in the stories? Which stories are being told? I was mainly interested in the construction of categories, such as carer, migrant, elderly, dependent, independent and how these categories are being used in the discursive processes. How people discuss care, which stories they tell and how they use and construct categories, describe what Williams (2004: 17) called the creation of "the proper thing to do". The discursive accounts below are representative for the discourses in question. As can be expected people usually refer to their own experiences when talking about care. The categories and narratives they use, however, represent broader societal features. People draw on some moral consensus (Honneth 1995) which can be seen as a dominant form of moral understanding in society. Similarly I could not identify significant differences between men and women or between different age groups in the ways care is constructed. That does not mean that every individual thinks the same about care. It rather means that on a societal level a certain attitude and routine is constructed through which everyone makes sense of ageing and care.

At the time of the beginning of the newspaper analysis, the theme of migrants caring in Austrian households became a much discussed issue in the public realm. In August 2006 the topic of a "Pflegenotstand" [care emergency] became a significant issue in the pre-election debate. The fact that many Austrian households "illegally" employed migrant carers challenged the government's position that there are no difficulties with the provision of care in the country. From summer 2006 onwards migrant carers were a topic of discussion in every newspaper and featured in every 
International Journal of Ageing and Later Life

contribution on care. This was also partly reflected in the focus groups organised in May and June 2008. Several participants have employed migrants as carers for a family member or knew people who had done so. All participants were familiar with the discourses on migrant carers in the media.

\section{The Discourse on Migrant Carers - Reproduction of a Moral Consensus}

\section{The Austrian Situation}

As Doyle and Timonen (2009) note, for migrant care workers both their region of origin and the situation in the country they are working in play an important role for their life circumstances. I will therefore first present some information on the Austrian system of care, followed by the specifics of the discourse. The Austrian arrangement for the provision of care for elderly people is largely based on informal settings, usually within the care receiver's family (Österle \& Hammer 2004). This also reflects the more general construction of the Austrian welfare state and its foundation on family ideals. The literature on welfare state regimes and in particular care regimes provides a useful approximation for the analysis (Abrahamson 1999; Arts \& Gelissen 2002; Lewis 1992; Orloff 1993; Sainsbury 1994; Scruggs \& Allan 2006; Simonazzi 2009). Austria is usually described as a corporatist-conservative welfare system with a strong emphasis on the role of care provision by the family (Badelt \& Österle 2001; Hammer \& Österle 2003; Strell \& Duncan 2001). Social rights in Austria are usually closely connected to either individual employment or family relationships (see Hammer \& Österle 2003). Strell and Duncan (2001) in their research also focus on the strong role of Austria's family policy, both socially and ideologically. They describe the Austrian welfare model as a male breadwinner model (Strell \& Duncan 2001) which is built on the ideals of what a "proper family" means (Strell \& Duncan 2001: 153). For much of the Austrian social welfare system, and that counts specifically for the care context, an ideal of family is needed and reproduced (Strell \& Duncan 2001). This is particularly important in the context of long-term care arrangements. About $80 \%$ of people with care needs in Austria are cared 
for at home by close relatives, of whom $80 \%$ are women (Österle \& Hammer 2004: 36). Interestingly, men caring for relatives are usually retired whereas the majority of women caring are under 55 years old. Only between $4 \%$ and $5 \%$ of people aged 65 or older live in institutional settings (retirement homes and nursing homes) and 5\% of those 65 and older receive some form of formal home help (Österle \& Hammer 2004).

In Austria long-term care is formally organised by the payment of "Pflegegeld", a financial benefit based on the hours of care that are necessary (see Badelt \& Österle 2001). The intention and goal of the "Pflegegeld" can be found in $\$ 1$ of the relevant law, the Austrian Pflegegeld-Gesetz where it says:

\footnotetext{
The purpose of the "Pflegegeld" is to compensate for care-related additional expenditures in order to assure the necessary care and support for care-dependent people as far as possible and to improve the possibility to lead a self determined, needs-oriented life. (BPGG:§ 1, own translation)
}

One explicit goal of the implementation of this law was to financially secure and support the possibility of care within the family (see Badelt et al. 1997: 2) and to therefore strengthen the (personally felt) responsibility to care. This conception of care based on a "strong ideology of family responsibility" (Hammer \& Österle 2003: 47) obviously requires many people who are willing to perform care services in an informal context. When Österle and Hammer (2004: 69) summarise the various factors which are relevant for the design of informal care, traditions, roledescriptions and emotional bonds play a crucial role. The fact that care is still largely seen as a family issue, which is also reflected in public and political discourses, is challenged by demographic developments related to an ageing society and changing family structures (Österle \& Hammer 2004). Care work, and in particular the organisation of round-the-clock care, place a large burden on family members, emotionally, financially and physically. Changes in and requirements of the labour market, family expectations and attitudes and the ageing societies require new answers. But have these developments led to a reconsideration of family responsibilities? Is a process of "defamilisation" (McLaughlin \& Glendinning 1994) which describes the freedom not to care (Hammer \& Österle 2003) imaginable? 
International Journal of Ageing and Later Life

In Austria the answer for many families has been the employment of migrant carers working and living in the house of the person cared for. In Austria there are approximately 40,000 people employed as carers in private settings (Jandl et al. 2007). The large majority of these people are women from Eastern European neighbour countries (in particular Slovakia). The live-in arrangements are usually organised by specialised agencies and the carers work on a fortnightly cycle (Gendera in press). This example of rotational (Bettio et al. 2006) or pendulum migration (Glucksmann \& Lyon 2006) is a situation which inevitably raises several difficulties for the construction of care as emotional labour based on proximity, love and intimacy. The traditional dependence on the nuclear family and other informal bonds correlates with a construction of care work being based on emotional attributes such as closeness, love and intimacy. These values and virtues can be found in both public and private discourse and can thus be summarised as a moral consensus in society. Central features of the meaning of care are reciprocal relationships, love, affection and intimacy (Lynch 2007; van der Geest et al. 2004). In relation to migrant carers in Austria these relationships are emphasised and reciprocity is not only mentioned in relation to financial exchange but by highlighting the particular relationships.

\section{"Care is Something Different Than Minding" (Die Presse, 30/08/07)}

To understand the specific discourse on care in Austria it is useful to highlight the different words in German being used. Whereas Betreuung rather refers to care as support (mainly emotional minding, assistance and physical and emotional presence) Pflege more specifically means care as labour. Not only do these differences bear different legal implications, they also emphasise the split between professional care workers and informal carers. Several authors argue that migrant carers' work is mainly to be described as minding (Bettio et al. 2006; Glucksmann \& Lyon 2006) which can indeed be identified in the discursive context of Austria. This can be exemplified by narratives and images such as the "Helping hands from middle and Eastern Europe" (several newspaper articles) or references to "40,000 illegal foreign supporters" (Der Standard, 09/02/07). Lynch (2007), distinguishing between three forms of care labour, states that love labour, which describes the most intimate form of care, is not commodifiable as it 
is "emotionally agaped work" with the principle goal of the well-being of the other. ${ }^{2}$ Thus, it can be argued that in Austria migrants are employed to perform love labour, i.e. intimate, affective minding in people's own environments. However, how is loving, intimate care being understood? What are the parameters according to which people construct "informal" caring? One very striking component is the provision of care in people's own homes.

\section{Home}

Much care-related literature focuses on the meaning of home for individuals in general and ageing or ill people in particular (Andrews \& Phillips 2005; Conradson 2003; Kontos 1998; Milligan 2003; Parks 2002; Phillips 2007). Here I only want to emphasise the importance of a notion of home in the context of the discursive construction of care being performed by migrant workers. Bettio et al. (2006) observe a widespread aversion against institutionalisation in Italy and link this to the motivations to employ migrant carers (see also Degiuli 2007). Similarly the analysis of the Austrian discourse suggests that the home is constructed as the sphere in which informal care based on affection and love can be practiced, even when performed by non-family carers. The public discourse shows that care in institutional settings (i.e. care homes) is constructed as dependent living, based on the good will of the employed staff. This is insofar important as the idea and notion of "informal care" is intrinsically associated with the own home in which independence, autonomy and a self-determined life can be lived. An ideological link between the home and the family is constructed as exemplified in the following newspaper extract:

One who cares for his relatives at home shows heart with that (...) And everyone who wants to care within the family should receive help. (Kurier, 22/11/06)

The broad public discussion on 24-h care focused exclusively on care "at home". The following extract is a reader's comment that appeared in an

2Beside "love labour" the other forms of care Lynch (2007) describes in her work are "general care labour" and "solidarity work". 
International Journal of Ageing and Later Life

Austrian newspaper in response to the political discussion on the then illegal status of employing migrant carers in people's own homes. It describes the possibility of people staying at home and being cared for in their own houses as a situation that is honourable and which should be supported. Politicians and the political process are criticised for interfering with what is happening in the own home. This raises an argument about the interference of politics and bureaucracy into the physical realm that represents family care:

We have really reached a point in the state of Austria! Now, apparently, you get already penalised if you don't push your helpless, old parents off into a care home, but let them be cared for by foreign care workers in their own familiar home! (Kronen Zeitung, 19/08/06)

For family members' performance of intimate, affectionate care the most important feature is the provision of care in people's homes and the analysis suggests that family members can fulfil their moral duty resulting from their familial connection to the person in need, at least partly by arranging their relatives to be cared for in their own house. Mehta and Thang (2008) focusing on the situation in Singapore argue that there society approves of people's filial responsibility as long as care at home is ensured. In the context of responsibility in the Austrian discourses it is not clearly defined what the role of family members should be. There rather can be found an idealisation of family "minding". In other words, the family is seen as being responsible for "being there for someone". Reflecting the Austrian discourse, Der Standard (07/02/07) writes that it is clearly stated that the goal is "to enable care and minding at home". Thus, migrant carers who live with the cared-for ensure the execution of informal care, also in replacement of family members. People whose moral duty might be thought to be actively involved in intimate care for the elderly can be engaged by ensuring that their loved-ones are "saved from" or "prevented from" other-dependent care in institutions. As the main emphasis lies on the presumption that everyone's wish is to be cared for at home (e.g. Der Standard, 12/02/07) the very home becomes the focus of the realm of intimate, loving and affectionate care. And in this context migrant carers take the role of domestic, informal carers and are therefore able to provide the services that are usually restricted to family members. 
When the Kronen Zeitung (08/07/07) therefore writes about "families, who sacrificially care for their relatives at home with Eastern European help" the inclusion of migrants into the home seems to correlate with an inclusion into the family. Migrant carers living with the cared for person, are constructed as ideal actors who ensure informal home care:

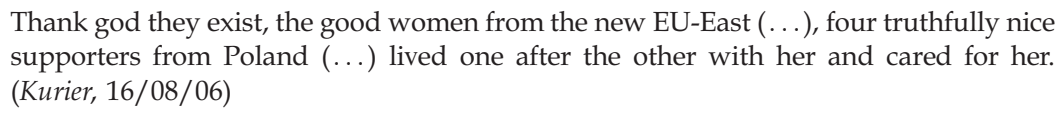

Thank god they exist, the good women from the new EU-East (...), four truthfully nice supporters from Poland (...) lived one after the other with her and cared for her. (Kurier, 16/08/06)

Living with the cared-for person is an important part of the creation of the ideal care relationship. Additionally, the accounts presented above sketch an image and a language usually associated with close family members. It could be argued, therefore, that migrant carers are discursively included into the family in question.

\section{Fictive Kin}

Barker, in her discussion of care for the elderly outside family settings in the USA, emphasises that often in these situations "strangers act like kin" (2002: 159) and she identifies a development of these carers towards "fictive kin", a process which is based on and allows for emotional proximity and social intimacy. Interviewees in her study refer to themselves therefore as being "just a friend, not a caregiver" (Barker 2002: 160) and define their work, similarly to family members' labour, as a moral duty. Similarly, Karner (1998) discusses the development in which carers are "adopted" as fictive kin which again suggests that this quality of the relationship might serve as a replacement for higher status and payment. Bettio et al. (2006: 272) summarise this development as a "transition from a "family" to a "migrant in the family" model of care", emphasising the inclusion of the migrant worker into the family setting.

Similarly, in Austria migrant carers are discursively constructed as belonging to the family under question. If migrants do not only perform certain roles of family members but are also taking over particular family identities, can this creation of the fictive kin be identified? The discourse shows some references to kin-like relationships and bonds ("the two are grown together" (Kurier, 13/08/06)) and migrant carers are constructed in 
International Journal of Ageing and Later Life

sharp contrast to professional workers as "good friends who help us" (Der Standard, 14/02/07). The care which is provided by migrants is seen as help for the family, rather than as care labour. People care for their parents via migrant domestic workers. So are migrant carers seen as fictive kin? Many of the descriptions of the intimacy performed by migrant carers entail a reference to the broader family setting as a sign of an "adoption" of the migrant worker:

When Mr B. got dementia, Kati and Maria entered his life. Today, the two Slovaks are more for the family than only cheap care-workers. (Der Standard, 14/02/07)

Becoming part of the family and not being seen as workers or employees is an important feature of the Austrian discourse. Two participants of a focus group discussion talk about their experience with employing two Slovakian women to care for an elderly family member, referring to them as angels:

Caroline: Yeah, we also indeed often call our Slovaks, uhm, the Slovakian angels [laughs].

Gita: Yes, now, for three years I have now had the same ones, mother and daughter (...) And she again had also a daughter, there was also a grandchild, and she, with her it was always somehow, because the woman who was not with me at that moment, was then caring for this other child. (...) And mother and daughter have switched places at mine, and this really was one unit indeed.

Betty: they were lovely, yes. They really were $(\ldots)$

Caroline: Yes, it is, they have actually become part of the family.

In this extract the migrant workers are included in the family in question. Additionally, a concept of a broader, extended family, based on different care arrangements is presented. Of course, it is important to state that the fact that the "members" of this extended family are described as equals is a situation which from an economic and social perspective proves questionable. However, a construction of a new family is happening and knowledge over the other's family is emphasised. This can also be seen in the following extract: 
Caroline: Yeah, with the Slovakian nurses I must say, they really become part of the family, (...) this daughter indeed, who cared at ours, she also brought her daughter with her to ours from time to time, during school holidays or so. (...) They've also brought their dog with them once, because they didn't know where to put it, because the friend was also not there, so

Gita: You also know the problems of these Slovaks

Caroline: You really become intimate.

Gita: and you discuss the problems, your own, with them

Caroline: The Slovaks, then we also, from time to time(...), half an hour, or an hour, $(\ldots)$ we went for a coffee with them and things like that $(\ldots)$ yeah, it is like that, they become part of the family. Absolutely.

The discussion which started with a representation of the carers' identity as "angels" describes the links that have developed over time and various aspects characteristic for close family bonds (discussing each other's problems, knowing each other's friends, going out for a coffee). Additionally, the importance of this familiarity for the wellbeing of the cared for person, is identified. Brigit Anderson in her discussion of migrant domestic workers quotes one woman saying that "the problem is they treat me as family" (Anderson 2000: 123). The recurring discussion of the commitment, the reliability and the "angel-like" devotion to the elderly people demonstrates this ideological relation to a moral consensus based on family responsibilities. I argue therefore with Glucksmann and Lyon (2006: 6.4) that the employment of migrant carers "is done in order to sustain the practice and ideal of family care as delivered through love and personal connection". As a consequence, however, migrant carers are constructed as quasi-kinlike "with all the ambivalence obligation, exasperation, trouble, joy and pleasure that kin relations entail" (Barker 2002: 166 with reference to Sussman). This is probably best exemplified by the following quote from Kurier (06/09/06) which colourfully highlights the different aspects of the construction of kinlike relationships:

Two qualified Slovakian supporters took the family's heart by storm. The two women devotionally looked after the 91-year-old mother, who found new courage to face life in her own familiar home. 
International Journal of Ageing and Later Life

I have also used this newspaper extract in some of the focus groups and asked the participants about their opinions. The following discussion acknowledges the possibilities of an inclusion of migrant workers into the family and links it to particular attitudes and identities of the care workers:

Walter: That the two qualified Slovakians, of course, if they are doing the work well, that they took the family's heart by storm, is clear, isn't it? (...)

Barbara: they have a specific charm, they have, these people

Walter: but as you rightly say, they have a, a very motherly and womanly quality

Barbara: yes, yes, they have a specific

Walter: $(\ldots)$ not too hard

Barbara: not too hard, they become, yes

Walter: that also counts for the Hungarian women, like, they do, there is also a

Barbara: (...) yes, is also still softer.

In this quote there are very problematic assumptions about gender and ethnicity. There is also, however a nostalgic element present. It almost seems that because these women are better in practicing family they are welcome to care for elderly people like family members. Intimacy between people is possible because these workers are in their identity constructed as being similar to family members. Many of the descriptions of the intimacy performed by migrant carers entail a reference to the family setting as a sign of an "adoption" of the migrant workers. A relationship is emphasised which relies on physical proximity and social intimacy in which migrant carers are discursively constructed as intimate friends or family members. The following extract also demonstrates the enormous intimacy that can result from the very relationship, and which, eventually, is used in the discourse to describe the relationship between cared-for, migrant carer and the family:

The first impression: There are two that really get along well - even though they see each other 24 hours a day. For two years, since Mrs P.'s stroke, the young nurse Maria 
cares for the 67-year-old Viennese. (...) [L]egal 24 hours care is too expensive (and difficult to get) and she panics to go into a care home: "I have experienced that with my mother. I don't even want to think about it." What's left? Maria. (Die Presse, $14 / 08 / 06)$

\section{Representing the Ideal of Care}

In the discourse migrant carers are included in family settings and constructed as fictive kin. I have already mentioned possible consequences for carers, such as being vulnerable to exploitation. However, this discursive construction also affects the meaning of care in general. In this section I will argue that the discourse on migrant carers is an expression of a longing for the ideal care arrangement. This nostalgia for care for elderly people being based on love, affection and family commitment is reproduced through the inclusion of migrant workers into the realm of families. The following newspaper extract describes what being a migrant carer entails:

\footnotetext{
Anna does really everything that comes up. (...) But over everything else she faithfully looks after "Granny". (...) "The two are extremely close. Every three to four months, when Anna goes to see her family in Slovakia, Granny gets ill." (...) A care home, however, is out of the question for the family. Margit: "Mother always refused to be pushed off." (Kurier, 14/08/06)
}

Clearly, being a carer is not reduced to the performance of certain tasks; rather, it refers to a physical and emotional presence of the carer. It could be argued that a carer identity is created which cannot sufficiently be explained with the fulfilment of tasks but which suggests an idea of care that is idealised. I have discussed Strell and Duncan's (2001) account of the "proper family" which is reproduced through the Austrian care system. The discourses on migrant carers employed within these structures also underline this tendency. In that sense, a continuation of the family care model also in times of changing family structures and social and economic developments can be realised. The discourses enable an integration of the migrant worker into the family and place him/her as a part of the proper family. Bonds and family-like relations are emphasised and linked to the cared-for person's wellbeing. The institution, on the other hand, is constructed as the opposite of an ideal care arrangement. 
International Journal of Ageing and Later Life

The migrant carer thus enables the ideal of care, which is wished and longed for. Also Ida, in a focus group, talks about a promise she has given to her elderly mother, that she would never put her mother into a care home. She therefore employed a Slovakian woman who embodied the ideal care relationship and who satisfied the family's desire for care. Again, a family relation is emphasised and as a consequence of the practice of care the carer got closer to her mother than Ida herself:

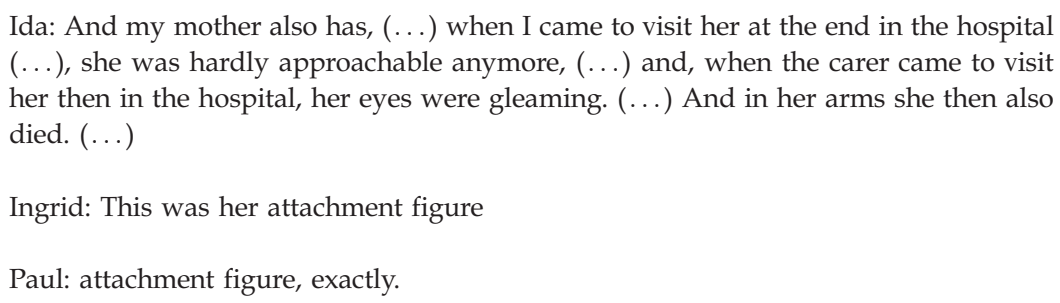

Ida: There she was sparkling, because Martina, that was absolutely her favourite. (...) there she was really gleaming, with me she wasn't gleaming, and with Martina she was gleaming. And in her arms she also died.

The constructed ideal care relationship can therefore be established by living with the cared-for person. Due to the strong link between the own home and real care and the importance of the former for the latter migrant carers are constructed as the only available option for people which still represents the family care ideal. Anything else (especially institutional solutions) would challenge the idea of care itself. As mentioned earlier the construction of migrant workers as representing the nostalgically idealised notion of care is often linked to a description of some carers as particularly qualified and having a caring character. These explanations, however, are also based on an idealisation of the family care model. The migrant carer is constructed as the personification of the longing for what care ideally should be. I want to quote one extract from a discussion in which several problematic aspects appear. However, rather than pointing out the stereotypes, essentialisations and reductions that are undoubtedly present I want to focus on the meaning of discursive narratives for the ideal of care: 
Vera: but I can't imagine $(\ldots)$ that there are Austrian women who, apart from the financial side, would care so sacrificially for other people. For strangers in fact.

Walter: 24 hours

Vera: Is this somehow a particular kind, these Eastern women?

Barbara: yes, they are still different $(\ldots)$

Vera: Yes, indeed.

Barbara: they still have (...) That's it (...), I find, that these women are still more like women. So, they still have a more womanly appearance. (...) Not, not yet like here, into this business world ...

It is important to note that the characterisations of migrant carers in this example follow a particular discursive narrative on care. Ideal, natural care is seen as not being provided anymore and as not being possible in the present society, due to economic and social developments and pressures. The employment of migrant carers enables the building up of a relationship which closely resembles the idealised care arrangement and represents what is lost in Austrian society. The argumentation that Eastern European women are still different and that they are still more like women is a result of this nostalgia of an idealised notion of care which is thought of as an issue of the past generations. Davies (1979) situates nostalgia as a yearning for the continuity of identities in a time when people experience subjective discontinuities. The present life conditions are "felt to be, and often reasoned to be as well, more bleak, grim, wretched, ugly, derivational, unfulfilling, frightening and so forth" (Davis 1979: 15). Coontz (1992: 9) argues that the imagined ideal family of the past is "an ahistorical amalgam of structures, values and behaviors that never co-existed in the same time and place". This resonates as being very important for the construction of migrant carers as well. Ideal care, how it is constructed, is not a historical phenomenon, but a combination of feelings, ideals, wishes and emotions. For Coontz (1992) the existence of nostalgia is also related to a feeling of being unsatisfied with the economic demands and pressures.

So it can be said that nostalgia for a particular idea of care includes a realisation that this form of care is impossible and unachievable. In other words, the construction of migrant carers as fictive kin enables a 
International Journal of Ageing and Later Life

continuation of the normative Austrian care model within times of societal changes. And not only do migrant carers provide the care family members cannot or do not want to deliver anymore; migrant carers also morally and emotionally fulfil a nostalgic desire for a particular ideal of care. That this idealised care is seen as an issue of the past (or of other countries indeed) accommodates the employment of migrants to become the ideal carers. And finally, the provision of care is linked to a broader discussion of social conditions. Self-centredness, economic involvement and family breakdown are linked to an image of the busy, self-absorbed and selfish modern society. There is a strong notion of the idea that "real care" is something from the past or from other cultures and does not fit in with the present societal arrangements, whether this is seen positively or (as most often) negatively.

\section{Conclusion}

In this article I have analysed the public discourse on migrant carers in Austria. I have argued that within this discourse migrant carers are constructed as the ideal carers in the sense that their identity is seen as similar to traditional family carers. The process of the discursive construction is based on several narratives, the distinction between professional care work and informal minding, the construction of the home as the realm of intimate care and the incorporation of migrant carers into the family. The analysis has shown that socio-economic pressures and forces are said to require arrangements that partly challenge a society's moral framework. The discursive arrangements, however, are used to enable a re-configuration of care by constructing intimate care as being bound to the own home and being performed by kin or fictive kin based on minding and supporting rather than care labour. Using the example of the employment of migrant carers in Austrian families I could demonstrate how the discourse on family care is extended to other care options as well. Additionally, it has also been shown that the discourse on migrant carers reproduces the notions of what ideal care is and that it reproduces ideals and images of the notion of family relations. If the discussion is used to understand what care means for people it can be argued that ideal care is characterised by notions of love, intimacy and being there for each other and care within the family is understood as 
being based on "affective, quasi-familial and asymmetrical relations" (Bakan \& Stasiulis 1997: 10).

But does the process of the employment of migrant carers in Austrian households enable or foster the process of "defamilisation" (McLaughlin \& Glendinning 1994) in which families, and in particular women, gain the possibilities not to care? On the one hand it seems that the idealised forms of "family care" can also be carried out by other actors. On the other hand, however, the general construction of the normative model of family care remains untouched and the basic ideal of family based care is not challenged. The "prevailing family ideology of separate spheres, that is, a strict gender division of family work with women being responsible for providing care work on an unpaid basis" (Hammer \& Österle 2003: 45) is adapted but in its main characteristics reproduced in the public discourses. In a sense a partly commodified version of care (cf. Ungerson 2003) in which migrant workers are paid to be "family carers", allows defamilisation for family members without challenging the ideological conception of family care. The employment of migrant carers in Austria needs to be understood as a paradoxical form of paid informal care. On the one hand the care arrangements are based on formal contractual relations; on the other hand, however, the discourse on care paints a different picture. Migrant carers are constructed in explicit opposition to professional care workers and the care they provide is seen in contrast to institutional, professionalised arrangements. The moral construction of care is a main determinant of the construction of the roles, positions and identities of migrant carers. This suggests also a broader, underlying sentiment, described by Zelitzer (2005) about the "two hostile worlds" of intimate relationships and economic transactions. Zelitzer argues that we tend to live with the dogma of these two social aspects being clearly separated and actions that bridge this separation are seen critically and unfavourably. The analysis in this article supports this idea in the sense that one way of the two "hostile worlds" needs to be chosen, either the care relationship is constructed as an intimate relationship, exemplified by the notion of the fictive kin, or it is based on an economic transaction in which the carer is constructed as worker.

I also want to point to the role of the state in these discourses in Austria. I have argued that migrant carers are constructed in contrast to formally employed workers and there is an implicit assumption that long-term care 
International Journal of Ageing and Later Life

has to be provided within the family. However, in many accounts people express a request that the financial costs involved are the state's or the society's responsibility. On the one hand recognition and (financial) support is sought, on the other hand, the employment of migrants at home is seen as a private, personal issue in which the state should not interfere. This also links to the issue of family responsibilities. Because family responsibilities are not clearly spelled out but remain diffuse and vague as some duty to "be there for someone" the employment of migrant carers is not seen as a challenge or re-constitution to the traditional care model.

The characteristics of the discursive construction of migrant carers resemble traditional gender stereotypes in its focus on closeness, empathy, intimacy and minding. As expected, it is mostly women doing caring work, but their status as women is furthermore constructed with particular connotations. In the sense that nostalgia for "ideal" care is reproduced in the construction of migrant care, the relationship between women and care is reproduced as well. In her discussion of gendered care Ungerson (2000) shows that care is partly based on practices that "bear such a close resemblance to the practices based on the experiences of mothering and hence are construed as "natural" aptitudes of women" (2000: 636). If "ideal" care is imagined as a state of loving, devotional minding, it is important to be conscious of the potential gender reductions in this context. Migrant women in particular are constructed as "the other", which is representing the ideal of a caring identity. It is also important to hold here that the discursive arrangements have huge effects on migrant carers themselves, leaving them with "differing work and emotional relations, creating hybrids of contract and affect" (Glucksmann \& Lyon 2006: 5.5) and putting them therefore in a, at least potentially, exploitative and disadvantaging position and role. The ideological and moral differentiation between formal and informal arrangements and the construction of the own home as the realm of delivery of close intimate care are significant features of what people feel about care. They are also, however, the route of potential exploitation of migrant workers, whose position is morally defined by an imagination of "ideal" care. This analysis, treating care not only as a practice but more as a cultural symbol in society which is based on an important moral framework, can explain the paradoxical situation identified by Glucksmann and Lyon (2006: 6.4), in which 
much of the labour of care is performed by a relative stranger in a cultural context which prizes kinship in care. This might help explain the widespread depictions of fictive familial ties and the caring qualities of the migrant women themselves.

\section{Acknowledgements}

I have presented earlier and alternative versions of this paper at the Transforming care conference in Copenhagen, Denmark (June 2008), the ISA conference in Barcelona, Spain (September 2008) and the ESFR conference in Jyväskylä, Finland (September 2008). I thank the participants at these conferences for their input. I also want to thank the anonymous referees for their useful and insightful comments.

\section{Corresponding Author}

Bernhard Weicht, School of Sociology and Social Policy, Law and Social Sciences Building, University of Nottingham, University Park, Nottingham NG7 2RD, UK. Email: bernhard.weicht@nottingham.ac.uk

\section{References}

Abrahamson, P. (1999). The welfare modelling business. Social Policy $\mathcal{E}$ Administration 33(4): 394-415.

Ackers, L. (2004). Citizenship, migration and the valuation of care in the European Union. Journal of Ethnic and Migration Studies 30(2): 373-396.

Akalin, A. (2007). Hired as a caregiver, demanded as a housewife becoming a migrant domestic worker in Turkey. European Journal of Women's Studies 14(3): 209-225.

Aldridge, M. (1994). Making Social Work News. London: Routledge.

Anderson, B. (1997). Servants and slaves: Europe's domestic workers. Race $\mathcal{E}$ Class 39(1): 37-49.

Anderson, B. (1999). Overseas domestic workers in the European Union: Invisible women. In J. Henshall Momsen (ed.), Gender, Migration, and Domestic Services (pp. 113-130). London: Routledge.

Anderson, B. (2000). Doing the Dirty Work? The Global Politics of Domestic Labour. London: Zed Books. 
International Journal of Ageing and Later Life

Andrews, G. J. \& Phillips, D. R (eds.). (2005). Ageing and Place: Perspectives, Policy, Practice. Abingdon: Routledge.

Arat-Koc, S. (1997). From 'Mothers of the Nation' to migrant workers. In A. Bakan \& D. Stasiulis (eds.), Not One of the Family: Foreign Domestic Workers in Canada (pp. 53-79). Toronto: University of Toronto Press.

Arts, W. \& Gelissen, J. (2002). Three worlds of welfare capitalism or more? Journal of European Social Policy 12(2): 137-158.

Badelt, C., Holzmann-Jenkins, A., Matul, C. \& Österle, A. (1997). Analyse der Auswirkungen des Pflegevorsorgesystems [Analysis of the Results of the Care System]. Research report on behalf of the Bundesministerium für Arbeit, Gesundheit und Soziales, Vienna.

Badelt, C. \& Österle, A. (2001). Grundzüge der Sozialpolitik: Spezieller Teil, Sozialpolitik in Österreich [Basics of Social Policy: Specific Part, Social Policy in Austria] (2nd ed). Vienna: Manzsche Verlags- und Universitätsbuchhandlung.

Bakan, A. \& Stasiulis, D. (1997). Introduction. In A. Bakan \& D. Stasiulis (eds.), Not One of the Family: Foreign Domestic Workers in Canada (pp. 328). Toronto: University of Toronto Press.

Barker, J. C. (2002). Neighbors, friends, and other Nonkin caregivers of community-living dependent elders. Journal of Gerontology 57B(3): 158167.

Baxter, J., Hewitt, B. \& Western, M. (2009). Who uses paid domestic labor in Australia? Choice and constraint in hiring household help. Feminist Economics 15(1): 1-26.

Bednarek, M. (2006). Evaluation in Media Discourse: Analysis of a Newspaper Corpus. London: Continuum.

Bettio, F., Simonazzi, A. \& Villa, P. (2006). Change in care regimes and female migration: The 'care drain' in the Mediterranean. Journal of European Social Policy 16(3): 271-285.

Bittman, M., Matheson, G. \& Meagher, G. (1999). The changing boundary between home and market: Australian trends in outsourcing domestic labour. Work, Employment and Society 13: 249-273.

Bloor, M., Frankland, J., Thomas, M. \& Robson, K. (2001). Focus Groups in Social Research. London: Sage Publications. 
Bonifacio, G. L. A. T. (2008). I Care for You, Who Cares for Me? Transnational Services of Filipino Live-in Caregivers in Canada. Asian Women 24(1): 25-50.

BPGG. (1993). Gesamte Rechtsvorschrift für Bundespflegegeldgesetz [Complete Legal Regulations for the Federal Law for Care Cash Benefits]. Available on http://www.ris.bka.gv.at/GeltendeFassung.wxe?Abfrage= Bundes normen\&Gesetzesnummer $=10008859$ (Accessed: November 15, 2009).

Brijnath, B. (2009). Familial bonds and boarding passes: Understanding caregiving in a transnational context. Identities - Global studies in Culture and Power 16(1): 83-101.

Brush, B. L. \& Vasupuram, R. (2006). Nurses, nannies and caring work: importation, visibility and marketability. Nursing Inquiry 13(3): 181185.

Bryman, A. (2004). Social Research Methods (2nd ed). Oxford: Oxford University Press.

Cangiano, A., Shutes, I., Spencer, S. \& Leeson, G. (2009). Migrant Care Workers in Ageing Societies: Research Findings in the United Kingdom. Executive Summary. Oxford: COMPAS.

Chang, K. A. \& Ling, L. H. M. (2000). Globalization and its intimate other: Filipina domestic workers in Hong Kong. In M. H. Marchand \& A. S. Runyan (eds.), Gender and Global Restructuring (pp. 27-43). New York: Routledge.

Cheng, S. J. (1996). Migrant women domestic workers in Hong Kong, Singapore and Taiwan: A comparative analysis. Asian Pacific Migration Journal 5(1): 139-152.

Chouliaraki, L. \& Fairclough, N. (1999). Discourse in Late Modernity: Rethinking Critical Discourse Analysis. Edinburgh: Edinburgh University Press.

Conradson, D. (2003). Geographies of care: Spaces, practices, experiences. Social \& Cultural Geography 4(4): 451-454.

Coontz, S. (1992). The Way We Never Were: American Families and the Nostalgia Trap. New York: Basic Books.

Cox, R. (1999). The role of ethnicity in shaping the domestic employment sector in Britain. In J. Henshall Momsen (ed.), Gender, Migration, and Domestic Services (pp. 131-144). London: Routledge. 
International Journal of Ageing and Later Life

Coyle, A. (2007). Resistance, regulation and rights: The changing status of polish women's migration and work in the 'New' Europe. European Journal of Women's Studies 14(1): 37-50.

Daly, M. \& Lewis, J. (2000). The concept of social care and the analysis of contemporary welfare states. British Journal of Sociology 51(2): 281-298.

Da Roit, B. (2007). Changing intergenerational solidarities within families in a Mediterranean welfare state: Elderly care in Italy. Current Sociology 55(2): 251-269.

Da Roit, B., Bihan, B. \& Österle, A. (2007). Long-term care policies in Italy, Austria and France: Variations in cash-for-care schemes. Social Policy $\mathcal{E}$ Administration 41(6): 653-671.

Davis, F. (1979). Yearning for Yesterday: A Sociology of Nostalgia. New York: The Free Press.

Degiuli, F. (2007). A job with no boundaries. European Journal of Women's Studies 14(3): 193-207.

Doyle, M. \& Timonen, V. (2009). The different faces of care work: Understanding the experiences of the multi-cultural care workforce. Ageing \& Society 29: 337-350.

Dyer, S., McDowell, L. \& Batnitzky, A. (2008). Emotional labour/body work: The caring labours of migrants in the UK's National Health Service. Geoforum 39: 2030-2038.

Escriva, A. \& Skinner, E. (2008). Domestic work and transnational care chains in Spain. In H. Lutz (ed.), Migration and Domestic Work: A European Perspective on a Global Theme (pp. 113-126). Aldershot: Ashgate Publishing.

Fine, M. D. \& Mitchell, A. (2007). Review article: Immigration and the aged care workforce in Australia: Meeting the deficit. Australasian Journal of Ageing 26(4): 157-161.

Flaquer, L. \& Escobedo, A. (2009). The metamorphosis of informal work in Spain: Family solidarity, female immigration and development of social rights. In B. Pfau-Effinger, L. Flaquer \& P. Jensen (eds.), Formal and Informal Work in Europe. The Hidden Work Regime. London: Routledge.

Gendera, S. (in press). Gaining an insight into central European transnational care spaces: The case of migrant live-in care workers in Austria. In M. Bommes \& G. Sciortino (eds.), Irregular Migration in Europe: 
Empirical Research and Structural Implications. IMISCOE Research Series. Amsterdam: Amsterdam University Press.

Gerling, V. (2003). Die britische und deutsche Antwort der Altenhilfe auf zugewanderte Senioren/innen im Vergleich [The British and the German Elderly Care Answers to Immigrated Senior Citizens in a Comparison]. Zeitschrift für Gerontologie und Geriatrie 36(3): 216-222.

Glucksmann, M. \& Lyon, D. (2006). Configurations of care work: Paid and unpaid elder care in Italy and the Netherlands. Sociological Research Online 11(2). Available on http://www.socresonline.org.uk/11/2/ glucksmann.html (Accessed: August 10, 2009).

Haidinger, B. (2008). Contingencies among households: Gendered division of labour and transnational household organization - the case of Ukrainians in Austria. In H. Lutz (ed.), Migration and Domestic Work: A European Perspective on a Global Theme (pp. 127-144). Aldershot: Ashgate Publishing.

Hammer, E. \& Österle, A. (2003). Welfare state policy and informal longterm care giving in Austria: Old gender divisions and new stratification processes among women. Journal of Social Policy 32(1): 37-53.

Henshall Momsen, J (ed.). (1999). Gender, Migration, and Domestic Services. London: Routledge.

Hillmann, F. (2005). Migrants' care work in private households, or: The Strength of bilocal and transnational ties as a last(ing) resource in global migration. In B. Pfau-Effinger \& B. Geissler (eds.), Care Arrangements in Europe - Variations and Change. Bristol: Policy Press.

Hondagneu-Sotelo, P. (2007). Doméstica: Immigrant Workers Cleaning and Caring in the Shadows of Affluence. London: University of California Press.

Honneth, A. (1995). The Struggle for Recognition: The Moral Grammar of Social Conflicts. Cambridge: Polity Press.

Hugo, G. (2009). Care worker migration, Australia and development. Population Space and Place 15(2): 189-203.

Huh, R. K. (2008). Politics of meaning: Care work and migrant women. Asian Journal of Women's Studies 14(3): 37-60.

Jandl, M., Hollomey, C. \& Stepien, A. (2007). Migration and Irregular Work in Austria: Results of a Delphi-Study. Geneva: ILO. 
International Journal of Ageing and Later Life

Karner, T. C. (1998). Professional caring: Homecare workers as fictive kin. Journal of Ageing Studies 12(1): 69-82.

Kontos, P. C. (1998). Resisting institutionalization: Constructing old age and negotiating home. Journal of Ageing Studies 12(2): 167-184.

Kreimer, M. (2006). Developments in Austrian care arrangements: Women between free choice and informal care. In C. Glendinning \& P. A. Kemp (eds.), Cash and Care: Policy Challenges in the Welfare State (pp. 141-154). Bristol: Policy Press.

Krzyżanowski, M. (2008). Analyzing focus group discussions. In R. Wodak \& M. Krzyżanowski (eds.), Qualitative Discourse Analysis in the Social Sciences (pp. 162-181). Basingstoke: Palgrave Macmillan.

Lan, P.-C. (2003). Maid or madam? Filipina migrant workers and the continuity of domestic labor. Gender \& Society 17(2): 187-208.

Lewis, J. (1992). Gender and the development of welfare regimes. Journal of European Social Policy 3: 159-173.

Lorenzo, F. M. E., Galvez-Tan, J., Icamina, K. \& Javier, L. (2007). Nurse migration from a source country perspective: Philippine country case study. Health Service Research 42(3): 1406-1418.

Lutz, H. (1997). The Limits of European-ness: Immigrant women in Fortress Europe. Feminist Review 57(1): 93-111.

Lutz, H. (2002). At your service madam! The globalization of domestic service. Feminist Review 70: 89-104.

Lutz, H. (2004). Life in the twilight zone: Migration, transnationality and gender in the private household. Journal of Contemporary European Studies 12(1): 47-55.

Lutz, H (ed.). (2008). Migration and Domestic Work: A European Perspective on a Global Theme. Aldershot: Ashgate Publishing.

Lynch, K. (2007). Love labour as a distinct and non-commodifiable form of care labour. The Sociological Review 55(3): 550-570.

Lyon, D. \& Glucksmann, M. (2008). Comparative configurations of care work across Europe. Sociology 42(1): 101-118.

Mattingly, D. J. (1999). Making Maids: United States immigration policy and immigrant domestic workers. In J. Henshall Momsen (ed.), Gender, Migration, and Domestic Services (pp. 61-78). London: Routledge.

Mautner, G. (2008). Analyzing newspapers, magazines and other print media. In R. Wodak \& M. Krzyżanowski (eds.), Qualitative Discourse 
Analysis in the Social Sciences (pp. 30-53). Basingstoke: Palgrave Macmillan.

May, T. (2001). Social Research: Issues, Methods and process (3rd ed.). Buckingham: Open University Press.

McGregor, J. (2007). 'Joining the BBC (British Bottom Cleaners)': Zimbabwean migrants and the UK care industry. Journal of Ethnic and Migration Studies 33(5): 801-824.

McLaughlin, E. \& Glendinning, C. (1994). Paying for care in Europe: Is there a feminist approach? In L. Hantrais \& S. Mangen (eds.), Concepts and Contexts in International Comparisons: Family Policy and the Welfare of Women (pp. 52-69). Loughborough: University of Loughborough.

Mehta, M. \& Thang, L. (2008). Visible and blurred boundaries in familial care: The dynamics of multigenerational care in Singapore. In A. Martin-Matthews \& J. E. Phillips (eds.), Aging and Caring at the Intersection of Work and Home Life: Blurring the Boundaries (pp. 43-83). New York: Lawrence Erlbaum Associates.

Meyer, M. (2001). Between theory, method, and politics: positioning of the approaches to CDA. In R. Wodak \& M. Meyer (eds.), Methods of Critical Discourse Analysis (pp. 14-31). London: Sage Publications.

Milligan, C. (2003). Location or dis-location? Towards a conceptualization of people and place in the care-giving experience. Social $\mathcal{E}$ Cultural Geography 4(4): 455-470.

Orloff, A. S. (1993). Gender and the social rights of citizenship: The comparative analysis of gender relations and welfare states. American Sociological Review 58(3): 303-327.

Österle, A. \& Hammer, E. (2004). Zur zukünftigen Betreuung und Pflege älterer Menschen: Rahmenbedingungen - Politikansätze - Entwicklungsperspektiven [On Future Support and Care of Elderly People: General Conditions - Political Approaches - Perspecives for Develoment]. On behalf of Caritas Österreich. Vienna: Kardinal König Akademie.

Österle, A. \& Hammer, E. (2006). Care allowances and the formalisation of care arrangements: The Austrian experience. In C. Ungerson \& S. Yeandle (eds.), Commodified Care Work in Developed Welfare States (pp. 13-31). London: Palgrave Macmillan.

Österreichische Auflagenkontrolle (2008). Auflagenliste 1. Halbjahr 2008 [List of Circulations]. Available on http://www.oeak.at/content/ 
International Journal of Ageing and Later Life

intern/Auflagenlisten/OEAK_2008_1HJ_KORR.pdf (Accessed: July 25, 2009).

Parks, J. A. (2002). No Place Like Home? Feminist Ethics and Home Health Care. Bloomington: Indiana University Press.

Parreñas, R. S. (2000). Migrant filipina domestic workers and the international division of reproductive labor. Gender $\mathcal{E}$ Society 14(4): 560-581.

Parreñas, R. S. (2001). Servants of Globalization: Women, Migration and Domestic Work. Stanford: Stanford University Press.

Pfau-Effinger, B. (2005). Welfare state policies and development of care arrangements. European Societies 7(2): 321-347.

Pfau-Effinger, B. \& Geissler, B. (eds.). (2005). Care Arrangements in EuropeVariations and Change. Bristol: Policy Press.

Phillips, J. (2007). Care. Key Concepts. Cambridge: Polity Press.

Reah, D. (2002). The Language of Newspapers (2nd ed.). London: Routledge.

Reisigl, M. \& Wodak, R. (2001). Discourse and Discrimination: Rhetorics of Racism and Anti-Semitism. London: Routledge.

Richardson, J. E. (2007). Analysing Newspapers: An Approach from Critical Discourse Analysis. Basingstoke: Palgrave Macmillan.

Roseneil, S. \& Budgeon, S. (2004). Cultures of intimacy and care beyond 'the family': Personal life and social change in the early 21st century. Current Sociology 52(2): 135-159.

Sainsbury, D (ed.). (1994). Gendering Welfare States. London: Sage Publications.

Sassen, S. (2003). The feminisation of survival: Alternative global circuits. In M. Morokvasic-Müller, U. Erel \& K. Shinozaki (eds.), Crossing Borders and Shifting Boundaries. Gender on the Move (pp. 59-78). Opladen: Leske \& Budrich.

Scrinzi, F. (2008). Migrations and the restructuring of the welfare state in Italy: Change and continuity in the domestic work sector. In H. Lutz (ed.), Migration and Domestic Work: A European Perspective on a Global Theme (pp. 29-42). Aldershot: Ashgate Publishing.

Scruggs, L. \& Allan, J. (2006). Welfare-state decommodification in 18 OECD countries: a replication and revision. Journal of European Social Policy 16(1): 55-72. 
Simonazzi, A. (2009). Care regimes and national employment models. Cambridge Journal of Economics 33: 211-232.

Strell, M. \& Duncan, S. (2001). Lone motherhood, ideal type care regimes and the case of Austria. Journal of European Social Policy 11(2): 149-164.

Ungerson, C. (2000). Thinking about the production and consumption of long-term care in Britain: Does gender still matter? Journal of Social Policy 29(4): 623-643.

Ungerson, C. (2003). Commodified care work in European labour markets. European Societies 5(4): 377-396.

Ungerson, C. (2004). Whose empowerment and independence? A crossnational perspective on 'cash for care' schemes. Ageing \& Society 24: 189-212.

van der Geest, S., Mul, A. \& Vermeulen, H. (2004). Linkages between migration and the care of frail older people: Observations from Greece, Ghana and The Netherlands. Ageing \& Society 24: 431-450.

van Dijk, T. A. (2001). Multidisciplinary CDA: A plea for diversity. In R. Wodak \& M. Meyer (eds.), Methods of Critical Discourse Analysis (pp. 95-120). London: Sage Publications.

van Leeuwen, T. (1996). The representation of social actors. In C. R. CaldasCoulthard \& M. Coulthard (eds.), Texts and Practices: Readings in Critical Discourse Analysis (pp. 32-70). London: Routledge.

von Kondratowitz, H.-J. (2005). Die Beschäftigung von Migranten/innen in der Pflege [The Employment of Migrants in the Care Sector]. Zeitschrift für Gerontologie und Geriatrie 38(6): 417-423.

Weicht, B. (forthcoming). Loving care by strangers: Crossing the boundaries of closeness, love and foreignness. In A. Cervantes-Carson (ed.), Persons, Intimacy \& Love: Probing the boundaries. e-book. Oxford: InterDisciplinary Press.

Weiss, G. \& Wodak, R. (2003). Introduction: Theory, interdisciplinarity and critical discourse analysis. In G. Weiss \& R. Wodak (eds.), Critical Discourse Analysis: Theory and Interdisciplinarity (pp. 1-32). Basingstoke: Palgrave Macmillan.

Williams, F. (2004). Rethinking Families. ESRC CAVA Research Group. London: Calouste Gulbenkian Foundation.

Williams, F. \& Gavenas, A. (2008). The intersection of childcare regimes and migration regimes: A three country study. In H. Lutz (ed.), 
International Journal of Ageing and Later Life

Migration and Domestic Work: A European Perspective on a Global Theme (pp. 13-28). Aldershot: Ashgate Publishing.

Wodak, R. (2001a). What CDA is about - a summery of its history, important concepts and its developments. In R. Wodak \& M. Meyer (eds.), Methods of Critical Discourse Analysis (pp. 1-13). London: Sage Publications.

Wodak, R. (2001b). The discourse-historical approach. In R. Wodak \& M. Meyer (eds.), Methods of Critical Discourse Analysis (pp. 63-94). London: Sage Publications.

Wodak, R. (2008). Introduction: Discourse Studies - important concepts and terms. In R. Wodak \& M. Krzyżanowski (eds.), Qualitative Discourse Analysis in the Social Sciences (pp. 1-29). Basingstoke: Palgrave Macmillan.

Yeates, N. (2004). A dialogue with 'global care chain' analysis: nurse migration in the Irish context. Feminist Review 77: 79-95.

Yeoh, S. A., Huang, S. \& Gonzalez, J. (1999). Migrant female domestic workers: Debating the economic, social and political impacts in Singapore. International Migration Review 33(1): 114-136.

Zelitzer, V. A. (2005). The Purchase of Intimacy. Princeton and Oxford: Princeton University Press.

Zimmerman, M. K., Litt, J. S. \& Bose, C. E. (2006). Global Dimensions of Gender and Carework. Stanford, CA: Stanford University Press. 


\title{
Tasks performed by primary caregivers and migrant live-in homecare workers in Israel
}

\author{
By ESTHER IECOVICH*
}

\begin{abstract}
The issue of migrant live-in homecare workers has been barely addressed in the gerontological literature, in spite of the increase of older persons being cared for by such persons in many Western countries. The purposes of the study are to examine the extent to which migrant live-in homecare workers substitute family caregivers or complement the care that is provided by primary caregivers, and to examine if there are differences in primary caregivers' involvement in providing help with activities of daily living (ADL) and instrumental activities of daily living (IADL) before and after hiring a migrant live-in homecare worker, by caregivers' employment status and gender. The data were drawn from a study that included 335 triads (care recipients, their primary caregivers, and their Filipina live-in homecare workers).

The findings show that for the most part primary caregivers continue to play a significant role in providing care, in particular with regard to IADL tasks, even when there is a migrant live-in homecare worker. Several patterns of division of labor between the formal and informal caregivers were identified; that is, in some cases they complement each other while in
\end{abstract}


International Journal of Ageing and Later Life

other cases the migrant live-in homecare workers substitute for the care previously provided by the primary caregivers. Significant differences between male and female caregivers and between working and nonworking caregivers were found with regard to involvement in providing care before and after employment of a migrant homecare worker.

Keywords: frail elderly, migrant live-in homecare workers, primary caregivers, tasks, substitution, complementary.

\section{Introduction}

There is a growing general unmet demand for professional and paraprofessional health care workers in high-income countries, due in part to rapidly aging populations, resulting in more agencies actively sourcing workers internationally (WHO 2006). However, the rapid increase in the population of frail elderly people who need domiciliary long-term care services, in particular those who live alone or without easily available family members to care for them, has increased the demand for paid carers. The shortage of local manpower to meet these growing needs has increased the demand for migrant live-in homecare workers who provide care around the clock. These workers compensate for insufficient or unavailable informal caregivers by providing homemaking services and personal care (Browne \& Braun 2008; Howe 2009; Polverini \& Lamura 2004; Redfoot \& Houser 2005), thus enabling elderly persons to age in place and avoiding or delaying institutionalization.

The issue of migrant live-in homecare workers has been barely addressed in the gerontological literature, in spite of the increase in many Western countries of older persons being cared for by such persons, either legally or illegally (Doyle \& Timonen 2009). Most of the migrant workers come from countries, such as the Philippines, India, China, sub-Saharan Africa, Mexico, the Caribbean, Eastern Europe, and the Pacific Islands (AARP, 2005). Thus, although the family remains the most important caregiver and is expected to continue to be so, the use of live-in migrant homecare workers is also expected to expand. Van der Geest et al. (2004) provide several examples in which the involvement of a stranger in the care of a parent was regarded as a respectable and appropriate solution for the 
problem of absent children and grandchildren, provided there is good quality of care.

In most cases, the elderly person lives alone with the migrant paid caregiver. In Italy and Greece, for example, most of those with migrant homecare workers were severely dependent, in particular, mentally frail (Rothgang \& Lamura 2005). These homecare workers are considered an irreplaceable support for older persons and their families. Their presence around-the-clock helps to significantly decrease the family's burden and allows many families to work and lead normal lives, while continuing to provide some care for their elderly members, thus filling the traditional role played by family caregivers (Iecovich 2007; Polverini \& Lamura 2004). This raises several key questions about the extent to which these workers substitute for or complement the care provided by the family. Specifically, the question that is raised is to what extent do family caregivers continue to be involved in care provision to frail family members when there is a migrant live-in homecare worker who is co-residing with the care recipient and providing care around the clock. Another question is to what extent are there differences in patterns of family involvement in caring for their frail elderly family members following the employment of migrant live-in homecare workers and what affects these differences.

The purposes of this study are, therefore, three-fold: first, to examine the extent to which the primary caregivers share the activities of daily living (ADL) and instrumental activities of daily living (IADL) caregiving tasks when there is a migrant live-in homecare worker, that is the extent to which any of them is currently involved in performing each of the tasks; second, to examine changes in primary caregivers' roles following the employment of a migrant live-in homecare worker. Specifically, the study aims to examine the extent to which primary caregivers are involved in performing ADL and IADL tasks prior to the employment of migrant livein homecare workers and the extent to which their involvement in performing these tasks ceased afterwards, which can provide a perspective on the that extent to which tasks that were performed by primary caregivers in the past continue to be performed also at present. Finally, the third purpose is to examine if there are employment and gender-based differences between primary caregivers that affect the roles performed by them before and after employment of a migrant homecare worker. In other 
International Journal of Ageing and Later Life

words, the major aim is to examine the extent to which migrant live-in homecare workers substitute family caregivers or complement or supplement the care that is provided by primary caregivers.

\section{The Interface Between Informal and Formal (Paid) Care}

Several theoretical approaches address the interaction between formal and informal caregiving (Denton 1997). The first is the substitution hypothesis that implies that there is a hierarchy of support providers who may be replaced by others when needed (Cantor \& Bernnan 2000), suggesting that when informal care is unavailable or inadequate, formal care, as like assistive technology, is used to substitute for informal care, thus reducing the informal care (Agree et al. 2005; Penning \& Keating 2000). However, evidence for a substitution effect is scarce (Litwin \& Attias-Donfut 2009; Noelker \& Bass 1989). The second approach is supplementary or complementary according to which family caregivers are in charge of providing care to their elderly family members; the formal care is supposed to complement or supplement the care provided by the informal care system (Litwak 1985; Noelker \& Bass 1989). Several studies that were conducted in various countries lend empirical support to this approach. For example, Noelker and Bass (1989) found that elderly persons with higher levels of physical impairment and morbidity used more formal service care. This type included households in which both the primary caregiver and service provider jointly helped the care recipient with one or more tasks. Several studies that were conducted in Israel examined the interplay between the formal and informal care systems in providing care to frail elderly people found consistent findings supporting the complimentary model. For example, Brodsky and colleagues (2004) found that almost two-thirds of family members were involved in providing assistance with personal care and most help with homemaking. Most of the care recipients received assistance in all areas of care from both formal services and family members. Another study (Green \& Auslander 2008) found that frail elderly persons received help from formal carers, but the most extensive instrumental help with personal care was received from their families. A comparative study (Litwin \& Attias-Donfut 2009) between France and Israel examined whether formal home care services delivered 
Tasks performed by primary caregivers and migrant live-in homecare workers

to frail older persons substituted for or complemented informal support. The pattern that was most common was that of complementarity, suggesting co-existence of formal and informal care and mixed provision, in particular in situations of greater need. In other words, research findings suggest that frail elderly persons receive instrumental help with personal care and housekeeping from both systems, formal and informal, and that family caregivers play a key role in providing care to their elderly members even if there is a paid homecare worker.

These approaches are criticized for not being comprehensive because they assume that the two systems of care are not only different, but that informal care is preferred to formal care and that the latter is supposed to supplement the former (Ward-Griffin \& Marshall 2003). Furthermore, Ungerson (1990) argues that the conceptual splitting of "formal" and "informal" care is a false dichotomy by assuming that the nature of the relationship that prevails in each of these spheres is totally different. In contrast to this approach, she argues that it is important to analyze formal and informal care together. Furthermore, from a research perspective, very few studies examined the perspectives of dyads of caregivers (formal and informal) as did WardGriffin and Marshall (2003). They argue that there is a dialectic relationship between informal and formal care systems and provide empirical evidence that both the substitution and supplemental models are interwoven and occur simultaneously. However, most of these studies did not examine these issues with respect to this dialectic between primary family caregivers and migrant live-in homecare workers, who co-reside with the care recipients and form some kind of hybrid caregiver (Ungerson 1999). Thus, in this study changes in primary caregivers' roles will be examined by comparing the ADL and IADL performed by them before and after the employment of a migrant homecare worker. Furthermore, the extent to which primary caregivers and migrant homecare workers performed different or same tasks simultaneously will be examined.

\section{Homecare Services to Frail Elderly Person When the Homecare Worker is a Migrant Live-in Worker}

One question is to what extent family caregivers are involved in providing instrumental help to their frail elderly family members when there is a 
International Journal of Ageing and Later Life

migrant live-in homecare worker who co-resides with the care recipient and provides care around the clock. It was hypothesized that primary caregivers of care recipients who have a migrant live-in homecare worker will be less involved in providing instrumental help. Few qualitative studies that related to the roles and tasks performed by migrant live-in workers found that family carers continued to play a key role in providing care to their elderly persons even when there was a migrant live-in homecare worker who was available around the clock, although their roles shifted from providing direct care to care management. For example, Doyle and Timonen (2009) found that in Ireland high demands and expectations were placed on the live-in homecare workers. They had to carryout generic care-work duties and domestic chores. Their personal freedom was limited because they had to provide care round-the-clock. Ayalon's (2009) study on Filipina live-in homecare workers in Israel found that family members did not relinquish their roles as caregivers but rather their roles changed by assuming the role of care managers and being in charge of all aspects of the life of the care recipient, including managing the personal care, housekeeping, and finances. Yet, children refrained from performing intimate personal care tasks, such as changing diapers and bathing due to traditional taboos, and expected the migrant workers to perform all the instrumental tasks related to personal care as well as to housekeeping tasks.

However, there are no quantitative studies that examined the involvement of family caregivers when there is a migrant live-in homecare worker, neither is there an in-depth examination of the changes in specific ADL and IADL roles performed by primary caregivers prior to hiring a live-in homecare worker and their involvement after hiring a migrant live-in homecare worker. These issues are addressed in this study.

\section{Migrant Live-in Homecare Workers in Israel}

To meet the growing needs for homecare services on the one hand and to face the shortage of local manpower on the other, the Israeli Government decided to allow the recruitment of migrant live-in homecare workers to fill these gaps. Thus, during the early 1990s manpower agencies started 
Tasks performed by primary caregivers and migrant live-in homecare workers

to recruit migrant live-in homecare workers. To-date, there are about 57,300 migrant live-in homecare workers in Israel, who provide care to severely frail elderly persons who are either physically or mentally frail (Natan 2009). Most of these workers come from the Far East, in particular from the Philippines. These formal caregivers are employed by the care recipients and almost all of them co-reside with the care recipients. These workers are expected to perform all personal and housekeeping tasks, thus freeing family caregivers from providing direct instrumental help with these tasks. In spite of the very detailed regulations concerning the responsibilities and rights of migrant workers, there are neither explicit role definitions of the tasks that these workers have to perform, nor are there any instructions about what should they not perform. Thus, the issue of role definition is left to negotiation between the worker and his/her employers (the care recipient and his/her family).

\section{Methods}

\section{Sample}

Data for this study were drawn from a study that included 335 triads (care recipients, their primary caregivers, and their live-in migrant homecare workers) (Iecovich 2010). This article draws upon data from the interviews with the primary caregivers and the migrant live-in homecare workers. The sample included all care recipients that were registered in two national homecare organizations that the author had accessibility to and who employed Filipina homecare workers. It should be noted that, in general, homecare agencies do not provide data about their clients due to privacy rules and regulations, but since the author had accessibility to these two organizations data were drawn only from these two organizations. The first organization had four agencies in the central and northern regions of the country and the second organization had 16 agencies in the central and southern regions of the country, thus covering the entire country. These lists included 462 care recipients of whom only 237 were interviewed. Those who were not interviewed included 95 who were mentally frail and therefore were uninterviewable, 20 passed away, 79 refused, and 31 were 
International Journal of Ageing and Later Life

unavailable. In addition, 98 triads were recruited using a snowball procedure by asking the interviewees if they knew other elderly persons who employed Filipina migrant homecare workers. If their answers were positive they were asked to give their names and telephone numbers, and the interviewers contacted them. Data were collected through face-to-face interviews using a structured questionnaire at the care recipients' homes and/or at the primary caregivers' homes. Data collection was conducted during September 2008 and September 2009.

\section{Variables}

(a) Patterns of caregiving involvement - the primary caregivers and the homecare workers were presented with a list of eight tasks of ADL (washing, dressing, feeding, toileting, helping with indoor mobility, cutting nails, putting on shoes, and surveillance) and with ten IADL (light home chores, heavy home chores, light laundry, big laundry, meal preparation, shopping, arrangements, bringing medicines from the pharmacy, accompanying the care recipient to the clinic, and taking care of financial affairs). Every dyad of primary caregiver and homecare worker was asked if they performed each of the ADL and IADL tasks, with answers $1=$ yes and $0=$ no.

(b) Changes in roles performed by primary caregivers before and after hiring a migrant homecare worker - the primary caregivers were presented with eight ADL and ten IADL and for each task they were asked two questions: "Did you perform this task prior to employment of the migrant live-in homecare worker?" and the second question was: "Do you perform this task at present when there is a migrant live-in homecare worker?" For each question answers were $1=$ yes and $0=$ no.

(c) Socio-demographic characteristics of the respondents: both caregivers and migrant homecare workers were asked about their age, gender, education, and marital status. In addition, the primary caregivers were asked about their relationship to the care recipient (spouse, adult child, or other family member), and employment status $(1=$ work, 
Tasks performed by primary caregivers and migrant live-in homecare workers

$0=$ don't work). The paid carers were asked about their professional background (nurses and homecare workers versus otherwise), their length of stay in Israel, and how long they had been providing care to their current care recipients.

\section{Findings}

\section{Characteristics of the Primary Caregivers}

The mean age of the primary caregivers was $54.5(\mathrm{SD}=8.06), 53.5 \%$ were women, suggesting that a significant proportion of primary caregivers were men. Education attainment included $13.8 \%$ who had $0-8$ years of schooling, $17.6 \%$ had $9-12$ years, and $68.5 \%$ had high education ( $13+$ years). The vast majority $(80.5 \%)$ was married, $79.7 \%$ were either a son or a daughter of the care recipient, $13.1 \%$ were spouses, $3 \%$ were grandchildren, $3 \%$ were nonkin (friends, neighbors), and 1.2\% were other family members (siblings and daughters-in-law). The majority (70.4\%) were working caregivers and most of them $(75.85 \%)$ worked full-time jobs. More than half $(55 \%)$ shared the expenditures of the migrant homecare worker's salary and this expenditure ranged from 100 to 3500 NIS (about US\$920) a month with an average of NIS $658(\mathrm{SD}=790)$ a month (US\$173). Caregivers provided 1-60 h a week with an average of $13.6(\mathrm{SD}=10.29)$ weekly hours.

\section{Characteristics of the Migrant Live-in Homecare Workers}

As noted, the study included only Filipina homecare workers. The mean age of the Filipino homecare workers was $36.07(\mathrm{SD}=7.17), 85.4 \%$ were women and the majority $(58.5 \%)$ was married. Their education attainment included $11.7 \%$ with $0-8$ years of schooling, $23.1 \%$ with $9-12$ years, and $65.3 \%$ had high education (13+ years). On average, they cared for the current care recipients for 24.07 months $(\mathrm{SD}=22.37)$ and the profession of most of them was a nurse or caregiver $(69.3 \%)$ with the remainder coming from fields of teaching, business, or no profession. 
International Journal of Ageing and Later Life

Table 1. Tasks performed by primary caregivers and by migrant live-in homecare workers

\begin{tabular}{|c|c|c|c|c|c|}
\hline Task & $\begin{array}{c}\text { Neither } \\
\text { do }(\%)\end{array}$ & $\begin{array}{c}\text { Both do } \\
(\%)\end{array}$ & $\begin{array}{c}\text { Only } \\
\text { primary } \\
\text { caregiver } \\
\text { does }(\%)\end{array}$ & $\begin{array}{c}\text { Only } \\
\text { homecare } \\
\text { worker } \\
\text { does }(\%)\end{array}$ & $\chi^{2}$ \\
\hline \multicolumn{6}{|l|}{$A D L$} \\
\hline Washing & 3.3 & 14.6 & 0.6 & 81.5 & 0.00 \\
\hline Dressing & 7.2 & 15.5 & 0.3 & 77.0 & 2.84 \\
\hline Feeding & 27.8 & 10.4 & 3.9 & 57.9 & 0.54 \\
\hline Changing diapers & 49.5 & 5.1 & 0.9 & 44.5 & $10.69^{* * *}$ \\
\hline Mobility & 16.4 & 20.0 & 5.1 & 58.5 & 0.11 \\
\hline Cutting nails & 17.4 & 10.4 & 5.7 & 66.5 & $5.34^{*}$ \\
\hline Putting on shoes & 6.9 & 17.0 & 0.3 & 75.8 & 3.12 \\
\hline Surveillance & 26.9 & 20.9 & 16.1 & 36.1 & 0.03 \\
\hline \multicolumn{6}{|l|}{$I A D L$} \\
\hline Light home chores & 6.3 & 19.4 & 2.4 & 71.9 & 0.63 \\
\hline Difficult home chores & 35.5 & 5.7 & 3.6 & 55.2 & 0.00 \\
\hline Light laundry & 5.1 & 14.0 & 2.4 & 78.5 & $4.78^{*}$ \\
\hline Big laundry & 30.1 & 6.3 & 7.2 & 56.4 & $5.70^{*}$ \\
\hline Meal preparation & 4.2 & 27.5 & 13.4 & 54.9 & $37.08^{* * *}$ \\
\hline Shopping & 8.1 & 37.0 & 21.8 & 33.1 & $11.86^{* * *}$ \\
\hline Bring medicines & 6.9 & 34.9 & 12.8 & 45.4 & $9.96^{* * *}$ \\
\hline Accompany to the clinic & 6.0 & 37.6 & 6.9 & 49.5 & 1.62 \\
\hline Arrangements & 9.9 & 35.8 & 40.0 & 14.3 & $3.55^{*}$ \\
\hline Financial affairs & 18.8 & 3.6 & 76.7 & 0.9 & 0.00 \\
\hline
\end{tabular}

${ }^{*} p<0.05 ;{ }^{* *} p<0.01 ;{ }^{* * *} p<0.001$.

\section{ADL and IADL Tasks Performed by Primary Caregivers and Migrant Live-in Homecare Workers}

The tasks performed by the formal and informal caregivers and the extent to which either both or one of them performed each of these tasks are shown in Table 1.

The results reveal four patterns: only the primary caregiver performed the specific task, only the homecare worker performed the task, both 
Tasks performed by primary caregivers and migrant live-in homecare workers

performed the same task, and neither of them performed a specific task. The findings show that for all ADL tasks, for the most part, only homecare workers performed these tasks, in particular washing, dressing, and putting on shoes. Negligible percentages of primary caregivers were the only ones to perform these tasks, except for surveillance where about 16\% of them were the only ones to perform this task. Between $10 \%$ and $21 \%$ of both the primary caregivers and homecare workers shared the ADL tasks, except for changing diapers where only $5.1 \%$ shared this activity. Yet, significant proportions of primary caregivers and homecare workers did not perform some specific tasks, such as feeding, changing diapers, and surveillance because in most cases the care recipient did not need help with these activities.

The findings show that for most housekeeping tasks, such as cleaning the house, doing laundry, and preparing meals, the majority of homecare workers were the only ones to perform these tasks, while in most instances the primary caregivers were the only ones to managing the finances of the care recipients. Also, a significant proportion $(40 \%)$ of primary caregivers was solely responsible for making various arrangements. With regard to other IADL tasks, such as shopping and health care (bringing medicines from the pharmacy and accompany the care recipient to the health clinic), the primary caregivers and the homecare workers shared these activities. A significant proportion of neither the primary caregiver nor the homecare workers performed heavy home chores and big laundry because there was also a hired homemaker who performed these housekeeping chores.

In other words, while the most prevalent pattern regarding personal care tasks was that this was performed solely by the homecare workers, the next most prevalent pattern was shared responsibility by both the formal and informal caregivers, and the least prevalent pattern was that of primary caregivers who were the only ones to perform ADL tasks and this related in particular to surveillance. With regard to IADL tasks, the most prevalent pattern was that of homecare workers performing solely housekeeping tasks, while the majority of primary caregivers solely managed financial affairs. Yet, various errands (e.g. bringing medicines from the pharmacy, shopping) for the most part were either shared by both caregivers or performed only by the homecare workers. 
International Journal of Ageing and Later Life

\section{Changes in ADL and IADL Tasks Performed by Primary Caregivers}

In general, four major patterns of caregivers' involvement were identified: (1) primary caregivers who were not actively involved in performing a specific ADL and IADL task either before or after employment of the migrant live-in homecare worker, (2) primary caregivers who were actively involved in performing specific ADL and IADL tasks before and after employment of the homecare worker, (3) primary caregivers who were not actively involved in performing specific ADL and IADL tasks prior to employment of the migrant-live-in homecare worker but started to be involved afterwards, and (4) primary caregivers who were actively involved in performing specific ADL and IADL tasks prior to employment of the migrant-live-in homecare worker but ceased to be involved afterwards.

Figure 1. ADL tasks performed by primary caregivers before and after the employment of a migrant homecare worker (percentages)

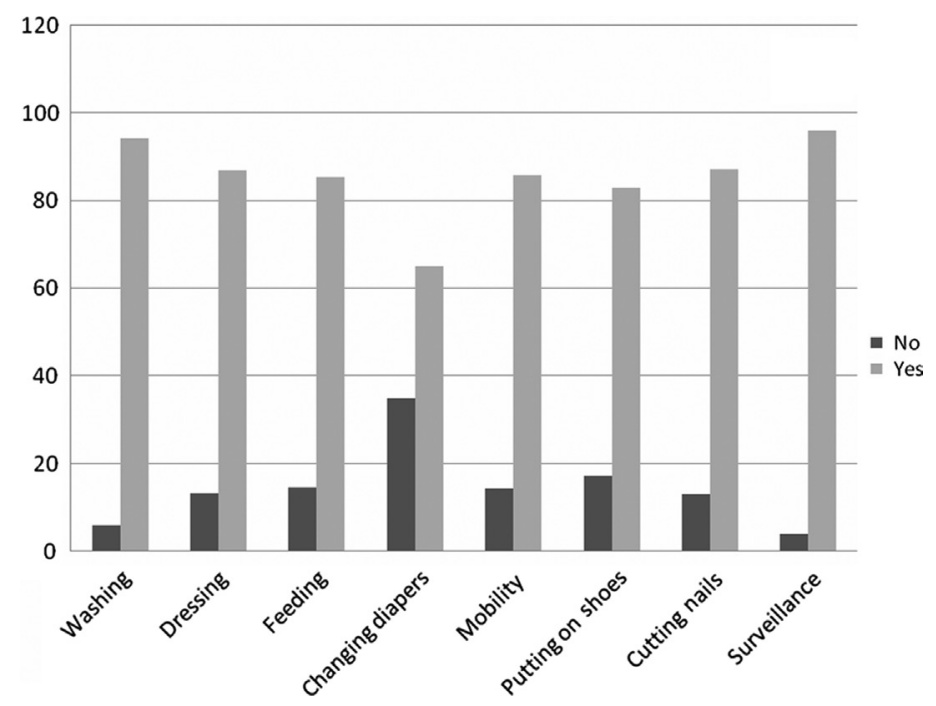


Tasks performed by primary caregivers and migrant live-in homecare workers

Figure 2. IADL tasks performed by primary caregivers before and after the employmnet of a migrant homecare worker (percentages)

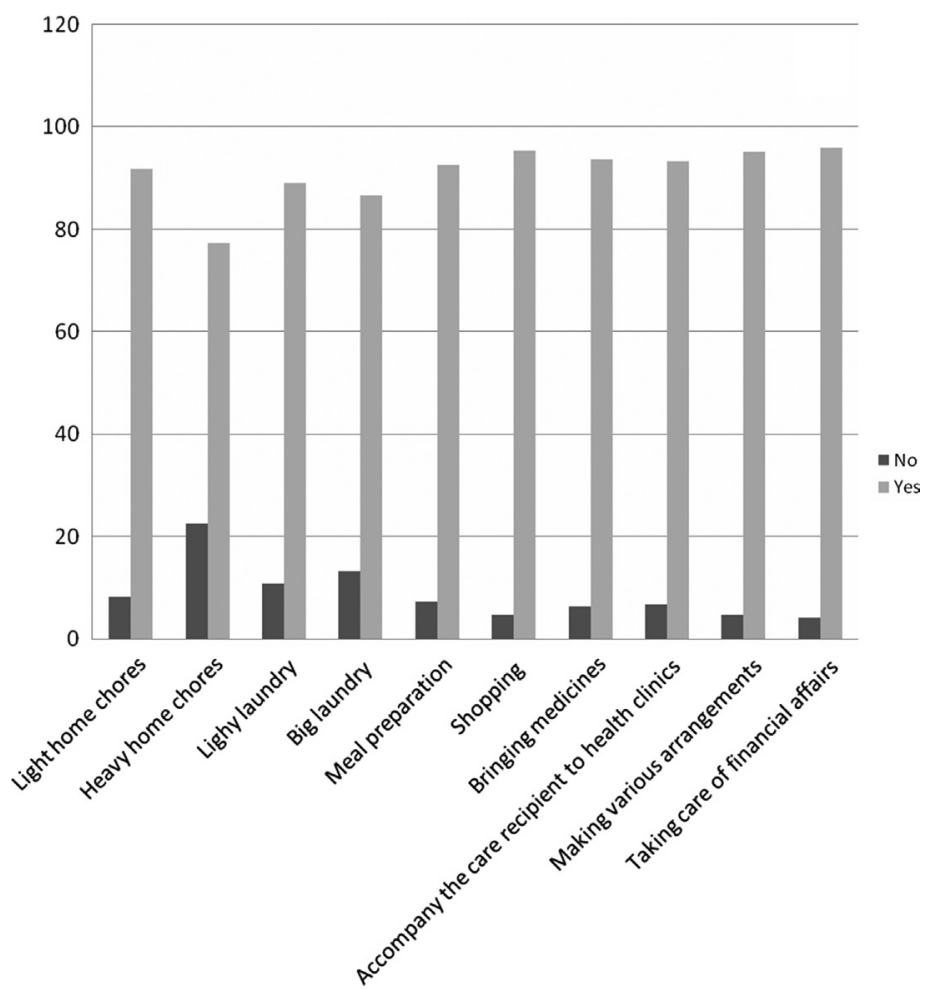

In general, as shown in Figure 1, among those primary caregivers who reported that they were currently involved in performing each of the ADL tasks, most of them were also actively involved in performing these tasks prior the employment of the migrant carer, whereas only a minority did not perform these tasks in the past. A similar picture is obtained with regards to IADL.

Figure 2 shows that among those primary caregivers who currently performed IADL tasks, the vast majority used to be actively involved in 
International Journal of Ageing and Later Life

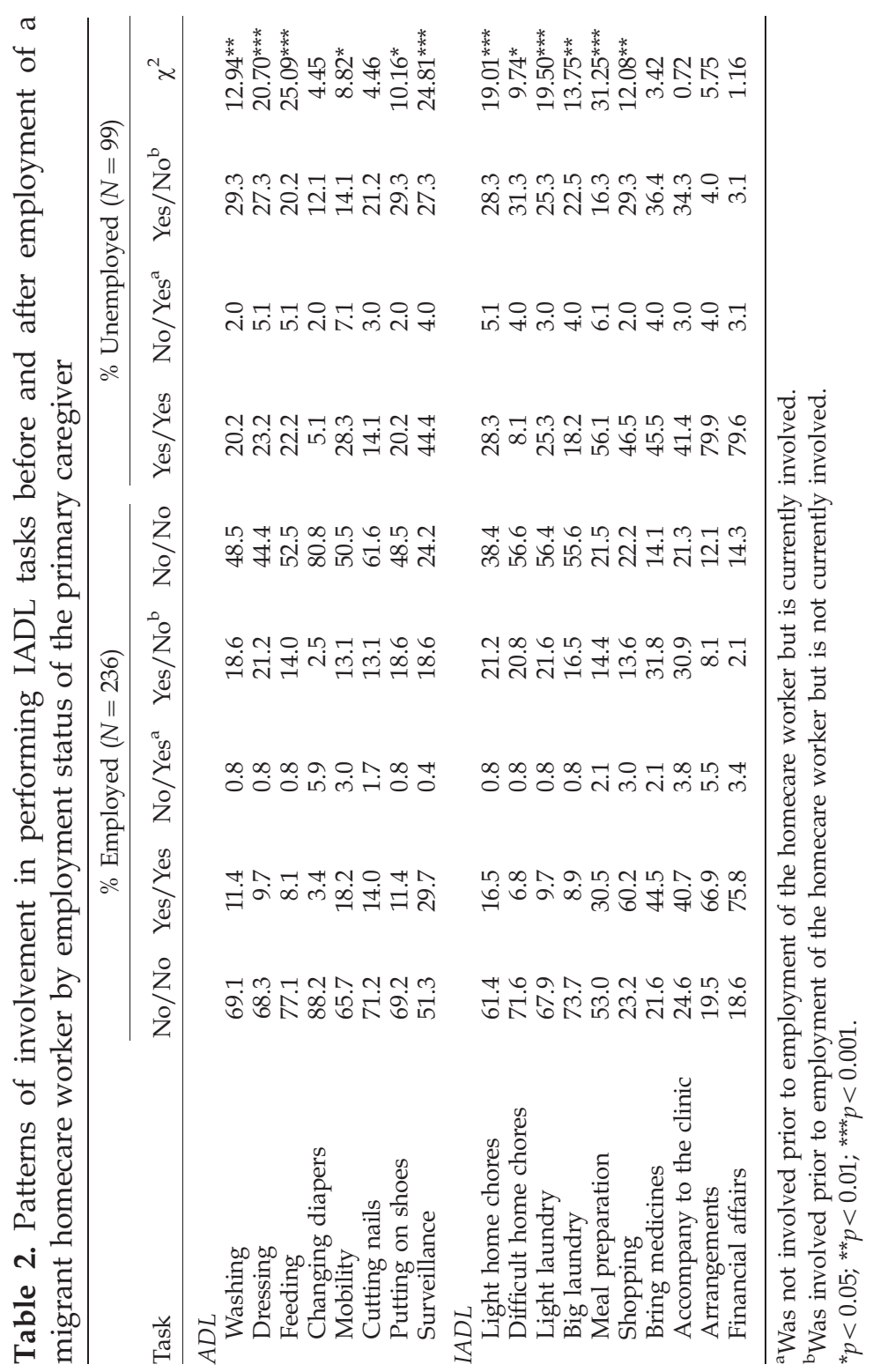


performing each of the IADL tasks also prior to the employment of the migrant homecare worker, in particular with regard to taking care of financial affairs. However, only a small minority who was involved before was not currently involved in performing any of the IADL tasks.

\section{Changes in Performing ADL and IADL Tasks by Employment Status of Caregivers}

The findings in Table 2 present the differences in patterns of caregiving tasks before and after employment of the migrant live-in homecare worker by employment status of the primary caregiver. The findings indicate significant differences between working and non-working caregivers in terms of patterns of personal care involvement. The findings show that significantly more employed caregivers were not involved in providing personal care, either before or after hiring of the migrant worker, except for changing diapers whereby the majority in both groups did not perform this task because the majority of care recipients did not need help with this task. A similar picture is obtained with regard to housekeeping tasks whereby significantly more working caregivers were not involved in helping with these tasks. Yet, in all other IADL tasks that are related to errands and financial management, except for shopping where significantly less working caregivers helped with this task, there were no significant differences between the two groups. However, the majority of the primary caregivers were involved in performing arrangements and taking care of financial affairs, while with regard to health care the majority in both groups either used to perform and share these tasks or were not involved in them in both points of time.

\section{Changes in Performing ADL and IADL Tasks by Gender of Caregivers}

When comparing changes in performing ADL tasks by gender of primary caregiver, significant differences are revealed. It is seen in Table 3 that the vast majority of male caregivers were not actively involved in performing most ADL tasks both before and after employment of the worker, except for changing diapers, while only a third to a half of the female caregivers were not involved in performing these tasks either in the past or at present. 
International Journal of Ageing and Later Life

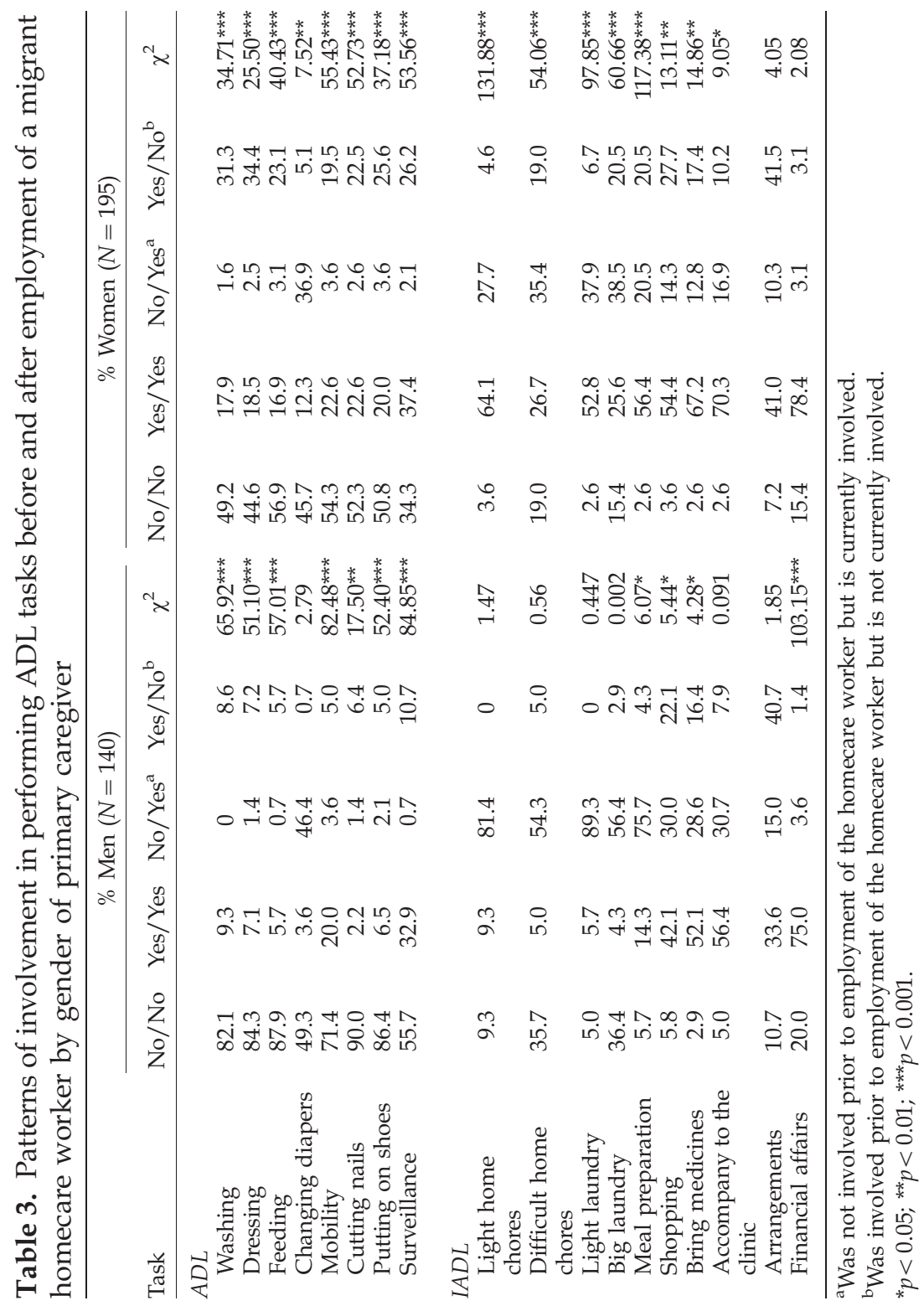


Tasks performed by primary caregivers and migrant live-in homecare workers

More female caregivers who used to be involved in providing help with ADL's continued to do so even after employment of the homecare worker, compared to male caregivers who continued to help with these tasks, except for indoor mobility and surveillance where no significant differences were found between male and female caregivers. Yet, more women than men ceased performing these tasks after the employment of the homecare worker. In addition, only minimal percentages of those who were not involved in performing ADL tasks became involved after the employment of a migrant live-in homecare worker, except for changing diapers, whereby a significant proportion of all caregivers became involved in helping with this task after the employment of the homecare worker and this proportion was higher among male than female caregivers. In general, when taking into account all those who were actively involved in performing ADL tasks before and after the employment of a migrant livein homecare worker, more female caregivers were involved in performing the personal care than male caregivers.

The IADL tasks performed by primary caregivers before and after employment of the homecare worker by gender are shown in Table 3. The findings show that only a small proportion of men and women were not involved in performing IADL tasks either before or after employment of a migrant live-in homecare worker. Yet, more male than female caregivers were not involved in housekeeping chores (e.g. difficult home chores and big laundry). Most female caregivers used to be involved in performing IADL tasks, except for hard housekeeping tasks (difficult home chores and big laundry) and arrangements before and after employment of the homecare worker. Most male caregivers who were involved in helping with most IADL tasks ceased doing so after the employment of migrant homecare workers, except for help with health care (bringing medicines and accompanying the care recipient to health clinics) and taking care of the financial affairs of the care recipients. Furthermore, most male caregivers who were not involved in providing help with IADL prior to the employment of the homecare worker helped with housekeeping tasks at present. It appears, however, that at present the majority of male and female caregivers alike were involved in providing help with all IADL tasks, in particular with financial affairs. 
International Journal of Ageing and Later Life

\section{Conclusions}

The findings of this study show that although there was a migrant live-in homecare worker who was available around the clock and who was supposed to perform all the personal and housekeeping tasks, some primary caregivers shared these activities while the majority of homecare workers solely performed these tasks when necessary. Yet, in activities that were connected with shopping and health care two patterns prevailed: either the homecare worker performed them or both caregivers shared these activities. In respect to arrangements and taking care of financial affairs, the most prevalent patterns were either the primary caregiver solely performed these tasks or s/he shared it with the homecare worker. Furthermore, when relating to changes in the involvement of the primary caregivers in the two points of time, those who used to be involved in providing personal care and helping with IADL prior to employment of the homecare worker, continued to be involved in assisting their elderly family members afterwards.

There are several reasons for this: first, from a cultural perspective, in Israel filial responsibility and intergenerational solidarity is still high, even more than in other western countries (Lowenstein \& Daatland 2006), and therefore primary caregivers continue to play a key role in caring for their elderly family members. Second, according to the labor laws in Israel, migrant live-in workers are entitled to take a weekly one-day leave, usually on Sundays. Thus, when the worker is on leave, she or he is replaced by the primary caregiver and therefore the latter performs personal care tasks on this day. However, the extent to which primary caregivers perform these tasks only on the worker's day off or on a more regular basis was not examined and therefore this point merits further investigation. Third, according to the regulations in Israel, to be entitled to employ a migrant live-in homecare worker the care recipient must be severely disabled (homebound, bedridden, or mentally frail). Thus, it might be that two persons are needed to share most of the ADL and IADL tasks because performing these tasks entails substantial physical effort. Therefore, even when there is a live-in migrant worker she or he might not be able to perform all the caregiving and housekeeping tasks without help from somebody else. 
Tasks performed by primary caregivers and migrant live-in homecare workers

The study identified four patterns of family caregivers' involvement in care provision following the employment of a live-in migrant homecare worker: (a) caregivers who were not involved in providing help either before or after employment of a migrant live-in homecare worker; (b) caregivers who were not involved in providing help prior to the employment of a migrant live-in homecare worker but started to help after their employment; (c) those who were involved in providing help prior to employment of the migrant worker but ceased afterwards; and (d) those who were involved in providing help prior to employment of the migrant worker and continued to be involved afterwards. These findings showed significantly different patterns between working and non-working caregivers with regard to involvement in performing most of the ADL and IADL. This suggests that while most working caregivers were not involved in performing personal care at any time, most non-working caregivers were involved in performing these tasks in the past and either continued to be involved or ceased performing these tasks. A similar picture is obtained with regard to housekeeping chores, but the majority in both groups used to perform the arrangements and taking care of financial affairs, whereas for health care the most prevalent patterns were that caregivers in both groups either performed these tasks in both points of time or used to perform them but were replaced by the homecare worker. In other words, as expected with respect to personal care and housekeeping chores, the substitution pattern was more prevalent among working caregivers, while the complementary or supplementary patterns were more applicable to non-working caregivers. With regard to other tasks such as arrangements and taking care of financial affairs, the majorities in both groups were the only ones to perform these tasks. A somewhat similar picture is obtained with regard to gender, where with personal care and housekeeping chores the substitution pattern was more prevalent among male caregivers, while the complementary or supplementary pattern was more applicable to female caregivers. Yet, with regard to other tasks such as arrangements and taking care of financial affairs, the majorities in both groups were the only ones to perform these tasks.

The findings, however, reflect the complexity of caregivers' involvement in help provision, suggesting that specific groups of caregivers are substituted by migrant live-in homecare workers for certain tasks, while for other tasks 
International Journal of Ageing and Later Life

they are complemented by the migrant workers. Furthermore, it can be concluded that when there is a migrant live-in homecare worker, the substitution and complementary models coexist simultaneously, thus providing support to Ward-Griffin and Marshall's (2003) findings. However, the present study found that the prevalence of each model differs by type of task and by the characteristics of the primary caregiver.

Taking into account that those who employ migrant live-in homecare workers are severely disabled, either physically and/or cognitively, the study may have several implications for policy. The study shows that significantly more working caregivers were uninvolved in providing personal care and in performing housekeeping chores neither prior nor after the employment of a migrant live-in homecare worker compared to their unemployed counterparts. Therefore, more awareness among employers to the specific needs of working caregivers is needed to enable them more flexibility in working hours and leaves in order to be more available to their older family members who need their help. The unemployed caregivers may experience an economic and physical burden due to the expenditures entailed in employing a live-in homecare worker in addition to direct care, taking into account that many of them are at the age of retirement. Thus, compensation schemes based on income tests should be adopted in order to financially support those with lower revenues and to avoid institutionalization of the care recipient.

Though, the study has several limitations: first, the study is based on a convenience sample and snowballing and included only Filipina workers. Therefore, care with generalization of the findings is warranted. Further studies that will include larger and random samples and workers from different cultural backgrounds can provide more information on the impact of the workers' ethnicity and cultural backgrounds on the division of labor between the formal and informal carers and enable generalization. Second, the study did not include multivariate analyses that could provide more insight into the factors that best explain the division of labor between the two carers as well as those explaining changes in primary caregivers' roles prior and after the employment of a migrant homecare worker. Third, the study did not examine the health and functional status of the care recipient prior to the employment of the migrant homecare worker. It might be that changes in the care recipients' health and functional status 
raised the need to employ a migrant worker, suggesting that the changes in primary caregivers' roles before and after the employment of the migrant homecare workers as well as the division of labor between the two carers may be influenced by the dynamic changes in the care recipients status in addition to primary caregivers' characteristics such as gender and employment status. Therefore, longitudinal studies may provide better insight into the dynamics changes in primary caregivers' roles and dialectics of the division of labor between the primary caregivers and migrant live-in homecare workers at different points of times. Fourth, further research is necessary to examine differences in caregivers' patterns of involvement in help provision when there is a migrant live-in homecare worker compared to a local live-out homecare worker. Therefore, further research is necessary to throw light and fill the gap in knowledge in this new challenging field of research.

\section{Acknowledgements}

This research was supported by a grant from the Israeli Ministry for Senior Citizens.

\section{Corresponding Author}

Esther Iecovich, Department of Sociology of Health and Gerontology, Faculty of Health Sciences, Ben-Gurion University, Beer-Sheva, Israel. Email: Iecovich@bgu.ac.il

\section{References}

AARP. (2005). AARP International forum on long-term care. Available on http://www.aarp.org/research/international/events/ltcforum_land ing.html (Accessed: December 16, 2004).

Agree, E. M., Freedman, V. A., Cornman, J. C., Wolf, D. A. \& Marcotte, J. E. (2005). Reconsidering substitution in long-term care: When does assistive technology take the place of personal care. Journals of Gerontology Series B 60(5): S272-S280. 
International Journal of Ageing and Later Life

Ayalon, L. (2009). Family and family-like interactions in households with round-the-clock paid foreign carers in Israel. Ageing \& Society 29(5): 671-686.

Brodsky, J., Naon, D., Resnizky, S., Ben-Noon, S., Morginstin, B., Graa, R. \& Schmeltzer, M. (2004). Recipients of Long-Term Care Insurance Benefits: Characteristics, Formal and Informal Assistance Patterns and Unmet Needs. Jerusalem: JDC-Brookdale Institute.

Browne, C. V. \& Braun, K. L. (2008). Globalization, women's migration, and the long-term care workforce. The Gerontologist 48(1): 16-24.

Cantor, M. H. \& Brennan, M. (2000). Social Care of the Elderly: The Effects of Ethnicity, Class and Culture. NY: Springer.

Denton, M. (1997). The linkages between informal and formal care of the elderly. Canadian Journal on Aging 16(1): 30-50.

Doyle, M. \& Timonen, V. (2009). The different faces of care work: Understanding the experiences of the multi-cultural care workforce. Ageing \& Society 29(3): 337-350.

Green, V. \& Auslander, G. (2008). Social networks and social support among functionally impaired older persons living in the community. Gerontologia 35(2): 111-126 [Hebrew].

Howe, A. L. (2009). Migrant care workers or migrants workers in longterm care? A review of Australian experience. Journal of Aging $\mathcal{E}$ Social Policy 21(4): 374-392.

Iecovich, E. (2007). Live-in and live-out homecare services and care recipient satisfaction. Journal of Aging and Social Policy 19(4): 105-122.

Iecovich, E. (2010). Primary Caregivers and Migrant Homecare Workers in Elder Care: Factors that Explain Caregiving Burden and Satisfaction of Primary Caregivers and Job Satisfaction of the Migrant Homecare Worker: A Research Report. Israel, Beer Sheva: Ben Gurion University.

Litwak, E. (1985). Helping the Elderly: The Complementary Roles of Informal Networks and Formal Systems. NY: Guilford Press.

Litwin, H. \& Attias-Donfut, C. (2009). The inter-relationship between formal and informal care: A study in France and Israel. Ageing and Society 29(1): 71-91.

Lowenstein, A. \& Daatland, S. O. (2006). Filial norms and family support in a comparative cross-national context: Evidence from the OASIS study. Ageing \& Society 26(2): 203-223. 
Natan, G. (2009). Migrant Workers in Israel: Key Issues and A Current Picture. Jerusalem: The Knesset [Hebrew].

Noelker, L. S. \& Bass, D. M. (1989). Home care for elderly persons: Linkages between formal and informal caregivers. Journal of Gerontology: Social Sciences 44(2): S63-S70.

Penning, M. J. \& Keating, N. L. (2000). Self, informal and formal care: Partnerships in community-based and residential care settings. Canadian Journal on Aging 19 (Suppl. 1): 75-100.

Polverini, F. \& Lamura, G. (2004). National Report on Italy: Labour Supply in Care Services, Ancona: Italy. Ancona, Italy: Instituto Nazionale di Riposo e Cura Anziani, Department of Gerontological Research.

Redfoot, D. L. \& Houser, A. N. (2005). “We Shall Travel On": Quality of care, economic development, and the international migration of long-term care workers: Research Report. AARP Public Policy Institute, AARP Public Policy Institute. Available on: http://www.aarp.org/research/long termcare/quality/inb104_intl_ltc.html (Accessed: November 27, 2005).

Rothgang, H. \& Lamura, G. (2005). Labour Market Participation, Income and Migrant Care Workers. Brussels: Pan European Network. EUROFAMCARE (Unpublished presentation).

Ungerson, C. (1990). The language of care: Crossing the boundaries. In C. Ungerson (ed.), Gender and Caring: Work and Welfare in Britain and Scandinavia (pp. 8-33). NY: Harvester.

Ungerson, C. (1999). Personal assistant and disabled people: An examination of hybrid form of work and care. Work, Employment and Society 13: 583-600.

Van der Geest, S., Mul, A. \& Vermeulen, H. (2004). Linkages between migration and the care of frail older people: Observations from Greece, Ghana and The Netherlands. Ageing and Society 24(3): 431-450.

Ward-Griffin, C. \& Marshall, V. W. (2003). Reconceptualizing the relationship between "public" and "private" eldercare. Journal of Aging Studies 17(2): 189-208.

WHO (World Health Organization). (2006). The World Health Report Working Together for Health. Available on: http://www.who.int/entity/ whr/2006/en/ (Accessed: December 10, 2006). 



\title{
Ethno-cultural diversity in home care work in Canada: issues confronted, strategies employed
}

\author{
By Anne Martin-Matthews ${ }^{1}$, Joanie Sims-Gould ${ }^{1,2}$ \& John \\ NASLUND $^{2}$
}

\begin{abstract}
Worldwide, immigrant workers are responsible for much of the care provided to elderly people who require assistance with personal care and with activities of daily living. This article examines the characteristics of immigrant home care workers, and the ways in which they differ from non-migrant care workers in Canada. It considers circumstances wherein the labor of care is framed by ethno-cultural diversity between client and worker, interactions that reflect the character of this ethno-cultural diversity, and the strategies employed by workers to address issues related to this diversity. Findings from a mixed methods study of 118 workers in the metropolitan area of Vancouver, British Columbia, Canada, indicate that while the discriminatory context surrounding migrant home care workers persists, issues of ethno-cultural diversity in relationships are complex, and can also involve non-foreign born workers.

1 Anne Martin-Matthews and Joanie Sims-Gould, Department of Sociology, The University of British Columbia, Vancouver, BC, Canada

2 Joanie Sims-Gould and John Naslund, Vancouver Coastal Health Research Institute, Vancouver, BC, Canada
\end{abstract}


International Journal of Ageing and Later Life

Multi-cultural home care is not always framed in a negative context, and there often are positive aspects.

Keywords: migrant care workers, ethno-cultural diversity, home care, paid carers.

\section{Introduction}

In analyses of non-professional workers' ${ }^{1}$ labor, home care work is recognised as low-paid domestic labor, and is frequently dominated by migrant workers (Doyle \& Timonen 2009; Phillips 2007). In many, if not most, developed countries, immigrant women workers are responsible for significant amounts of care work provided to elderly people who require assistance with personal care and with activities of daily living (Misra et al. 2006). In order to extend our understanding of the nature of care work by immigrant workers in supporting elderly clients, this article examines circumstances wherein the labor of care is framed by ethno-cultural diversity between client and worker. It addresses interaction issues that reflect the character of this ethno-cultural diversity and the strategies employed by workers to address them.

The characteristics and experiences of home care workers vary between countries as global capitalism is being differentially experienced across the world and is consequently having a varied impact on care systems. It is widely acknowledged that "migrant workers will fill shortages in the care economy" (Phillips 2007: 139). This expectation underscores concerns

\footnotetext{
${ }^{1}$ The job title for these workers varies from one part of Canada to the next (home support workers, personal support worker, community health worker), and from one country to another. In this article we use the term "home support worker" (HSW) to describe workers who provide services known as "home support," although a variety of occupations work in home care. Home support is typically defined as non-professional services involving personal assistance with daily activities, such as bathing, dressing, grooming, and light household tasks. Various job titles are used across Canada for persons who provide home support. Titles used in other parts of the world include Community Care Worker (Australia), Direct Care Worker (United States), and Social Carer (United Kingdom).
} 
about the rise in the number of both legal, and especially illegal, immigrant workers providing care to frail and potentially quite vulnerable elders. It is also seen as a further reflection of the low status of home care work. Such perceptions of home care undermine the importance of care work in general and increase the vulnerability not only of service users, but also of home care workers who may experience discrimination, including racial abuse, as a result of the invisibility of their work (Phillips 2007).

Around the globe, immigrants in the care workforce fill the gap in the provision of care (Ayalon 2009; Phillips 2007). However, these workers often face language barriers and abuse; illegal workers, in particular, are subject to exploitation through low pay and dangerous working conditions (Aronson \& Neysmith 1996; Phillips 2007; Stone \& Dawson 2008). This is particularly well illustrated within the Irish long-term care sector, wherein racial and cultural tensions not only affect the wellbeing of care workers but also the quality of care received (Timonen \& Doyle 2010). In a study of 40 care workers across the sectors of institutional and domiciliary care (and amongst live-in and "gray" labor market workers), Doyle and Timonen (2009) found that some members of the long-term care workforce are more likely to experience discrimination than others. The experiences of European, South Asian, and African carers differ significantly, and relationships exist between carers' region of origin and their experience of care work, employment mobility, and long-term plans for remaining in the sector. Much of the discrimination experienced by workers was "rooted in the informal nature of their work contracts and their illegal or conditional residency status, which put them in a relationship of dependency with their employers" (2009: 347).

Another recent study in Israel notes that foreign home care workers are primarily women from Asian and Eastern Europe, with almost half of the foreign home-care workforce being "undocumented" workers (Ayalon 2009). In Israel, almost all around-the-clock home care is provided by foreign workers who, in order to limit their stay in the country, are not allowed to bring their families into the country. With data from a study of 245 Filipino workers, Ayalon (2008) evaluated working conditions and exposure to abuse. Overall, $43 \%$ reported being asked to do more than was specified in their job description, $41 \%$ reported being verbally abused, 
International Journal of Ageing and Later Life

$40 \%$ reported not receiving adequate food, and almost half reported work related injuries.

The Canadian home care labor force is increasingly made up of lowpaid immigrant women, although, as will be discussed later in this article, this varies from one region of the country to another. Migrant home care workers undertake their work while dealing with differences between themselves and their clients in race, culture, and class. In the process, they can face racist attitudes and behaviors from clients and families, but often avoid confrontation because of concerns for their clients' wellbeing and their own job security (Neysmith \& Aronson 1997). A study of black female care workers in the predominantly French-speaking province of Québec found that they are more likely than are white care workers to be pressured into doing extra work for their clients (Meintel et al. 2006). Some clients treat their home care workers as "servants" or "cleaning ladies," and anti-immigrant prejudices emerge including the view that migrant care workers are "job thieves" (Meintel et al. 2006: 571). In the Québec study, migrant home care workers were found to have higher education levels than their Canadian-born colleagues, supporting the view that the home care field is a "deskilling ... so often part of the migrant experience" (Meintel et al. 2006: 573).

\section{The Canadian Context}

While issues of the ethno-cultural diversity of home care workers and their clients have been examined by xother researchers, these issues are particularly salient in the Canadian context. Canada's elderly population is more ethnically diverse than the Canadian population as a whole (Chappell et al. 2003). Indeed, $17 \%$ of the Canadian population overall is foreign-born, compared to $27 \%$ of those aged 65 years and older. This is in part due to significant waves of immigration throughout the last century, and especially in the decade following World War II. The majority of these post-war immigrants came from Europe and the United States (Durst 2008). Thus, a significant proportion of now-elderly "immigrants" came to Canada as children and aged in place. They are less likely to belong to a "visible minority" group than are more recent immigrants to Canada.

It is also important to note as a contextual backdrop to our analyses that the total visible minority population, as a percentage of the entire 
population, varies considerably from one region of Canada to another. The Atlantic and Prairie provinces, for example, have much lower concentrations of migrants, and particularly visible minority group migrants, than do Canada's largest cities (i.e. Toronto, Vancouver, and Montréal). Rural and small town areas have lower concentrations than do urban areas. In metropolitan Vancouver, British Columbia, the main site of our data collection, fully $40 \%$ of the population in 2006 were immigrants (Statistics Canada 2006). However, for a country such as Canada, where immigration has long been characteristic of the population, equally relevant for this study is the fact that the proportion of the Vancouver population who are members of visible minorities has increased substantially in recent decades, from $17 \%$ in 1986, to $31 \%$ in 1996, to $42 \%$ in 2006 (Statistics Canada 1996, 2006; Statistics Canada \& Employment Equity Data Program 1990). During this period, the Filipino population (the country of origin of most of the foreign-born home support workers (HSWs) in our study) grew from 1\% of the total Vancouver metropolitan population in 1986, to 2\% in 1996 to 4\% in 2006 (Statistics Canada 1996, 2006; Statistics Canada \& Employment Equity Data Program 1990). In addition, Chinese and South Asian (Indo-Pakistanis) population groups have increased from $8 \%$ and $4 \%$, respectively, in 1986; to $15 \%$ and $7 \%$, respectively, in 1996; to 18\% and 10\%, respectively, in 2006 (Statistics Canada 1996, 2006; Statistics Canada \& Employment Equity Data Program 1990). Thus, the findings of this study must be interpreted in the context of a country that defines itself as one of the most ethno-culturally diverse places on earth.

An important contextual feature of home care work in Canada is also its variability from one region of the country to another. Canada is divided into ten provinces and three northern territories. With few exceptions, health care delivery services, even those based on federal transfers of funds, are delivered at the level of the provinces and territories. Therefore, there are provincial/territorial differences in the nature of these home support services, in the job titles and classifications of workers, in client eligibility and funding schemes, and in how public and private sector services are integrated.

As Doyle and Timonen (2009) have examined for Ireland, so too does this article examine, in the Canadian context, the role of migrant care labor 
International Journal of Ageing and Later Life

in long-term care systems in a comparative context. This article seeks to develop an understanding of the experiences of migrant care workers in Canada, adding (to the earlier work of Neysmith \& Aronson 1997) an examination of their experiences of home care work as immigrants, and the strategies that they employ to address these issues in the workplace. Also, because immigrant workers are often perceived as homogeneous but in fact may have characteristics and experiences unique to their region of origin (Doyle \& Timonen 2010), this article begins with an examination of variability among different groups of immigrant care workers participating in our study.

Our analysis was guided by the following research questions: Are immigrant care workers different in significant ways from Canadian-born workers, in terms of training, experience, or job satisfaction? How do they experience ethno-cultural differences between themselves and their clients? How do they experience racism and prejudice? What strategies do workers employ to address issues of ethno-cultural diversity?

\section{Methodology}

In the Nexus Home Care Research Project, there were three phases of data collection (for more information see: http://www.nexus_homecare. arts.ubc.ca). In Phase I, from 2005 to 2006, pilot interviews were conducted with managers and owners of home care agencies, key informants, clients, and family members from British Columbia, Canada. In Phase II, from 2006 to 2007, in-depth interviews were conducted with home care workers, elderly clients, and family members from British Columbia, Canada. Lastly, in Phase III, from 2007 to 2008, comparative pilot studies were carried out with HSWs in two other Canadian provinces, Ontario and Nova Scotia. In this article, we focus primarily on findings from the Phase III data collected through interviews with 118 HSWs in British Columbia, although we will briefly consider findings from the pilot studies undertaken elsewhere in Canada.

\section{Recruitment}

Upon receipt of approval from the University of British Columbia Behavioural Research Ethics Board, data were collected from March to 
October 2007 in the Lower Mainland (metropolitan Vancouver and surrounding area) of British Columbia. Selection of study participants was limited to HSWs employed by home care agencies, who could speak English, and who provide primarily "non-professional" services (e.g. non-medical services) to clients over the age of 65 (for more detail on recruitment see: Sims-Gould \& Martin-Matthews 2010).

\section{Data Collection and Analyses}

Two methods were used to recruit study participants. First, three home care agencies were purposively selected to represent the spectrum of contracted agencies (two private and one not-for-profit) serving a mixture of both urban and rural clients. However, this method resulted in very low response rates, $3-11 \%$ depending on the agency (see Sims-Gould \& Martin-Matthews 2010). A second recruitment strategy involved randomly selecting names of workers from a membership list of the British Columbia Government Employees Union (BCGEU local 403). Workers were contacted by the Union, provided with a brief description of the study, and asked for their consent to be contacted by our team. The response rate through the Union recruitment proved to be better at $52 \%$, consistent with other studies involving HSWs (Sims-Gould \& Martin-Matthews 2010; Stone \& Dawson 2008).

Of the 118 HSWs interviewed, $84(71 \%)$ were recruited through the participating home support agencies method, and $35(29 \%)$ were recruited through the Union (all HSW's interviewed were unionized). Data were obtained through face-to-face, in-depth, and semi-structured interviews (with questions pertaining to work history and experience, a description of a "typical" visit with an elderly client, issues of time management, working in the privacy of clients' home, stressful aspects of the work, and safety concerns).

Questions were modified, added, or deleted based on feedback and results from the pilot study (Martin-Matthews \& Sims-Gould 2008). The interviews, which were approximately $60-90 \mathrm{~min}$ in length, were audio recorded and transcribed verbatim by a transcription agency. Data were saved using ID numbers and pseudonyms to ensure anonymity, and were uploaded into the qualitative data analysis program, NVivo 8. Descriptive and categorical data were analyzed using SPSS version 17.0. 
International Journal of Ageing and Later Life

The analyses reported in this article are based on data relating to work history and educational qualifications, and responses to one open-ended question: "Have you been in a situation where you experienced hostility from clients because of cultural differences?" During preliminary analyses of this question, the responses were isolated from all 118 HSW interviews. These responses were broadly organized into "yes" or "no" categories. Two members of the research team further analyzed the detailed "yes" responses from HSWs, both foreign-born and Canadianborn, through multiple independent readings of the transcripts. The content analysis of the transcripts (following the procedures as described by Stemler 2001) took place over an eight-month period.

In addition, a measure of job satisfaction was obtained through the analyses of responses to a standardized instrument, the BrayfieldRothe Job Satisfaction Index (Brayfield \& Rothe 1951). The BrayfieldRothe Index has been used to measure overall job satisfaction among other health care professionals (Agho et al. 1992, 1993). The scale is based on nine positively, and nine negatively worded questions in random order (e.g. I feel fairly well satisfied with my present job, I definitely dislike my work). Questions consist of five-point Likert scales that range from strongly agree (1) to strongly disagree (5). An item-total correlation analysis on the original 18-item scale revealed that seven items had corrected item-total correlations below the acceptable level of 0.300 (Okolo 1990). As a result, the measure was reduced to an 11-item subscale $(\alpha=0.83$; see Appendix A). Similar subscales of the Brayfield-Rothe Index have been used in other studies to measure overall job satisfaction (Babin \& Boles 1998; Curry et al. 1986; Shafer 2002).

Because one of the objectives of this analysis was to measure differences in job satisfaction between Canadian-born and foreign-born workers, the completed scale responses of all foreign-born participants were examined closely for response sets that might indicate they had difficulty comprehending the questions. The interviewers' field notes were consulted to see if language difficulties had been indicated at the time of the interview. Patterns in the scale responses were also examined closely for consistencies. In particular, we examined whether the responses to positively worded questions and negatively worded questions were congruent. This was followed by a comparison of responses to the global job satisfaction 
question (overall, how satisfied are you with your job?) and responses to the items on the Brayfield-Rothe subscale. Finally, the full transcripts of respondents who were identified as potentially having had difficulties in answering these questions were reviewed to examine whether they had had difficulties throughout the entire interview process. In all, three team members were involved in the process of determining that nine of the 81 foreign-born respondents had substantial difficulties understanding the job satisfaction subscale questions. A decision was made to exclude these particular respondents from any further analyses in order to be confident that between-group differences were not confounded by language difficulties.

\section{Results}

\section{Worker Characteristics}

As expected, the majority of HSWs interviewed were female (94\%). Workers ranged in age from 27 to 65 years of age, with a mean of 50 years ( $\mathrm{SD}=8$ years). Reflecting the growing international trend linking immigrant labor to home support work (Stacey 2005), over two-thirds $(69 \%)$ of the workers we interviewed were foreign-born. Of the foreignborn workers in this study, 17 (14\%) have lived in Canada for less than 10 years, 38 (32\%) between 10 and 20 years, and 25 (21\%) for over 20 years. The majority of immigrant workers in our sample came to Canada from the Philippines (30\%) or other parts of Asia (20\%), including China, Hong Kong, and India. Another 9\% were originally from Europe, and the remainder (under the "Other" category) were from countries within Africa, and from Central or South America. Although the HSW characteristics largely reflect the overall percentage breakdown of foreign-born populations in the Vancouver area, the notable exception is workers from the Philippines. While Filipino immigrants account for roughly $4 \%$ of the total population, they account for a much higher proportion in our sample. This reflects both the aggressive labor export policies of the Philippine Government and a shortage of skilled laborers in Canada 
International Journal of Ageing and Later Life

Table 1. Country of birth of home support workers - BC interviews

\begin{tabular}{lcc}
\hline Country of origin & Number of home support workers & Percentage (\%) \\
\hline Canada & 37 & 32 \\
Philippines & 36 & 30 \\
China & 9 & 8 \\
Hong Kong & 7 & 6 \\
Europe & 10 & 9 \\
Asia & 11 & 9 \\
Africa & 4 & 2 \\
Other & 5 & 4 \\
\hline
\end{tabular}

(Zaman et al. 2007). Nearly a quarter (23\%) of foreign-born HSWs in our sample entered Canada through the Federal Live-in Caregiver Program ${ }^{2}$ (see Table 1).

Among these workers, education ranged from less than high school $(11 \%)$ to completed post secondary $(52 \%)$. Most were employed full-time $(61 \%)$, with the others either part-time $(10 \%)$ or casual workers $(29 \%)$. Duration of employment ranged from 0.5 to 29 years $(M=12$; $\mathrm{SD}=7)$. Our sample was a very experienced workforce, with close to $60 \%$ having worked in home support for more than 10 years, and just over 10\% having worked for over 20 years in this sector. These workers had an average caseload of 4.2 clients per day $(\mathrm{SD}=1.5)$, although this ranged from a minimum of one to a maximum of nine clients per day.

In order to address our first research question as to comparisons between the Canadian-born and foreign-born workers, we first compared them, and then, following Doyle and Timonen (2009), examined differences between different groups of foreign-born workers, according to their country of origin. The more detailed comparisons of Canadian, Filipino, Asian-born, and workers born in other countries are presented in Table 2.

\footnotetext{
${ }^{2}$ The federal Live-In Caregiver Program allows individuals to immigrate to Canada to work as a carer, for children, adults, or the elderly. Canada has agreements with several countries (see http://www.cic.gc.ca/EnGLish/work/ caregiver/index.asp).
} 
Table 2. Differences in worker characteristics by country of origin

\begin{tabular}{|c|c|c|c|c|}
\hline & $\begin{array}{l}\text { Canada } \\
(n=37)\end{array}$ & $\begin{array}{l}\text { Philippines } \\
(n=36)\end{array}$ & Asia $(n=27)$ & Other $(n=18)$ \\
\hline Age $(n=117)$ & $\begin{array}{r}M=52.78 \\
(\mathrm{SD}=7.77)\end{array}$ & $\begin{array}{l}M=48.89 \\
(\mathrm{SD}=6.92)\end{array}$ & $\begin{array}{c}44.12 \\
(\mathrm{SD}=8.75)\end{array}$ & $\begin{array}{l}M=53.89 \\
(\mathrm{SD}=5.73)\end{array}$ \\
\hline \multicolumn{5}{|l|}{ Education $(n=118)$} \\
\hline Less than HS & $8(22 \%)$ & 0 & $2(7 \%)$ & $3(17 \%)$ \\
\hline High school & $10(27 \%)$ & $4(11 \%)$ & $3(11 \%)$ & $7(39 \%)$ \\
\hline $\begin{array}{l}\text { Some post } \\
\text { secondary }\end{array}$ & $13(35 \%)$ & $5(14 \%)$ & $1(4 \%)$ & $1(6 \%)$ \\
\hline $\begin{array}{l}\text { Completed post } \\
\text { secondary }\end{array}$ & $6(5 \%)$ & $27(75 \%)$ & $21(78 \%)$ & $7(39 \%)$ \\
\hline \multicolumn{5}{|c|}{ Hostility based on ethno-cultural differences $(n=113)$} \\
\hline Yes & $14(39 \%)$ & $17(49 \%)$ & $12(46 \%)$ & $8(50 \%)$ \\
\hline No & $22(61 \%)$ & $18(51 \%)$ & $14(54 \%)$ & $8(50 \%)$ \\
\hline \multicolumn{5}{|c|}{ Job satisfaction score (11-item Brayfield-Rothe) } \\
\hline$(n=109)$ & $\begin{array}{l}M=45.46 \\
(\mathrm{SD}=5.59)\end{array}$ & $\begin{array}{r}M=46.39 \\
(\mathrm{SD}=4.52)\end{array}$ & $\begin{array}{r}M=44.09 \\
(\mathrm{SD}=3.80)\end{array}$ & $\begin{array}{r}M=47.89 \\
(\mathrm{SD}=5.55)\end{array}$ \\
\hline
\end{tabular}

An independent samples $t$ test was conducted to determine statistical differences in mean age between Canadian-born and foreign-born HSWs. Results indicate that foreign-born workers $(M=48.46$; $\mathrm{SD}=8.09)$ were significantly younger than Canadian-born workers $(M=52.78 ; \mathrm{SD}=7.77)$, $t(115)=2.72 \quad(p<0.01)$. Comparisons between groups of foreign-born indicate that workers from Asia are the youngest, though the differences between groups are not large.

Cross-tabulations were computed to determine if a statistically significant difference exists in highest level of education reported by Canadianborn compared to foreign-born HSWs in our sample. The results show that 19 of the 37 Canadian-born HSWs (51\%) have some type of post-secondary education (some college, some university, or a college/university degree) compared with 62 of the 81 foreign-born HSWs (77\%). Of the ten HSWs $(9 \%)$ who identified themselves as Registered Nurses, nine were foreignborn. None of the Canadian-born HSWs reported having graduated from a 
International Journal of Ageing and Later Life

university. However, 27 of the 81 foreign-born HSWs (33\%) reported that they had graduated from a university. Furthermore, while eight $(22 \%)$ of Canadian-born HSWs had not completed high school, only five foreignborn HSWs (6\%) lacked this credential. As Table 2 illustrates, the workers from the Philippines were the most highly educated of the HSWs whom we interviewed.

An independent samples $t$ test was conducted to determine if statistically significant differences exist in mean rate of pay/hour earned by Canadian-born compared to foreign-born HSWs in our sample. Foreign-born workers earn on average $\$ 18.68$ per hour $(\mathrm{SD}=0.81)$, while Canadian-born workers earn on average $\$ 18.96$ per hour, a mean difference of 0.28 cents per hour $(\mathrm{SD}=0.64), t(113)=2.00(p<0.05)$.

Also shown in Table 2, there were no significant differences between Canadian and foreign-born workers in responses to the 11-item subscale of the Brayfield-Rothe Job Satisfaction Index. Further, there were no differences in reported levels of job satisfaction amongst groups of workers when compared in terms of their country of origin. However, in our revised 11-item subscale, which eliminated some of the most problematic questions, reliability was still an issue for data from Asian born workers $(\alpha=0.68$, see Table 2). Nonetheless, we are able to conclude that, with an average Brayfield-Rothe satisfaction score of 45.96, HSWs reported relatively high levels of job satisfaction in comparison to other studies that have measured employee satisfaction using this tool (Babin \& Boles, 1998; Curry et al. 1986; Shafer 2002). In addition, this finding is consistent with a one-item measure of overall satisfaction used in our study, in which $107(94 \%)$ of workers reported being "satisfied" or "very satisfied."

\section{Perceptions of Hostility in an Ethno-Cultural Context}

To measure HSWs' experience with hostility due to ethno-cultural differences in their work with elderly clients, participants were asked: "Have you ever been in a situation where you experienced hostility from clients due to cultural differences?" It should be noted that this question enquires about cultural differences between worker and clients, and therefore is not explicitly focused on any ethno-cultural characteristics of the workers themselves. Almost half of the workers (43\%) responded that they had experienced hostility from clients because of such ethno- 
cultural differences. No significant differences were found between Canadian-born and foreign-born workers in their response patterns to this question, although there was a trend in the data that showed $39 \%$ of Canadian-born workers reported hostility, compared to $45 \%$ of foreignborn workers.

The interview transcripts are replete with workers' accounts of hostility they encountered from clients due to perceived ethno-cultural differences, ranging from not wearing culturally appropriate footwear and not cooking or being able to cook the "right" (culturally appropriate) type of food, to outright racism and discrimination. For the Canadian-born workers, such hostility typically resulted from their (perceived) lack of understanding of, or respect for, the cultural preferences of clients who were also foreign-born. In a comment typical of Canadian-born Caucasian workers, the issue lies in the cultural preferences of the clients. "Especially Asians and East Indians. They really do not like us in there. Like white people, I should say." (Ming, 56-year-old woman, employed 18 years as HSW).

Foreign-born workers, and particularly those from visible minority groups, report many instances where clients did not trust them, were quite "mean," refused help (particularly with personal care), phoned the agency to specify that they did not want an ethnic person in their home, or, upon hearing the foreign HSW's accent, refused entry at the door. "They don't trust what you're going to do for them." (Erika, 49-year-old woman from Africa, employed 3 months as HSW).

In an illustrative verbatim account, a foreign-born HSW describes her experience:

They wouldn't let us touch them because [of] my skin colour... I had this client, regular ... and she couldn't see. She was legally blind. And ... my English is okay. So she couldn't get at first that I wasn't Canadian. And then I must've said something. But then she realized after the second visit or so, then she goes, "You are not Caucasian." She used that word. And I said, "No, I'm not." And she goes, "What colour are you?" And I said, "Well, my skin colour is brown and I'm ... Fijian." ... So she goes, "Oh, and you have been bathing me!" because of the day before. And I said, "Yeah, I think." [She replies ...] "I don't want you touching me," and so we have this hostility that come over. And she said, "I don't know why you immigrants come here," and so she kept on going and going. (Yvonne, 46-year-old woman, employed 21 years as HSW) 
International Journal of Ageing and Later Life

Other workers describe the source of the discrimination as not coming from the client, but rather a relative of the client: "... the boyfriend of a client's relative said: 'We should send all these Filipinos to where they came from on a slow boat.'" (Alegria, 51-year-old woman, employed 14 years as HSW). In other cases, workers attribute the perceived racism to the client's health status: "[My client is] too demented and then every time I come into her house, she says, 'Who are you and what are you doing here? You go back to your country.'" (Raquel, 38-year-old woman, employed nine years as HSW).

There was also evidence of hostility between co-workers based on ethno-cultural differences. Some HSWs report a distinct divide between workers from different ethno-cultural backgrounds. While workers do not have occasion to get together very often during training sessions and seasonal gatherings, it was noted that when they do, workers "stick with their own." In many of our interviews, HSWs also made subtle but racist remarks about other workers:

\footnotetext{
I hate to sound racist, I don't mean to, everybody does a good job and they all add to their own, there's a lot of things people have over me coming from a different culture, maybe, but I have, I think there needs to be more Canadian born people in this field. I don't know if that's a really bad thing to say. I know that, I know that's one thing I get told by the clients a lot, and that's one of the reasons I got into this. (Nancy, 29-year-old woman from Canada, less than 1 year as HSW)
}

In this interview, Nancy, like many other workers making these types of comments, had discomfort with her own racist remarks. She tried to balance her comment (or "back peddle") by saying:

And some of them prefer the other ethnics over me cause and they think that they're harder workers. I don't know. I know I'm sweating sometimes when they tell me that just cause I want to show them that I'm a good worker too, let me show ya. (Laughs) And I enjoy that right, cause I want to break that stereotype that they think you know.

These types of highly racialized comments were common among workers discussing other workers. 


\section{Strategies for Managing Hostility}

In order to contribute further to the emerging literature seeking to understand the implications of these ethno-cultural differences between HSWs and their elderly clients, we also enquired as to what workers do in response to these circumstances. Specifically, how do they respond when they experience this hostility, what strategies do they employ to deal with it, and how might these be the basis of training of workers by agency personnel? Thus, when workers described such circumstances, we followed with a question phrased in terms of: "And so what do you do when ...," in order to elicit workers' descriptions of actions and outcomes.

Strategies typically employed by HSWs in dealing with culturally based hostility include: phoning the supervisor; using coping strategies such as ignoring it, getting used to it, letting it go, not taking it personally, or remaining calm; using communication strategies; learning about the clients' cultures, preferences or routines; accommodating the clients and taking a "kind" approach to them; or, asking to be removed from the case, leaving the situation, or suggesting that the client call the agency.

In response to the question about their responses and strategies, some workers began with a description of their feelings, and their sense of general powerlessness (often fuelled by a fear of losing their job if the client complained about them). "Why am I so miserable every time people criticizing me like this and I feel unhappy and kind of very sensitive person." (Mei, 28-year-old woman from China, working 3 months as HSW). Common responses among workers were: "I ignore it. It's not a good way of how - sort of handling things but I just ignore it." (Heidi, 48year-old woman from Canada, employed 17 years as HSW) and "I don't want troubles at work so I just, you know, totally ignore everything". (Anabel, 36-year-old woman from the Philippines, employed 10 years as HSW).

Other workers, often those with more experience of such circumstances, describe use of humor (I try to be funny) as a way to make a point while not making an "issue" of the discriminatory remark or hurtful comment: 
International Journal of Ageing and Later Life

I said to the client, "Well," I go, "you know what? When God was giving skin away I got there at - I was the last one and I just guess God forgot to take the skin out of the oven on time. You know, I try to-to be polite but at the same time telling them." (Carolyn, 47-year-old woman from Scotland, employed 18 years as HSW)

Earlier we noted the recent rapid growth in the ethno-cultural diversity of the Vancouver metropolitan and Lower Mainland area which was the site of our study. Reflective, perhaps, of the changing context of interaction between workers and clients of different ethno-cultural groups, the accounts of some experienced HSWs note changes over time, and improvements across the decades. In this example, a foreign-born HSW compares and contrasts the ways in which she has been treated by her elderly clients over the course of her work experience:

... we used to have cultural slurs like, you know, "So you are brown ... Well, how come?" We tell them we come from a different country and things like that but you know you can't touch them or anything like that. Now, ... they know I'm from Fiji. Then they start asking, "Oh, I love spicy food." They start asking you about recipes. ... so it's a ... very big difference from 1983 to 1993 to 2003 ... they accept us more now in the house. They love us now. Some of them love us because they say, "Oh, you're the best workers." So, you know, you get so much compliment. (Yvonne, 46-year-old woman from Fiji, employed 21 years as a HSW)

There is a transition described by this HSW, from being treated negatively because of her ethnicity (So you are brown ... How come?), to receiving compliments reflective of perceptions of her ethnicity as well (Oh, you're the best workers). In both circumstances, the worker's ethnicity plays a role in how she is viewed by her clients, although the overall tenor of client comments changes over time.

\section{Discussion and Implications}

We have examined how the delivery and receipt of home support services, which occur at the intersection of the private sphere of a client's home and the public sphere of a paid carer's employment, is framed by ethnocultural diversity. We began by enquiring as to the issues that pertain to the foreign-born and visible minority status of migrant HSWs, and found that these issues are more complex and varied than we had expected. 
There is very little literature on this topic, and extant literature primarily focuses on immigrant women of colour employed in the non-professional end of home care.

Our data, gathered amongst immigrants employed by home care agencies in one province of Canada, reveal that many contexts and complexities exist. There were similarities as well as differences between Canadian and foreign-born workers, and few significant differences between workers with different countries of origin. Where differences are observed, foreign-born workers are by no means systematically worse off, or disadvantaged. Indeed, migrant workers are frequently better educated (and sometimes even better paid) than Canadian-born workers.

Issues of hostility due to ethno-cultural "differences" are, somewhat surprisingly, experienced by both Canadian-born and foreign-born workers, and are not restricted to workers from visible minorities. For example, Caucasian HSWs are not always wanted by clients who themselves have a strong ethno-cultural identification. These interactions highlight the "rapid ethnic diversification" that is occurring within Canada's growing elderly population (Koehn 2009: 586). Furthermore, such examples of hostility experienced by Caucasian workers providing home support to older people from ethnic minority groups, contribute to a growing body of evidence countering the assumption that ethnic minority group members take care of their own elders (Koehn 2009). Indeed, as the number of older adults from visible minorities increases, so too will the number of these adults requiring home care services. It is important to appreciate that through this shift in the ethno-cultural diversity of Canadian society, an increasing number of complex ethno-cultural issues will arise in the care of elderly persons. These may include differences experienced between Caucasian workers and ethnic minority clients, as illustrated earlier, as well as differences between workers and clients from differing ethnic minorities.

Overall, our analysis of the verbatim accounts by workers suggests a particular pattern of hostility experienced by workers from the Philippines, Asia, and Africa. It is sometimes very direct, but all too often it is more subtle and insidious. Our transcripts capture worker perceptions of an undertone of deeply held and at times highly racialized beliefs among some clients, reflecting more than a language barrier or a 
International Journal of Ageing and Later Life

disagreement about food preparation. As experienced by these HSWs, such deeply held beliefs frequently presume the dominance of one culture (or cultures) over another.

While our article has focused on the $43 \%$ of HSWs who reported having to deal with hostility from clients (or relatives and friends of clients) due to issues of ethno-cultural diversity, it is important to note that the majority of workers did not identify any such instances. Among the workers who did experience hostility, a variety of strategies for coping with instances of racism and discrimination were identified, ranging from the use of laughter, to phoning the agency or ignoring the situation altogether. Indeed, many workers referred to the opportunity to be in the homes of "real Canadians" as a benefit and bonus of their job, having an inside look at the dominant culture and learning from that experience.

Although less than half of the workers in our study reported having to deal with hostility, we must also be cognizant of those who did experience hostility but chose not to "name it" or report it. In other research on this data set, workers spoke of "not wanting to rock the boat" or appear as complainers by filling out incident reports or bringing concerns to their supervisor (Sims-Gould \& Martin-Matthews 2010). With respect to racialized hostility, evidence from our interviews suggests that it is likely underreported and potentially even "under-identified" by our respondents.

While the focus of this article has been on the 118 HSWs in our study in British Columbia, the immigrant profile of these workers stands in stark contrast to the profile that emerged in two other pilot studies conducted as part of our larger study, one in small town and rural Ontario, and the other in both urban and rural areas of Nova Scotia. In Ontario, $89 \%$ of the workers interviewed were Canadian born, with $7 \%$ of the others being from Europe, and in Nova Scotia, 95\% of the workers were Canadian-born. Thus, our findings cannot be generalized outside our specific study population in British Columbia. In the absence of a national registry of HSWs, we cannot know how the profile of the workers whom we studied compares with the larger Canadian context of workers in this sector. Even Canadian census data, with their range of occupational classifications, are ill-equipped to enable such comparisons, given the range of job titles and skill qualifications that characterize home support work in Canada. 
Other contextual issues frame the interpretation of our findings as well. Our original study was not designed to specifically address ethno-cultural issues in the provision of home support; rather, this emerged as a dominant theme throughout the data collection and analysis process. As such, the decision to employ the Brayfield-Rothe Satisfaction Index did not take language and comprehension issues into consideration. Future approaches to the assessment of job satisfaction amongst immigrant care workers should take into account language and perceptions of workrelated measures and constructs (Riordan \& Vandenberg 1994; Saari \& Judge 2004).

It is also important to note the issue of legal versus illegal migrant care workers. Doyle and Timonen's research in Ireland found that discrimination experienced by immigrant care workers was rooted in the informal nature of their work contracts and "their illegal or conditional residency status, which put them in a relationship of dependency with their employers" (2009: 347). However, these were not characteristics of the working conditions of the participants in our study in Canada (we spoke to legal migrants and all unionized workers).

In the interpretation of our findings, it is also important not to confuse Canadian-born and foreign-born status with visible minority status. In the cultural mosaic that is Canada, some of the immigrant workers were Caucasian; similarly, while $73 \%$ of the Canadian-born workers we interviewed identified themselves as being only Caucasian, $22 \%$ had some Aboriginal/First Nations heritage, one was Indo-Canadian and one was Chinese-Canadian.

\section{Summary and Conclusions}

This article has examined issues of ethno-cultural diversity in the characteristics of workers, and in the interaction of HSWs and their elderly clients, from the perspective of 118 HSWs in British Columbia, Canada. There are many issues similar to foreign-born and Canadian-born workers, but our findings show that, even when analysis is restricted to legal, unionized migrant care workers, there are indeed differences between the foreign-born and Canadian-born labor force employed in home care in one Canadian province. As have other Canadian studies, we 
International Journal of Ageing and Later Life

too found evidence, of the "deskilling" of immigrant labor, with many of the foreign-born workers having educational credentials well in excess of their Canadian-born counterparts, and indeed well beyond the basic requirements of their jobs.

Our article also examined the experiences of ethno-cultural hostility in the interaction between workers and clients. A substantial minority of workers, both Canadian and foreign-born, reported such incidents and described a complex range of (often) racially based experiences. However, in the Canadian context, it is overly simplistic to consider the experience of migrant labor in home care without considering the cultural diversity and the cultural mix of workers, clients, and family members together. Canadian-born workers, particularly those who are from visible minorities, experience discrimination from clients with different cultural backgrounds, be they immigrants or not.

In home care, workers encounter these experiences not in public view or in a typical "work" setting, but rather, when working alone in the private sphere of the home of the person who is treating them with hostility (Martin-Matthews 2007). Thus, we were particularly interested in the strategies employed by workers in response to these events. The more experienced workers had developed ways of dealing with such hostility from clients, although their strategies were more likely to involve individual management of the situation ("laughing it off," "ignoring it") than invoking agency policies or employer guidelines (calling the supervisor). Fear of recrimination or loss of employment frequently framed their responses and reactions.

How do agencies deal with these issues in their training of, and support to, workers? Our study did not examine how agency policies relate to ethno-cultural diversity in British Columbia, although evidence from elsewhere in Canada suggests that immigrant women of colour are less likely than Canadian-born workers to find home care jobs in the public sector, and thereby more likely to experience poorer working conditions, significantly lower pay, limited job security, and less supervision (Cognet \& Fortin 2003; Meintel et al. 2006). Our findings suggest the need to examine agency policies and hiring procedures in relation to ethnocultural diversity, and certainly they indicate a need for anti-racism training as part of the curriculum for new HSWs in Canada. However, it 
is worth noting that a majority of workers did not report such experiences. Even amongst those who did, there was some evidence of change and more tolerance over time, as more immigrants from visible minorities in Canada settle throughout the country and the society as a whole becomes more ethno-culturally diverse.

There are wider policy implications to these findings as well. Doyle and Timonen $(2009,2010)$ suggest the need to consider together policies of migration, labor market and long-term care, as migrant care workers "will continue to be of increasing relevance." Our findings similarly suggest that many migrant care workers confront unique obstacles and barriers that impact negatively upon their work. To facilitate their care work, policy, and practical interventions are required in order to address discrimination and provide support to this vital component of the care labor force of many countries worldwide.

\section{Acknowledgements}

Funding for the research on which this article is based was provided to the project "Home Care in Canada: Working at the Nexus of the Public and Private Spheres" (A. Martin-Matthews, PI), by the Canadian Institutes of Health Research (Grant No. IOP-70684). The authors acknowledge the contributions of Kerry Byrne, Krista Frazee, Catherine Craven, and Patrick Burnett in the analyses of these data.

\section{Corresponding Author}

Anne Martin-Matthews, Department of Sociology, The University of British Columbia, Vancouver, BC V6T 1Z1, Canada. Email: amm@ interchange.ubc.ca

\section{References}

Agho, A. O., Mueller, C. W. \& Price, J. L. (1993). Determinants of employee job satisfaction: An empirical test of a causal model. Human Relations 46(8): 1007-1027. 
International Journal of Ageing and Later Life

Agho, A. O., Price, J. L. \& Mueller, C. W. (1992). Discriminant validity of measures of job satisfaction, positive affectivity and negative affectivity. Journal of Occupational \& Organizational Psychology 65(3): 185-196.

Aronson, J. \& Neysmith, S. M. (1996). 'You're not just in there to do the work': Depersonalizing policies and the exploitation of home. Gender $\mathcal{E}$ Society 10(1): 59-77.

Ayalon, L. (2008). Evaluating the working conditions and exposure to abuse among Filipino home are workers in Israel: Characteristics and clinical correlates. International Psychogeriatrics 21(1): 40-49.

Ayalon, L. (2009). Family and family-like interactions in households with round-the-clock paid foreign carers in Israel. Ageing and Society 29(5): 671-686.

Babin, B. J. \& Boles, J. S. (1998). Employee behavior in a service environment: A model and test of potential differences between men and women. The Journal of Marketing 62(2): 77-91.

Brayfield, A. H. \& Rothe, H. F. (1951). An index of job satisfaction. Journal of Applied Psychology 35(5): 307-311.

Chappell, N., Gee, E., McDonald, L. \& Stones, M. (2003). Aging in Contemporary Canada. Toronto: Prentice Hall.

Cognet, M. \& Fortin, S. (2003). Le poids du genre et de l'ehnicité dans la division du travail en santé. Liens social et politiques 49: 155-172.

Curry, J. P., Wakefield, D. S., Price, J. L. \& Mueller, C. W. (1986). On the causal ordering of job satisfaction and organizational commitment. Academy of Management Journal 29(4): 847-858.

Doyle, M. \& Timonen, V. (2009). The different faces of care work: Understanding the experiences of the multi-cultural care workforce. Ageing \& Society 29: 337-350.

Doyle, M. \& Timonen, V. (2010). Obligations, ambitions, calculations: Migrant care workers' negotiation of work, career, and family responsibilities. Social Politics: International Studies in Gender, State $\mathcal{E}$ Society, 1-24. Advance online publication. doi: 10.1093/sp/jxp026

Durst, D. (2008). More snow on the roof: Canada's immigrant seniors. The Bridge, 2. Available on http://canada.metropolis.net/pdfs/durst_e.pdf (Accessed: November 15, 2010).

Koehn, S. (2009). Negotiating candidacy: Ethnic minority seniors' access to care. Ageing \& Society 29(4): 585-608. 
Martin-Matthews, A. (2007). Situating 'home' at the nexus of the public and the private spheres: Ageing, gender and home support work in Canada. Current Sociology 55(2): 229-249.

Martin-Matthews, A. \& Sims-Gould, J. (2008). Employers, home support workers and elderly clients: Identifying key issues in delivery and receipt of home support. Healthcare Quarterly 11(4): 69-75.

Meintel, D., Fortin, S. \& Cognet, M. (2006). On the road and on their own: Autonomy and giving in home health care in Quebec. Gender, Place $\mathcal{E}$ Culture: A Journal of Feminist Geography 13(5): 563-580.

Misra, J., Woodring, J. \& Merz, S. (2006). The globalization of care work: Neoliberal economic restructuring and migration policy. Globalizations 3(3): 317-332.

Neysmith, S. M. \& Aronson, J. (1997). Working conditions in home care: Negotiating race and class boundaries in gendered work. International Journal of Health Services 27(3): 479-499.

Okolo, B. N. (1990). Health Research Design and Methodolgy. Boca Raton, FL: CRC Press.

Phillips, J. E. (2007). Care. Cambridge, UK: Polity Press.

Riordan, C. M. \& Vandenberg, R. J. (1994). A central question in cross-cultural research: Do employees of different cultures interpret work-related measures in an equivalent manner? Journal of Management 20: 643-667.

Saari, L. M. \& Judge, T. (2004). Employee attitudes and job satisfaction. Human Resource Management 43(4): 395-407.

Shafer, W. E. (2002). Ethical pressure, organizational-professional conflict, and related work outcomes among management accountants. Journal of Business Ethics 8: 263-275.

Sims-Gould, J. \& Martin-Matthews, A. (2010). Strategies used by home support workers in the delivery of care to elderly clients. Canadian Journal on Aging 29(1): 97-107.

Stacey, C. L. (2005). Finding dignity in dirty work: The constraints and rewards of low-wage home care labour. Sociology of Health $\mathcal{E}$ Illness 27(6): 831-854.

Statistics Canada. (1996). Census of Canada 1996: Dimension series. Available on http://toby.library.ubc.ca/resources/infopage.cfm?id=916 (Accessed: September 23, 2009). 
International Journal of Ageing and Later Life

Statistics Canada. (2006). Census of Canada 2006: Special interest profiles. Available on http://toby.library.ubc.ca/resources/infopage.cfm?id= 1582 (Accessed: September 23, 2009).

Statistics Canada \& Employment Equity Data Program. (1990). Profile of Visible Minorities and Aboriginal Peoples: 1986 Census, 20\% Sample Data. Ottawa: Statistics Canada.

Stemler, S. (2001). An overview of content analysis. Practical Assessment, Research \& Evaluation 7(17). Available on http://PAREonline.net/ getvn.asp? $\mathrm{v}=7 \& \mathrm{n}+17$ (Accessed: April 28, 2010).

Stone, R. I. \& Dawson, S. L. (2008). The origins of better jobs better care. The Gerontologist 48(1): 5-13.

Timonen, V. \& Doyle, M. (2010). Migrant care workers' relationships with care recipients, colleagues and employers. European Journal of Women's Studies 17(1): 25-41.

Zaman, H., Cecilia, D. \& Scott, R. (2007). Workplace Rights for Immigrants in BC: The Case of Filipino Workers. Vancouver, BC: Canadian Centre for Policy Alternatives.

\section{Appendix A}

11-Item Job Satisfaction Subscale

1. I consider my job rather unpleasant

2. I am often bored with my job

3. I feel fairly well satisfied with my present job

4. Most of the time I have to force myself to work

5. I definitely dislike my work

6. I feel I am happier in my work than most people are in their work

7. Most days I am enthusiastic about my work 
Ethno-cultural diversity in home care work in Canada

8. I like my job better than the average worker does

9. My job is pretty uninteresting

10. I find real enjoyment in my work

11. I am disappointed I ever took this job 



\title{
Lonely older people as a problem in society - construction in Finnish media
}

\author{
By Hanna Uotilat, ${ }^{1,2}$ Kirsi Lumme-SAndt ${ }^{1}$ \& Marja \\ SAARENHEIMO ${ }^{3}$
}

\begin{abstract}
Loneliness is a prevalent stereotype of old age but there is a lack of studies of how it is represented in mass media. This study examines how the loneliness of older people is portrayed in mass media. The research material consists of 154 texts from the leading $50+$ magazines and daily newspapers in Finland. In the texts, loneliness was rarely seen solely as a lack of companionship and many negative attributes were connected to it. Among other things, loneliness was connected to the low status of older people in society, inhumane practices in elderly care, lack of meaning in life and neglect by relatives. Loneliness was also viewed as an inevitable part of ageing. However, many suggestions were made to alleviate loneliness. The extent of these suggestions varied from broad and collective actions to simple and perfunctory solutions.
\end{abstract}

Keywords: loneliness, older people, qualitative study, mass media.

\footnotetext{
${ }^{1}$ Hanna Uotila and Kirsi Lumme-Sandt, Tampere School of Public Health, University of Tampere, Finland

${ }^{2}$ Hanna Uotila, The Science Center of Pirkanmaa Hospital District, Tampere, Finland

${ }^{3}$ Marja Saarenheimo, The Central Union for the Welfare of the Aged, Helsinki, Finland
} 
International Journal of Ageing and Later Life

\section{Introduction}

The concept of loneliness has been interpreted and defined in various ways. In most studies, loneliness is understood as a negative feeling or an unpleasant and distressing experience of a lack of social contacts (Peplau \& Perlman 1982). Victor et al. (2005) emphasised a discrepancy between the actual and desired quality and quantity of social engagement. Two dimensions of loneliness have been postulated. Weiss (1973) distinguished between emotional and social loneliness. Emotional loneliness arises in situations where a reliable or intimate relationship is lacking, and social loneliness is caused by absence of social networks.

Scientific texts often define social isolation and loneliness as distinct but interrelated concepts. Social isolation refers to an objective, measurable state of having minimal contact with other people while the experience of loneliness refers to a subjective state that is recognisable only by the person in question (Jylhä \& Saarenheimo 2010; Victor et al. 2000, 2005). A person may suffer from loneliness even when surrounded by other people.

Loneliness has different meanings for different people and in different contexts. It has been seen as a highly subjective experience. In everyday talk, loneliness has several related meanings that are partly overlapping. Loneliness can be addressed by using different words. By talking about the time spent alone one can refer to feelings of loneliness, but not always and not necessarily. Being or living alone can also indicate a specific type of the household arrangement (Victor et al. 2000). Living alone can also be constructed as a neutral aloneness or a positive solitude (Pierce et al. 2003). However, there are no separate concepts for negative and positive loneliness in Finnish.

Traditionally, a particularly strong relationship has been postulated between loneliness and old age. In everyday talk and media, and also in academic studies, loneliness is frequently constructed as a common and intensive feeling in old age, and its prevalence has even been dramatised (Wenger \& Burholt 2004). However, surveys have reported that the majority (two-thirds) of older people do not suffer from loneliness (Savikko et al. 2005; Steed et al. 2007; Victor et al. 2005). It seems that there is a discrepancy between the public understanding and academic surveys about the frequency of loneliness in old age. The discrepancy may arise from common conceptions of loneliness as a harmful, painful and 
thoroughly negative feeling. According to the surveys, only one-third of older people feel lonely, but the prevalence of feelings of loneliness increases with age. This is not explained by age itself, but rather by changes and losses in health, functional capacity and social networks (Jylhä 2004; Savikko et al. 2005; Victor et al. 2005).

Public images of old age and loneliness of older people are partly constructed by mass media. Traditionally, public images of old age have been twofold. Old age has either been considered a time of frailty and loss or a time of wisdom and experience. Apart from these, a third view has appeared; one that represents agelessness and incessant activity as attributes of successful ageing. Despite the current focus on the active third age (Laslett 1989; Weiss \& Bass 2002), negative stereotypes of old age still exist. Media studies have shown that these also appear in mass media (Ellis \& Morrison 2005). Especially before the mid-1980s, foolish, senile, bitter or feeble minded characters represented old age in the media (Williams et al. 2010). At the same time there was generally an underrepresentation of older people in the media (Bazzini et al. 1997; Zhang et al. 2006). This solely negative portrayal and the under-representation of older people seem to be changing. Predominantly negative images have over the last decades been modified in different types of media by a tendency that Vincent (2003), among others, calls "the liberation of old age" and replaced by more positive images (Miller et al. 1999, 2004; Roy \& Harwood 1997; Williams et al. 2007, 2010; Zhang et al. 2006). Older people are now more likely to be represented as actors and in roles which break the former stereotypes of older people. Today, older people, particularly the third agers, also tend to appear more often in media. Magazines for active and healthy older people have emerged. Those magazines foster a positive self-image and a healthier and more positive lifestyle for older people (Lumme-Sandt 2010; Williams et al. 2007).

In recent years, research on media representations of older people has increased. Several studies have focused on media portrayals of ageing, especially in the USA (Zhang et al. 2006). However, the stereotype of lonely old age has not been studied in the context of mass media. Stereotypes of old age have an impact on how ageing is understood and what is possible and appropriate in later life. They also affect the way old people are treated in society and how elderly people see themselves 
International Journal of Ageing and Later Life

(Bazzini et al. 1997; Horton et al. 2007). Overly positive portrayals of later life as a care-free zone are as unrealistic as the portrayals of later life as a zone of decline and sickness. Therefore, more research is needed in this specific area.

In this study we approach loneliness pragmatically, based not on academic definition but on "everyday definitions" appearing in our data. We explore whether and how loneliness of older people is portrayed in the leading $50+$ magazines and daily newspapers in Finland. The purpose of our analysis is to identify how loneliness is formulated and defined in media. The general aim of this study is to explore how loneliness of older people is constructed in public talk: what is written about loneliness and what positions do the writers adopt.

\section{Material and Method}

The data for the study were drawn from a widely read magazine and the largest daily newspaper in Finland. ET magazine (ET) was chosen because it is the most popular general-interest magazine for people over 50 years of age in Finland. Originally aimed for retired people, the readership of ET now includes people over 50. ET focuses on the third age (Lumme-Sandt 2010). It offers human interest articles and features on well-being, travel, food, fashion and hobbies (Sanoma Magazines Finland 2009; Toppila 2009). Helsingin Sanomat (HS) was chosen because it is the leading national newspaper in Finland. HS has a significant role in shaping the public opinion in Finland. It reaches 22\% of Finns (Medianetti 2009) (see Table 1). Together these two very different representatives of print media give a fairly comprehensive view of how old age loneliness is represented in Finnish print media.

Table 1. Readers of the ET and the HS in 2007 (\%)

\begin{tabular}{lcc}
\hline & ET & HS \\
\hline Readers: age $50+$ & 80 & 49 \\
Readers: women & 74 & 48 \\
Reach of Finns: age $50+$ & 33 & 24 \\
\hline
\end{tabular}

Source: Finnish Audit Bureau of Circulations (2009). 
The data comprise all editions of ET and HS in 5 years (years 2003-2007). The composition of the data set and the basic steps of analysis are shown in Figure 1. Two criteria were set down for inclusion of a given text in the data set: the text must deal with loneliness and

Figure 1. Data composition and data analysis.

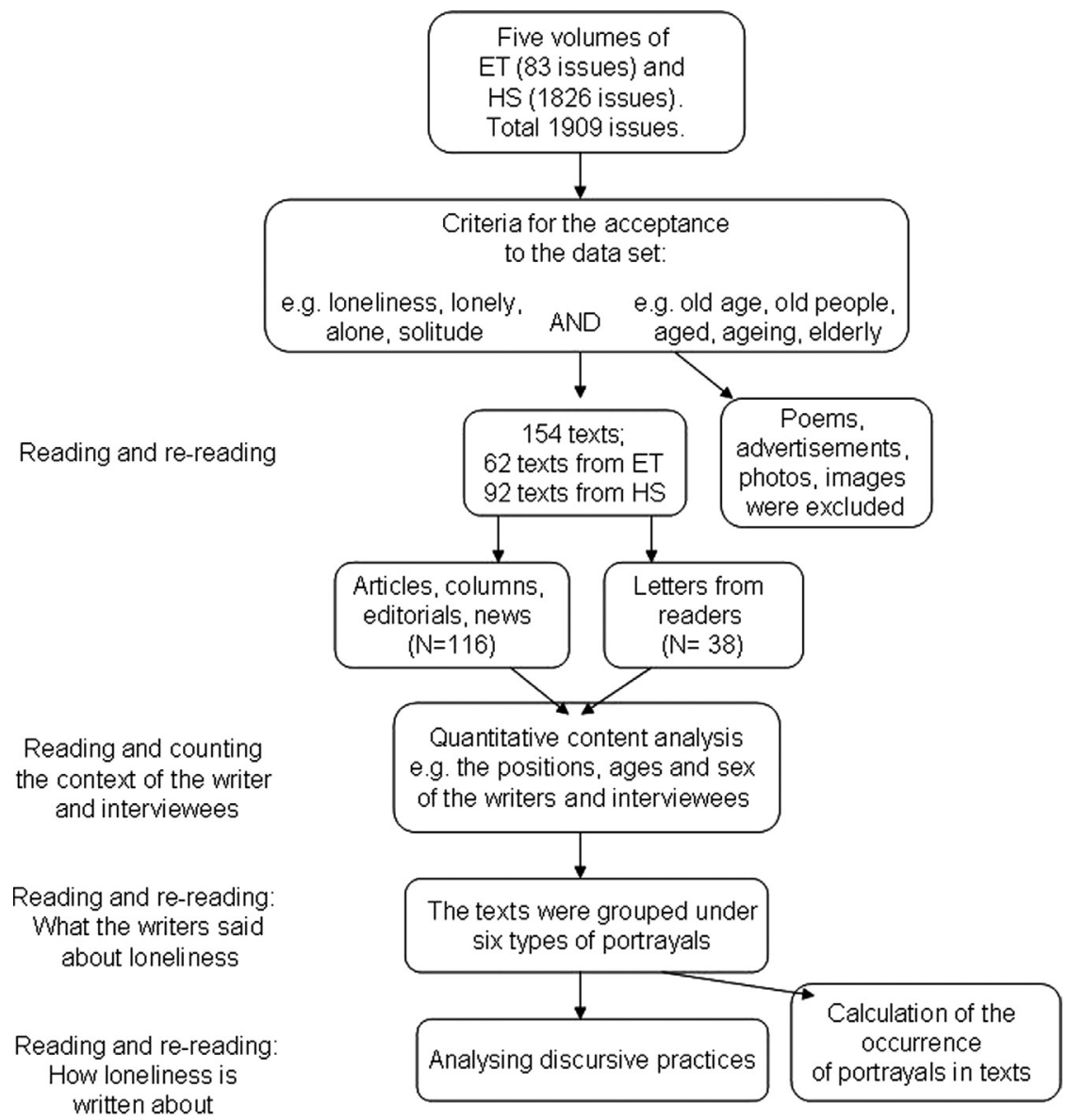


International Journal of Ageing and Later Life

ageing. Loneliness and other related words were used as a starting point for the collection of data. The five volumes of the printed editions of ET were read and the texts that dealt with loneliness and older people or old age were identified. Because of the large number of issues of HS, the texts were searched through the online archives. Different combinations of key words in Finnish were used, including loneliness, lonely, alone, old age, older people and ageing. All texts were read in order to determine whether they actually dealt with loneliness and ageing. Two text types were excluded from the data: poems because of their ambiguousness and advertisements because they serve economic purposes. Also photos and images were excluded from the data because the pictures and photos in HS were not available on the online archives. The final data set consists of 154 texts, 62 from ET and 92 from HS. There were considerable differences between the texts. They were written from different positions and had different intentions. There were articles, news, editorials and columns written by journalists (116) as well as letters written by readers (38) (see Figure 1).

First, we classified the contexts of the writers and interviewees. The data were heterogeneous. The writers included both women and men, although women were slightly more likely to write than men. The writers and interviewees represented a wide variety of social and occupational groups, and thus occupied different positions, although a position cannot be defined simply by occupation or social group. The writers included leaders of non-governmental organisations, medical doctors, journalists, researchers, singers, novelists, voluntary and church workers, and relatives of older people and old people themselves. More than half of the writers or interviewees, who have mentioned their occupation, came from the field of culture and caring/medicine or were leaders of various organisations (see Table 2). The explicit motives for the accounts varied. Some writers emphasised their occupational position, whereas others were speaking as citizens or as interested parties such as relatives or older persons. Loneliness was approached both from academic and lay perspectives. However, these different discourses were often intermingled even in texts written by professionals such as leaders of non-governmental organisations, medical doctors and researchers. Loneliness seems to be a diverse phenomenon, which is rarely addressed from only one position. Even 
Table 2. Amount of writers and main interviewees in the texts by separate occupational groups $(N=161)$

Leaders of non-governmental organisations

Field of culture

$\begin{array}{lr}\text { Field of caring and medicine } & 23\end{array}$

Researchers $\quad 18$

$\begin{array}{lr}\text { Church workers } & 16\end{array}$

$\begin{array}{lr}\text { Journalists } & 16\end{array}$

Politician 3

$\begin{array}{lr}\text { Others (e.g. retiree, student, other occupation) } & 15\end{array}$

Not mentioned $\quad 22$

professionals use their own personal experiences and emotions when dealing with the issue.

Second, we searched for the different portrayals of old age loneliness in the texts. This was done by analysing what the writers said about the causes, meanings, consequences and correlates of loneliness in old age. The analysis thus served the identification of different everyday conceptions and theories, and explanations given to loneliness. In accordance with a discourse analytic perspective (Wetherell et al. 2001; Wood \& Kroger 2000), the analysis was not based on any specific definition of loneliness or any social gerontological theory. Applying definitions or theories at this stage would have narrowed the scope of the analysis, since our aim was exploratory rather than definition-based. The discourse analytic approach means that the analysis is based on the data, and the meanings given to loneliness by ordinary people themselves are studied in their social and cultural contexts. Writers' accounts are highly contextspecific. The accounts construct different versions of the social world and serve different functions. Variability exists between persons and even within persons/texts. The texts use formulations available in current society, and therefore isolated accounts cannot be analysed outside the cultural and societal context in which they are produced (Edley 2001; Taylor 2001; Wood \& Kroger 2000). Following the more thorough analysis, the texts were grouped under six types of portrayals of old age loneliness. The occurrence of the portrayals in different text types was counted and this information was studied in the context of the writers' positions. It was 
International Journal of Ageing and Later Life

thus possible to identify relations and differences between the writer's position and the manner and content of writing (Table 3).

Finally, we performed a detailed analysis of the discourses used in writing about loneliness, and the positions taken by the writers and given to older people. Here, the concept of subject position was used and it was defined as a location within a context. Within a single text, different discourses can be used, different positions adopted and different audiences addressed (Edley 2001; Wood \& Kroger 2000). The concept of discourse is used here in a broad sense, referring to the ways of thinking and writing about loneliness in different everyday encounters, and also as ways of organising society and positions of individual people within society, which then have consequences for people's lives (Miller 2008; Wetherell \& Edley 1999). In this study, a pragmatic perspective is adopted, where language is seen as a vehicle in performing a variety of social acts. Discourse analysis offers tools for exploring different and sometimes conflicting meanings attached to loneliness of older people (Edley 2001; Taylor 2001). Attention was also paid to the different nuances of language, choice of words, writing styles and metaphors. Since the focus of the study was on old age loneliness in print media, the analysis concentrated on how the loneliness of older people was constructed in the texts, on the

Table 3. Portrayals of old age loneliness (\%)

\begin{tabular}{lccccc}
\hline & $\begin{array}{c}\text { Articles } \\
N=144\end{array}$ & $\begin{array}{c}\text { News } \\
N=34\end{array}$ & $\begin{array}{c}\text { Editorials } \\
N=43\end{array}$ & $\begin{array}{c}\text { Columns } \\
N=35\end{array}$ & $\begin{array}{r}\text { Letters } \\
N=75\end{array}$ \\
\hline $\begin{array}{l}\text { Lack of human } \\
\text { relationships }\end{array}$ & 42 & 41 & 32 & 26 & 29 \\
$\begin{array}{l}\text { Forgotten by } \\
\text { society }\end{array}$ & 22 & 35 & 49 & 40 & 38 \\
$\begin{array}{l}\text { Lack of meaning } \\
\text { in life }\end{array}$ & 21 & 24 & 12 & 23 & 16 \\
$\begin{array}{l}\text { Neglect of older } \\
\text { people by relatives }\end{array}$ & 6 & 0 & 0 & 8 & 9 \\
$\begin{array}{l}\text { Inevitable part of } \\
\text { old age }\end{array}$ & 3 & 0 & 5 & 3 & 4 \\
$\begin{array}{l}\text { Positive loneliness } \\
\text { Old }\end{array}$ & 6 & 0 & 2 & 0 & 4 \\
& 100 & 100 & 100 & 100 & 100 \\
\hline
\end{tabular}


intentions and expected consequences of the texts, and on the meanings attached to loneliness.

\section{What Do People Say When They Write About Loneliness?}

Six different portrayals of old age loneliness were identified in the data set (see Table 3). Even if the writers wrote from different positions and had different motives for writing, nearly all portrayals appear in every text type. There are no major differences between text types, except in the last three portrayals (Table 3). Lack of human relationship appeared most often in the texts; a little more often in articles and news than in other text types. Forgotten by society is mentioned more often in editorials, columns and letters than in other text types. It seems that writing about one's own thoughts and opinions invites to write about loneliness from this point of view. These two portrayals are most general in all text types. Lack of meaning in life appeared fairly often in all text types. Neglect of older people by relatives, positive loneliness and inevitable part of old age are very rarely present in the data and there are text types where these portrayals were entirely absent.

As can be seen in Table 3, it is not relevant to argue that loneliness is constructed differently in different text types. There are some differences in the emphasis between text types. However, a single text can characterise loneliness in different or even opposite ways. The next extract is a good example of this phenomenon. It shows how a single writer can write about loneliness employing several different portrayals. The text is an extract from a letter written by a reader.

... What would you think if nobody had time to come and visit you anymore? How would you feel if your children had the time to take a two-week vacation in Spain and a weeklong skiing vacation in Lapland, but not for Mothers' Day, for just a very short visit to you, bringing along one more set of bed sheets or a tablecloth to put to the chest of drawers? And you weren't even able to change the sheets, and your lamp was broken last autumn, and nobody has replaced it. ... Oh sure, the granny will thank them for the visit and the presents with tears in her eyes, but really what she is crying over is her loneliness before the visit, and thinking about what lies ahead. It is my opinion that longing and loneliness lead to premature dementia. There is too much time to dwell upon your thoughts and nobody to break the chain of sad memories, and we all have those. It is human contact that keeps you abreast of things. (12/2005 ET) 
International Journal of Ageing and Later Life

Here, the writer identifies loneliness of older people mostly with a lack of human relationships and neglect by relatives. She also writes about a lack of meaning in life and being forgotten by society since nobody takes care of older people. Of the six portrayals identified above, only loneliness as a positive experience and inevitable part of old age are not present in this text. A detailed analysis of this extract is presented later in this article.

\section{Lack of Human Relationships}

Previous studies have often defined loneliness as a deficiency in social relationships and lack of contact with others (de Jong Gierveld 1987; Wenger \& Burholt 2004). At its simplest, being lonely is synonymous with a yearning for company and suffering as a result of being alone. However, our data show that in public talk loneliness is connected to a variety of psychological, social and cultural phenomena. The next extract, which is an excerpt from an editorial written by a journalist, presents a typical example of the traditional construction of loneliness.

... The saddest and unfortunately also the most frequent case of social silence is a lonely old man or woman who has absolutely nobody to talk to. Especially now that the popular TV news anchorman Arvi has retired. When you do not talk, your words, thoughts, and emotions start to wither away. Eventually you yourself will wither away too. (24.12.2004 HS)

The lack of human relationships is here presented as a typical tragedy for an older person; there is absolutely nobody to talk to. "A lonely oldie" is actually being constructed as a social category, which is here used as a tool for political argumentation and as a sign of collective or societal "disease". The climax of loneliness is the loss of contact with a TV personality. The lack of company is here constructed as the main reason for loneliness. Generally, however, while this reasoning is often present in the texts and in all text types, loneliness is rarely viewed purely as a lack of company. Friends and companions do not necessarily alleviate loneliness as the next excerpt attempts to show.

... When outdoors, $\mathrm{R}$ even talks to strangers. She does have friends but still - during the quiet moments, loneliness oppresses her.... "Last winter, I started feeling 
depressed and lonely. Especially in the evenings when I sat here and stared at the darkness. No one called or came to visit. I felt worthless." (1.6.2003 HS)

In this excerpt, written by a journalist, the old woman is positioned as an active and spontaneous actor, yet she is lonely. There is a substantial discrepancy between the subjective experience of loneliness and the apparent behaviour viewed by an outsider. The active efforts of the old woman actually underline the intensity of her inner loneliness, which is here described as a kind of depressive mood.

\section{Forgotten by Society}

Sometimes loneliness is associated with the low status of older people in society. Old people are represented as forgotten by society and the inhumanity of elderly care is emphasised. The next citation is an excerpt from a column written by the leader of an organisation working to alleviate loneliness.

\footnotetext{
... One word is enough for the lack of presence: Loneliness. Social exclusion and depression follow quickly. Older people - together with children - pay the most chilling price for the lack of presence in contemporary Finland. The aged are the group which has gotten the least attention in mental health work. ... Older people's biggest problems are loneliness, depression, and the increased suicide risk which follows. It might come as a surprise, but older people do commit suicide. In Finland, every other day, an older person decides to take his or her life. (4/2003 ET)
}

The writer emphasises the marginalisation of older people in society: they are invisible and forgotten by society. The writer has chosen a highly expressive style with drastic generalisations. He mentions many threats, such as alienation, depression and suicide. The same expressive style characterises all texts by this particular and very active writer. In two of his writings, he uses the word "battle" when referring to the efforts to alleviate loneliness (1/2005 ET; 16.11.2006 HS). The provocative style, together with the writer's position in society, may be effective if the intention is to agitate and arouse people or induce pity and guilt in readers. The writer represents an organisation that needs volunteers as well as financial support, and therefore provocation may be beneficial. On the other hand, a provocative style of writing is also welcomed by media. It can even be 
International Journal of Ageing and Later Life

called a standard that writers intensify, dramatise and simplify their messages in order to get more attention. However, dramatic expressions may increase anxiety in older people as well as in their relatives.

\section{Lack of Meaning in Life}

The absence of significant relationships is brought up in many texts in the same ways as in scientific texts (Pinquart \& Sörensen 2001; Routasalo et al. 2006; Victor et al. 2000). In the data the death of a spouse or the children living far away is assumed to cause longing and a feeling that there is "nobody to care for" (10/2006 ET). The days and weeks of an old person are characterised as waiting, getting bored and being dependent on other people. The lack of meaningful activities and significant relationships is often portrayed through metaphors. Older people are described as "the flies in the bottle" (29.3.2004 HS) or "prisoners in their homes" (8.5.2006 HS). The portrayals of declining resources and diminishing physical capacity are reflected in the metaphors. The next citation is an extract from an interview with a 76-year-old woman. The central issue here is the closing of the day hospital.

... GN, a 76-year-old woman who lives in Kallio, is in the day hospital Sofia for the third time. "I came here for the first time a couple of years ago." She is worried about losing the only way she can relax. "Because walking is difficult for me, I cannot go out. And because my friends are old too, I'm often alone. If it wasn't for this, I would be at home staring at the wall." (26.8.2003 HS)

The woman finds meaningful activity and social contacts at the day hospital. Especially in the HS, there are plenty of articles about activities organised by different service providers. The comments of older people about the clubs, meetings and discussion groups are positive without exception. These activities provide escape from everyday routine and also alleviate loneliness. Although older persons are interviewed in some texts, the activities are often described from the viewpoint of organisers or outsiders. It seems that from their perspective any relationship is good enough for an older person and that "professional friends" could suffice as the source of meaning in life (3.12.2003 HS). 


\section{Neglect by Relatives}

In the context of loneliness, the role of relatives appears contradictory. Both empathic and critical tones are present when dealing with this issue. The question of moral responsibility positions the relatives either as neglectful or exhausted by their many responsibilities and thus unable to care for their older family members. The relationship between children and aged parents is often a concern in the scientific literature, but the results for loneliness are also contradictory (Drageset 2004; Zhang \& Hayward 2001; Zhang \& Liu 2007). Neglect of older people by relatives is fairly seldom addressed in the texts. The few texts with this portrayal - especially the letters of the readers - are generally very affective with tones of guilt built in them. Old people are described as abandoned and forgotten, waiting for their relatives in hospital beds or having professional home help as their only social contact. Old people themselves are positioned as passive objects, capable only of waiting.

The first citation of this article is from the letter of a reader, who uses the pseudonym mother-in-law still going strong. On the first six lines in that excerpt the writer suggests that the loneliness of older people is a result of the neglect by relatives. She complains that even if the children have no time to come and visit the older mother or father, they have still time for long vacations. They do not spend enough time with older family members, and thus are not aware of their life situation. The relatives bring material gifts which are not even needed by the old parent, but they are not available when older parents need help. This text equates loneliness with a feeling evoked by a lack of a caring person. The writer appeals to the reader's sense of sympathy for a lonely old person's situation in order to catch the meaning of loneliness. It is not evident whether the writer is telling about the experiences of someone close to her, but the details of the text suggest this. The details create an impression of authenticity, as if they alluded to a personal knowledge of the matter. On the other hand, the pseudonym used by the writer constructs otherness. While she may not consciously realise it, she highlights the difference between herself (still going strong) and the forgotten old protagonist of her text. Such a writing style is common in the texts. It seems that people want to avoid being categorised as lonely older people. 
International Journal of Ageing and Later Life

\section{Loneliness as an Inevitable Part of Old Age}

Some articles consider loneliness as a natural part of old age. The writers emphasise that "ageing makes you feel lonely" (8/2003 ET), and loneliness is "an inevitable part of ageing" (8/2005 ET). The next excerpt comes from an interview with a photographer, who has conducted a photography project with older people. She discusses whether it is better to live at home or in an institution when you are old.

... "All older people are lonely, it is a part of being old. But still, wouldn't it be better if there was a community around you?", she contemplates. (23.11.2003 HS)

In this excerpt, loneliness and old age are strongly connected. However, there is a certain paradox in the writings conveying this connection: loneliness is understood as inescapable, yet actions are demanded to alleviate loneliness. The writers do not represent a particular group - they may be journalists as well as older people themselves or people from volunteer organisations. From the moral perspective the paradox of loneliness may be somewhat relieving: it is possible to do something to alleviate loneliness, yet it is unimaginable that loneliness as such could be removed from old age.

\section{The Possibility of Positive Loneliness}

In the scientific articles, especially in surveys, loneliness is widely seen as a solely negative state. In contrast, our data set includes a few texts where loneliness is constructed as a positive state. All of these texts are written from a subjective viewpoint. Here, the older person is positioned as an active person, "a third ager" who has chosen to be alone. Positive loneliness was rarely described after the active phase of the third age. The next text is an excerpt from an interview with a novelist.

... Good loneliness. MK has enjoyed being alone for about ten years. It gives her the freedom to write. - Loneliness is a great pleasure, although many do not believe it. $(15 / 2007$ ET)

The text suggests that solitude, silence and privacy are necessary requirements for creative work. Furthermore, positive loneliness is not 
merely a prerequisite for writing or painting, but it also has other beneficial meanings. Expressions such as "blessed loneliness" (24.4.2004 HS) and "enjoying aloneness" are examples of these (6/2003 ET). In the excerpt, MK argues that many people do not believe in positive loneliness. Positive loneliness seems to be based on freedom and voluntariness. In previous studies, loneliness as a subjective experience has been constructed in several ways. As shown by a Finnish study, the meanings of loneliness in old age given by old people themselves, include independence, peace and privacy, and a conscious decision to be alone (Palkeinen 2005a), but also lack of meaningful activity, a sense of insecurity, feelings of being an outsider and longing (Palkeinen 2005b). In the Finnish language, there is only one word for loneliness, which describes both negative and positive aspects of loneliness.

\section{How Should Loneliness Be Dealt With?}

The analysis showed that alleviation of loneliness was a crucial theme when loneliness and old age were covered in the media. The writers and interviewees often treated loneliness as a problem that should be avoided. The newspaper included in the study, HS, had a great many texts about alleviating loneliness. Among the writers, there is a considerable agreement that something should be done to alleviate loneliness among older people. The reasons for this vary, as do the perspectives. Negative consequences for individuals are frequently mentioned: suffering, feelings of worthlessness, insecurity and health problems, difficulty recovering from illnesses and increased risk of suicide. These consequences of loneliness have also been reported by previous studies (see Cacioppo et al. 2002; Heikkinen \& Kauppinen 2004). In the data, from the perspective of society, loneliness is said to be related with health expenses, inhumanity of care and marginalisation of older people. Loneliness is thus constructed as a problem for society as well as for individuals, and thus solutions are needed. The tone of the writings varies from neutral to very affective.

... The theme of the recent Mental Health Week was Alone amidst Everything. The theme affects many of us; loneliness is not something to play with. Everyone who has really suffered from loneliness knows how big a risk it is. Loneliness induces feelings 
International Journal of Ageing and Later Life

of worthlessness, insecurity and exclusion. Being alone can be positive, if it is voluntary. But when there is no alternative, loneliness hurts and paralyses you. (3.12.2006 HS)

In this excerpt from an editorial, negative consequences of loneliness are listed. According to research, some further ill-effects include psychological distress: anxiety, depression and boredom (see Killeen 1998). The negative consequences and the frequency of loneliness are presented as common knowledge not to be questioned. Only very rarely did the writers refer to their own experiences. The position of an outsider seems to offer an opportunity to use strong expressions. However, there are also emotionally neutral texts, written from the position of an outsider, such as in the next excerpt from news.

... According to researchers, loneliness raises health expenses. According to KP, a medical doctor specialised in elderly care, those who are lonely are more likely than others to get illnesses such as depression and dementia. (1.6.2003 HS)

The writer refers to scientific studies and to a medical authority in order to make her argument more plausible. Loneliness is here addressed from the scientific viewpoint. The matter-of-fact style makes the account appear as if it came from a research report. The data contain many texts dealing with the connection between loneliness, health problems and abuse of alcohol, but health expenses are rarely mentioned. These are mentioned exclusively by researchers and health and social care professionals. It seems that bringing up the economic viewpoint is here used as an effective strategy to call the policymakers' attention to the issue of loneliness. However, the economic discourse may in fact divert readers from seeing loneliness as an individual experience.

Many writers suggest remedies for alleviating loneliness. The spectrum of the suggestions ranges from broad and collective responsibility to sporadic and perfunctory solutions. In the next excerpt, coming from a column, the suggestion involves all people collectively.

... It is not sad when people have lain dead in their apartments for who knows how long. What is sad is that an old person lives in total oblivion. It is the culmination of loneliness. Trying to find someone to blame is useless. The authorities cannot take all responsibility for taking care of them - not to mention remembering and caring. The 
working population, mummified by their everyday busyness, cannot be collectively obliged to work in voluntary senior care groups either. Still, something should be done. Saying hello to or having a few words with the older person next door could be a good start. (12.3.2006 HS)

In this excerpt, the solution lies in enhanced interaction between people in general. Nobody in particular is to blame or held responsible; rather, it is the general atmosphere or collective attitude that needs to be changed. Comparably to "saying hello to the old person next door", some writers suggest that people should try to "restore a culture, where people take care of their neighbours who live alone" (3.9.2003 HS) or claim that "every one of us has an opportunity to care for other people" (3.12.2003 HS). Some of the suggestions are fairly naïve or perfunctory, such as the suggestion that schoolchildren should regularly phone older people living in the neighbourhood (16/2007 ET). Pragmatic measures are also suggested, such as discounted travel on local transport, radio programmes aimed at older people or virtual services. These suggestions often seem to be written from the layman's point of view. In the next excerpt, the solution is a pet.

\footnotetext{
... A pet will relieve loneliness. Raili recommends everybody who complains of loneliness to get a pet. Maybe not a sheep, but a cat or a dog. Raili has both, more than one each. $(15 / 2005$ ET)
}

The person interviewed in this article has perceived the company of pets to relieve her loneliness, and she recommends these as a general strategy to anyone suffering from being alone. Here the responsibility is delegated to older persons themselves. Analogously, some writers suggest that older people find out places where they can meet other people (8/2007 ET) or take on a new hobby or a pen-friend or a friend from the internet (11.10.2004 HS). The idea behind these solutions seems to suggest that any kind of activity or company decreases loneliness.

In the majority of articles, the responsibility for alleviating loneliness is delegated to society and relatives. Paradoxically, however, the suggestions are rather abstract. Social interaction and activity are generally considered important for older people, and interested parties are expected to take action against loneliness, but otherwise, the demands remain rather 
International Journal of Ageing and Later Life

abstract. The next text is an exception: the writer, a medical practitioner, makes a concrete suggestion.

\begin{abstract}
... In taking care of lonely seniors, funding relevant research or opening cafés is not enough. The voters as well as decision-makers hopefully have enough common sense and compassion to recognise what is really needed, apart from research and statistics. What is needed is action, not talk. The money should be spent on hiring helping hands, perceptive eyes and listening ears. (8.5.2006 HS)
\end{abstract}

In this excerpt from a column, a strong argument is made. The writer calls for prioritisation in terms of money and more staff in elderly care. Current attempts to alleviate loneliness with research or meeting places are portrayed as useless and even naïve. Common sense should be applied instead of research. The provocative style is probably directed at decisionmakers, and the frustration with the benefits of research seems all the more persuasive coming from an academic. The writer is irritated and frustrated in the face of powerlessness to alleviate loneliness, but many even more distressing accounts are found in the data. One of these is a letter from a reader, relating to her own parents. The writer herself is not able to meet her parents' needs, and she is desperate about who should help. For her, as well as for many other writers, the ideal solution is communal living, where "older people keep each other company and no staff is needed" (26.3.2007 HS). None of the writers refers to the problems inherent in this type of arrangement, namely generational segregation. Besides, previous studies have shown that older people living in institutions or residential homes are more likely to suffer from loneliness than community-dwelling elders (Jylhä 2004; Savikko et al. 2005). The living arrangement suggested by the writers may be something more than simply living together in the same building.

The magazine and the newspaper in this study have very different profiles, but the writings about loneliness are fairly similar (cf. differences in previous studies; see Lumme-Sandt 2010; Rozanova 2006; Vakimo 2001; Williams et al. 2010). HS seemed to emphasise societal aspects more whereas ET emphasised emotional aspects. However with this data of different medias we were able to form a quite comprehensive view of the cultural understanding of loneliness in Finland. 
A study on loneliness of older people

\section{Discussion}

In the scientific literature, loneliness has been defined in several ways. It is often defined as a deficiency in a person's social relationships as well as a subjective feeling. Loneliness has also been described as an unpleasant and distressing condition (Peplau \& Perlman 1982). Even if those attributes are present in the data, loneliness is rarely seen solely from the perspective mentioned above. In our data, loneliness was charged with many other unpleasant and even dangerous things. The meaning of loneliness may differ from one individual to another because of the subjective and contextspecific nature of the concept (Killeen 1998). It appears that in our culture, loneliness as a negative concept is easily associated with various unpleasant and negative attributes. It may also have negative consequences, such as physical symptoms, depression and suicidal behaviour, which are talked about from both the scientific and the layman's points of view. In this study loneliness is represented as lack of human relationships, being forgotten by society, lack of meaning in life, neglect of older people by relatives, an inevitable part of old age and also positive loneliness, but also significance of alleviation of loneliness as well.

Even if the solely negative portrayal of older people seems to be changing in media, and people in the third age are portrayed in affirmative ways (Williams et al. 2007), older people in the fourth age are mostly constructed in a negative way (Bonnesen \& Burgess 2004; Rozanova 2006). The data presented here clearly show that there are two different conceptions/representations of old age at the moment. The first is the active and productive third age, which is characterised by pleasure, and the second is the weak and passive fourth age, constructed as suffering caused by disease and dependency on others (see Weiss \& Brass 2002). In this study, the loneliness of the third age is represented mostly as a temporary or even positive feeling, whereas loneliness in the fourth age seems to be very different: it has negative consequences and is difficult to avoid. It seems that negative stereotypes as well as the demands to alleviate loneliness are located in the fourth age. The fourth age - the "actual" old age - appears to include the attributes of loneliness and illnesses, and it would be absolutely impossible for the weak and sick old people to be socially active. 
International Journal of Ageing and Later Life

The media is one vehicle for shaping attitudes towards age and ageing, and it has often been blamed for perpetuating ageism and cultural stereotypes about seniors, particularly older women (Carrigan \& Szmigin 2002; Cohen 2002). Even then the studies of the media rarely look at ageism. Vakimo (2001) and Mulley (2007) summarised that newspapers tend to write about older people in a problem-oriented way. Old age is described as an illness, dependency and a threat to the economy and healthcare system (Mulley 2007; Vakimo 2001). Inaccurate and biased images of older people and also under-representations in media are seen as ageism (Hilt \& Lipschultz 2005; Vernon et al. 1990). In our data, focusing on loneliness, older people are almost solely portrayed in negative ways. Constructing older people as victims of loneliness because of their age is a form of ageism. In our data, loneliness is partly represented as a consequence of ageing and thus as an inseparable part of old age. However, the images of older people are not solely negative or ageist in media. There are magazines, including the ET magazine, which clearly address the positive aspects of ageing and can even be described as anti-ageist (Lumme-Sandt 2010; Williams et al. 2007). In this study, the selection criteria excluded the texts which dealt with ageing in some other context than loneliness. Therefore, our data do not allow conclusions concerning the presence or absence of ageism in ET and HS.

In most of the texts, the writers view old age loneliness from an outsider's position (see Vakimo 2001). The outsider's position seems to legitimise a more provocative style and moral irritation than a position where the writer discusses his/her own loneliness. However, loneliness as a personal experience is rarely present in the texts. In those texts, loneliness is presented as a complicated phenomenon, and it is often connected with concepts of the third age. To write or talk about one's own loneliness seems to require a certain amount of empowerment. On the other hand, previous literature has shown that older people may view loneliness as a stigma, and are therefore reluctant to discuss it. It may be embarrassing to admit that you are lonely (Killeen 1998; McInnis \& White 2001). Positioning lonely older people as others (see Anderson 2007; Kulmala 2006), enables the writers to avoid the negative stigma of loneliness. "A lonely old person" is a category to which people do not want to belong. The shamefulness of loneliness might connect to the feeling that loneliness 
is a person's own fault and there is something wrong with a lonely person because she/he cannot form relationships. In the data of this study, lonely older people are constructed as pitiable and sometimes texts evoke empathy of the readers.

The writer's position necessarily affects the perspective on loneliness as well as the style of writing. In these data, the strongest voices often belong to those whose work is somehow connected to the area of alleviating loneliness. This could be an attempt to arouse discussion, but also a way of marketing "loneliness industry". Talking about "a battle" against loneliness hints at the role and importance of various organisations. The organisations may legitimise their existence in that way. A large part of the actors involved in alleviating loneliness among older people are non-profit organisations whose primary purpose is not selling, but it seems that loneliness sells. Rokach (2004) argues that a loneliness industry has been developed to meet the desire of those who do not know what to do about their loneliness. The loneliness business includes semi-forced joint activities, mate-finding agencies and self-help books, and it is a growing business (Rokach 2004).

In the scientific literature, several interventions and programmes for alleviating loneliness have been introduced, most of them have not been effective (Cattan et al. 2005a; Findley 2003). Our data include many perfunctory and even naive solutions to the problem of loneliness. Some involve the whole society while others are just isolated actions. Previous studies have not addressed the fact that the low status of older people in society or the alleged inhumanity in elderly care may cause feelings of loneliness. Improving the social status or elderly care practices would then be one solution to alleviate loneliness. However, in our data the suggestions are often presented as universal solutions. The scientific loneliness literature, however, comes up with a different view: solitary interventions do not apply universally to alleviation of loneliness (Findley 2003). The anxiety induced by loneliness probably makes the writers desperate to try to find solutions and offload the responsibility of alleviating loneliness on to someone else.

In the articles dealing with the alleviation of loneliness, older people are typically cast as objects in the mass media. Other people should organise activities, collect money, help and take care of older people. This kind of 
International Journal of Ageing and Later Life

writing constructs older people as passive persons who do not have the opportunity to influence their lives and make decisions. It seems as if older people themselves are not even expected to take action. Previous research has reached a similar conclusion. Cattan and colleagues (2005b), for example, found that activities are usually built on professional assumptions, and older people are rarely involved in planning and implementing programmes; other people seem to know better what is best for older people.

According to our data, loneliness is often represented as a political issue. There is a dispute over who is responsible for alleviating loneliness among older people. The voluntary organisations appear to be the main actors but the responsibility is shifted to the decision-makers and collectively to society. The texts are often written from the viewpoint of voluntary work. Sometimes the writers refer to the role of older people themselves in alleviating loneliness. In research, older people have reported that reading, gardening and watching television alleviate loneliness (Palkeinen 2005a; Pettigrew \& Roberts 2008), but in the texts of this study, there are only few mentions of these activities. The emphasis is on social activities where other people play the active role. Only in a few texts are older persons themselves considered as agents who could phone or visit their children and grandchildren or take the first step to contact the younger generation. Contacts between generations are seen almost solely as the responsibility of the younger generation.

These findings were based on print media, so there is a need for further research about portrayals of loneliness in the different media types internationally, for example, in TV-programmes, films, internet as well as literature. Previous studies have shown that alleviation of loneliness is difficult, therefore it is important to know more about the construction of loneliness and identify all dimensions which are attached to it in our society. When loneliness in better understood and conceptualised, it would be also easier to build effective programmes aimed to relieving loneliness.

Although the importance of relieving loneliness is often discussed on a general level, loneliness is simultaneously presented as a natural part of ageing. The prevalence of loneliness and inseparability of loneliness and old age are constructed as mutually shared knowledge in our society. It seems that in Finnish print media, the typical lonely person is old, and the 
typical older person is lonely. However, lonely older people are often constructed as outsiders in human relationships, and also outsiders in society.

\section{Corresponding Author}

Hanna Uotila, Tampere School of Public Health, FI-33014 University of Tampere, Finland. Email: hanna.uotila@uta.fi

\section{References}

Anderson, K. T. (2007). Constructing "otherness": Ideologies and differentiating speech style. International Journal of Applied Linguistics 17(2): 178-197.

Bazzini, D. G., McIntosh, W. D., Smith, S. M., Cook, S. \& Harris, C. (1997). The ageing woman in popular film: Underrepresented, unattractive, unfriendly, and unintelligent. Sex Roles 36(7/8): 531-543.

Bonnesen, J. L. \& Burgess, E. O. (2004). Senior moments: The acceptability of an ageist phrase. Journal of Aging Studies 18(2): 123-142.

Cacioppo, J. T., Hawkley, L. C., Crawford, E., Ernst, J. M., Burleson, M. H., Kowalewski, R. B., Malarkey, W. B., Van Cauter, E. \& Berntson, G. G. (2002). Loneliness and health: Potential mechanisms. Psychosomatic Medicine 64(3): 407-417.

Carrigan, M. \& Szmigin, I. (2002). Advertising and older consumers: Image and ageism. Business Ethics: A European Review 9(1): 42-50.

Cattan, M., White, M., Bond, J. \& Learmonth, A. (2005a). Preventing social isolation and loneliness among older people: A systematic review of health promotion interventions. Ageing \& Society 25(1): 41-67.

Cattan, M., White, M., Learmonth, T. A. \& Bond, J. (2005b). Are services and activities for socially isolated and lonely older people accessible, equitable, and inclusive? Research, Policy and Planning 23(3): 149-164.

Cohen, H. L. (2002). Developing media literacy skills to challenge television's portrayal of older women. Educational Gerontology 28(7): 599-620.

Drageset, J. (2004). The importance of activities of daily living and social contact for loneliness: A survey among residents in nursing home. Scandinavian Journal of Caring Science 18(1): 65-71. 
International Journal of Ageing and Later Life

Edley, N. (2001). Analysing masculinity: Interpretative repertoires, ideological dilemmas and subject positions. In M. Wetherell, S. Taylor \& S. Yates (eds.), Discourse as Data. A Guide for Analysis (pp. 189-228). London: Sage.

Ellis, S. R. \& Morrison, T. G. (2005). Stereotypes of ageing: Messages promoted by age-specific paper birthday cards available in Canada. International Journal of Aging and Human Development 61(1): 57-73.

Findley, R. A. (2003). Interventions to reduce social isolation amongst older people: Where is the evidence? Ageing $\mathcal{E}$ Society 23(5): 647-658.

Finnish Audit Bureau of Circulations. (2009). KMT lukija syksy 2007/kevät 2008. [KTM the Reader Autumn 2007/Spring 2008]. Helsinki: Finnish Audit Bureau of Circulations. Available on http://www.levikintarkastus.fi/ mediatutkimus/KMT_Lukija_S07-K08_paakohderyhmat.pdf (Accessed: February 23, 2009).

Heikkinen, R-L. \& Kauppinen, M. (2004). Depressive symptoms in late life: A 10-year follow-up. Archives of Gerontology and Geriatrics 38(3): 239-250.

Hilt, M. L. \& Lipschultz, J. H. (2005). Mass Media, An Aging Population, and the Baby Boomers. Mahwah, NJ: Lawrence Erlbaum Associates.

Horton, S., Barker, J. \& Deakin, J. M. (2007). Stereotypes of aging: Their effects on the health of seniors in North American Society. Educational Gerontology 33(12): 1021-1035.

de Jong Gierveld, J. (1987). Developing and testing a model of loneliness. Journal of Personality and Social Psychology 53(1): 119-128.

Jylhä, M. (2004). Old age and loneliness: Cross-sectional and longitudinal analyses in the Tampere longitudinal study on aging. Canadian Journal on Aging 23(2): 157-168.

Jylhä, M. \& Saarenheimo, M. (2010). Loneliness and aging: Comparative perspectives. In C. R. Phillipson \& D. Dannefer (eds.), The SAGE Handbook of Social Gerontology (pp. 317-328). Thousand Oaks, CA: Sage.

Killeen, C. (1998). Loneliness: An epidemic in modern society. Journal of Advanced Nursing 28(4): 762-770.

Kulmala, A. (2006). Kerrottuja kokemuksia leimatusta identiteetistä ja toiseudesta [Narrated Experiences of Stigmatised Identity and Otherness]. Tampere: Acta Universitatis Tamperensis. 
Laslett, P. (1989). A Fresh Map of Life. The Emergence of the Third Age. London: Weidenfeld and Nicolson.

Lumme-Sandt, K. (2010). Images of ageing in a 50+ magazine. Journal of Aging Studies. DOI: 10.1016/j.jaging.2010.08.013.

McInnis, G. J. \& White, J. H. (2001). A phenomenological exploration of loneliness in the older adult. Archives of Psychiatric Nursing 15(3): $128-139$.

Medianetti. (2009). HS Product Family. Helsinki: Helsingin Sanomat. Available on http://medianetti.helsinginsanomat.fi/english/HS+ Product + family/1101979183413 (Accessed: February 23, 2009).

Miller, D. W., Leyell, T. S. \& Mazachek, J. (2004). Stereotypes of the elderly in U.S. television commercial from the 1950s to the 1990s. International Journal of Aging and Human Development 58(4): 315-340.

Miller, L. (2008). Foucauldian constructionism. In J. A. Holstein \& J. F. Gubrium (eds.), Handbook of Constructionist Research (pp. 413-428). New York: The Guilford Press.

Miller, P. N., Miller, D. W., McKibbin, E. M. \& Pettys, G. L. (1999). Stereotypes of the elderly in magazine advertisements 1956-1996. International Journal of Aging and Human Development 49(4): 319-337.

Mulley, G. (2007). Myths of ageing. Clinical Medicine 7(1): 68-72.

Palkeinen, H. (2005a). "Tässä on kaikki parasta, nyt kun mä elän yksin." Yksin olemisen hyvät puolet iäkkäiden naimattomien naisten puheessa [Single, elderly women's attitudes toward solitude]. Naistutkimus 18(1): 30-41.

Palkeinen, H. (2005b). Yksinäisyys iäkkäiden ihmisten kirjoituksissa [Loneliness in the texts of elderly people]. Gerontologia 19(3): 111-120.

Peplau, A. L. \& Perlman, D. (1982). Perspectives on loneliness. In A. L. Peplau \& D. Perlman (eds.), Loneliness: A Sourcebook of Current Theory, Research and Therapy (pp. 1-18). New York: John Willey.

Pettigrew, S. \& Roberts, M. (2008). Addressing loneliness in later life. Aging \& Mental Health 12(3): 302-309.

Pierce, L. L., Wilkinson, L. K. \& Anderson, J. (2003). Analysis of the concept of aloneness. As applied to older women being treated for depression. Journal of Gerontological Nursing 29(7): 20-25. 
International Journal of Ageing and Later Life

Pinquart, M. \& Sorensen, S. (2001). Influences on loneliness in older adults: A meta-analysis. Basic \& Applied Social Psychology 23(4): 245-266.

Rokach, A. (2004). Loneliness then and now: Reflections on social and emotional alienation in everyday life. Current Psychology 23(1): 24-40.

Routasalo, P. E., Savikko, N., Tilvis, R. S., Strandberg, T. E. \& Pitkälä, K. H. (2006). Social contacts and their relationship to loneliness among aged people - a population-based study. Gerontology 52(3): 181-187.

Roy, A. \& Harwood, J. (1997). Underrepresented, positively portrayed: Older adults in television commercials. Journal of Applied Communication Research 25(1): 39-56.

Rozanova, J. (2006). Newspaper portrayals of health and illness among Canadian seniors: Who ages healthy and at what cost? International Journal of Ageing and Later Life 1(2): 111-139.

Sanoma Magazines Finland. (2009). ET-lehti. [The ET Magazine]. Helsinki: Sanoma Magazines Finland. Available on http://asiakaspalvelu. sanomamagazines.fi/tutustu/default.asp?lehti=ET (Accessed: February 23, 2009).

Savikko, N., Routasalo, P., Tilvis, R. S., Strandberg, T. E. \& Pitkälä, K. H. (2005). Predictors and subjective causes of loneliness in an aged population. Archives of Gerontology and Geriatric 41(3): 223-233.

Steed, L., Boldy, D., Grenade, L. \& Iredell, H. (2007). The demographics of loneliness among older people in Perth, Western Australia. Australasian Journal on Ageing 26(2): 81-86.

Taylor, S. (2001). Locating and conducting discourse analytic research. In M. Wetherell, S. Taylor \& S. Yates (eds.), Discourse as Data. A Guide for Analysis (pp. 5-48). London: Sage.

Toppila, M. (2009). Suomen suurin aikakauslehti [The Largest Magazine in Finland]. Helsinki: Sanoma Magazines Finland. Available on http:// www.sanomamagazines.fi/mediaopas/kohderyhmat-ja-lehdet/lehdet/ et.html (Accessed: February 23, 2009).

Vakimo, S. (2001). Paljon kokeva, vähän näkyvä. Tutkimus vanhaa naista koskevista kulttuurisista käsityksistä ja vanhan naisen elämänkäytännöistä. [Out of Sight But Full of Life. A Study of Cultural Conceptions of Old 
Women and Their Life Practices]. Helsinki: Suomalaisen Kirjallisuuden Seura.

Vernon, J. A., Williams, Jr. J. A., Phillips, T. \& Wilson, J. (1990). Media stereotyping: A comparison of the way elderly women and men are portrayed on prime-time television. Journal of Women \& Aging 2(4): $55-68$.

Victor, C., Scambler, S., Bond, J. \& Bowling, A. (2000). Being alone in later life: Loneliness, social isolation and living alone. Reviews in Clinical Gerontology 10(4): 407-417.

Victor, C. R., Scambler, S. J., Bowling, A. \& Bond, J. (2005). The prevalence of, and risk factors for, loneliness in later life: A survey of older people in Great Britain. Ageing \& Society 25(3): 357-375.

Vincent, J. (2003). Old Age. London: Routledge.

Weiss, R. S. (1973). Loneliness. The Experience of Emotional and Social Isolation. Cambridge: The MIT Press.

Weiss, R. S. \& Brass, S. A. (2002). Introduction. In R. S. Weiss \& A. S. Brass (eds.), Challenges of the Third Age: Meaning and Purpose on Later Life (pp. 3-12). New York: Oxford University Press.

Wenger, G. C. \& Burholt, V. (2004). Changes in level of social isolation and loneliness among older people in a rural area: A twenty-year longitudinal study. Canadian Journal on Aging 23(2): 115-127.

Wetherell, M. \& Edley, N. (1999). Negotiating hegemonic masculinity: Imaginary positions and psycho-discursive practices. Feminism Psychology 9(3): 335-356.

Wetherell, M., Taylor, S. \& Yates, S. (eds.). (2001). Discourse as Data. A Guide for Analysis. London: Sage.

Williams, A., Wadleigh, P. M. \& Ylänne, V. (2010). Images of older people in UK magazine advertising: Towards a typology. The International Journal of Aging and Human Development 71(2): 83-114.

Williams, A., Ylänne, V. \& Wadleigh, P. M. (2007). Selling the "Elixir of Life": Images of the elderly in an Olivio advertising campaign. Journal of Ageing Studies 21(1): 1-21.

Wood, L. A. \& Kroger, R. O. (2000). Doing Discourse Analysis. Methods for Studying Action in Talk and Text. Thousand Oaks, CA: Sage. 
International Journal of Ageing and Later Life

Zhang, W. \& Liu, G. (2007). Childlessness, psychological well-being, and life satisfaction among the elderly in China. Journal of Gross Cultural Gerontology 22(2): 185-203.

Zhang, Y. B., Harwood, J., Williams, A., Ylänne-McEven, V., Wadleigh, P. M. \& Thimm, C. (2006). The portrayal of older adults in advertising. A cross-national review. Journal of Language and Social Psychology 25(3): 264-282.

Zhang, Z. \& Hayward, M. D. (2001). Childless and the psychological wellbeing of older persons. Journal of Gerontology: Social Science 56B(5): S311-S320. 


\title{
Christina Victor, Sasha Scambler and John Bond (2009). The Social World of Older People. Understanding Loneliness and Social Isolation in Later Life. Maidenhead: Open University Press, 262 pp. ISBN 9780335215218 (paperback)
}

\author{
REVIEWED BY LARS ANDERSSON*
}

Every once in a while it is useful to have updates of central research areas. Hence, the book by Victor, Scambler and Bond is a timely and welcome contribution to the research on loneliness and kindred phenomena.

Unfortunately, the book also functions as a summary report of one of the projects in the Growing Older Program funded by the Economic and Social Research Council, which is of less interest to the general reader. The book offers a detailed account of loneliness and social isolation among older people, particularly in Britain. The latter specification, of course, is a limitation for an international audience; however, having said that, the volume nevertheless is very useful for those interested in these issues.

As outlined in the Introduction, the specific objectives have been to describe the prevalence of social isolation and loneliness and to contribute (1) to our understanding of secular trends in the experience of quality of life (2), to knowledge and understanding of later life by investigating the relationship between loneliness and social isolation and living alone, and (3) to contribute to policy and practice by identifying the factors, resources and coping mechanisms that protect older people from experiencing

* Lars Andersson, NISAL, Linköping University, Sweden 
International Journal of Ageing and Later Life

loneliness and isolation. Having the seminal work of Townsend, in particular, as exemplar, one stated ambition has been to argue for the revival of the explicitly sociological contribution to the analysis of older people's social worlds.

Following the Introduction, Chapter 2 elucidates theoretical and methodological issues with regard to loneliness and social isolation. It includes an exposition of various measures of loneliness that have been developed over the years, which is instructive given that the reason for the choice of measure is seldom qualified in articles. In the same chapter, the reader is also introduced to the authors' own study, which is comprised of a quantitative survey of 999 individuals aged 65 and above and a qualitative study with 45 participants. The presentation of the studies exposes some problems and lack of clarity. One such problem is the low response rate in the quantitative study (63\%). It surely has some implication for the results. Another problem, or lack of clarity, is that the authors claim to challenge the objective nature of loneliness and social isolation (p. 38), while in Chapter 3, essentially objective measures are presented from the quantitative study (cf. Tables 3.1 through 3.4). As the questionnaire is not included, it is not possible to get a complete picture of the measures. In Chapter 4, the main focus is on loneliness, and can be seen as a continuation of Chapter 2. Here, comparisons are made with several both British and international studies. To get some indication of whether people "tell the truth" about loneliness, a comparison was made between the answers to the single item question in the quantitative study and the way the (same) participants talked about loneliness in the qualitative interview. The agreement turned out to be quite good.

In Chapter 5, the focus is shifted to social exclusion and inclusion and their relationships to social networks. Based on the results from the qualitative study, the authors note that isolation is conceptualised by older people as having a strong spatial or neighbourhood component. In order to facilitate historical comparison a social contact score was generated. The results of the comparisons have to be interpreted carefully. In regard to comparative studies, the authors earlier (p. 74) noted the difficulty of comparing older populations over time as the composition, for example the proportions of marital status and of people living alone, differ 
substantially. The phenomenon of, for example, living alone may also have shifted meaning over the years.

In spite of all the data, the book does not add many new thoughts on the issue. The outcome merely confirms what we already know. Maybe the ambition to partly make a "follow up" of the classic studies by Townsend and others has restricted the design of the studies. It is concluded in the final Chapter (6) that the levels of severe isolation and loneliness have remained remarkably constant over time, and that the authors do not see vast increase in levels of loneliness and isolation in future decades; that the lonely can be divided into a variety of differing subgroups; that the telephone and the mobile phone enable families and friends to stay in touch; that a variety of different pathways lead to loneliness and isolation, and finally that loneliness and isolation will remain an experience that is confined to a minority of older people. Hence, most disappointing with the book is that the authors did not take the opportunity to take the area of loneliness and social isolation further by way of their own studies.

I acclaim the authors' sociological approach. However, it seems to have a restricting effect on their analysis in that their starting point is that isolation and loneliness can only be understood by locating them within the broader context of relationships (pp. 4-5). My standpoint is quite the opposite. I have become critical of the obsession with social contacts, social isolation or social networks in connection with loneliness. 

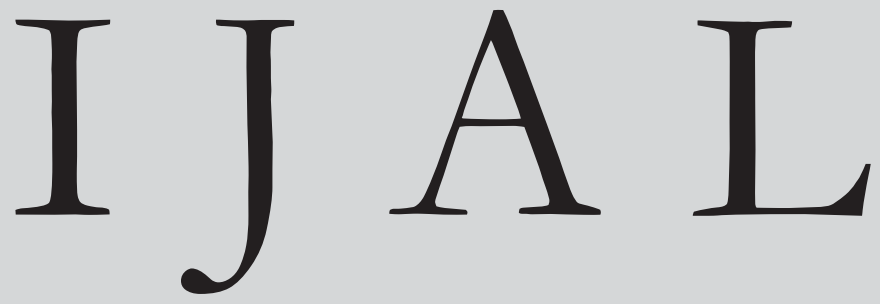

\section{Intemational J oumal of Ageing and Later Life}

The International Journal of Ageing and Later Life (IJAL) serves an audience interested in social and cultural aspects of ageing and later life development. The title of the journal reflects an attempt to broaden the field of ageing studies. In addition to studies on later life, IJAL also welcomes contributions focusing on adult ageing as well as relations among generations.

Being an international journal, IJAL acknowledges the need to understand the cultural diversity and context dependency of ageing and later life. IJAL publishes country- or cultural-specific studies as long as such contributions are interesting and understandable for an international audience.

In order to stimulate exchange of ideas on ageing across many parts of the world, IJAL is available free of charge to anyone with Internet access (www.ep.liu.se/ej/ijal). 